\title{
Spatially Referenced Models of Streamflow and Nitrogen, Phosphorus, and Suspended-Sediment Loads in Streams of the Midwestern United States
}
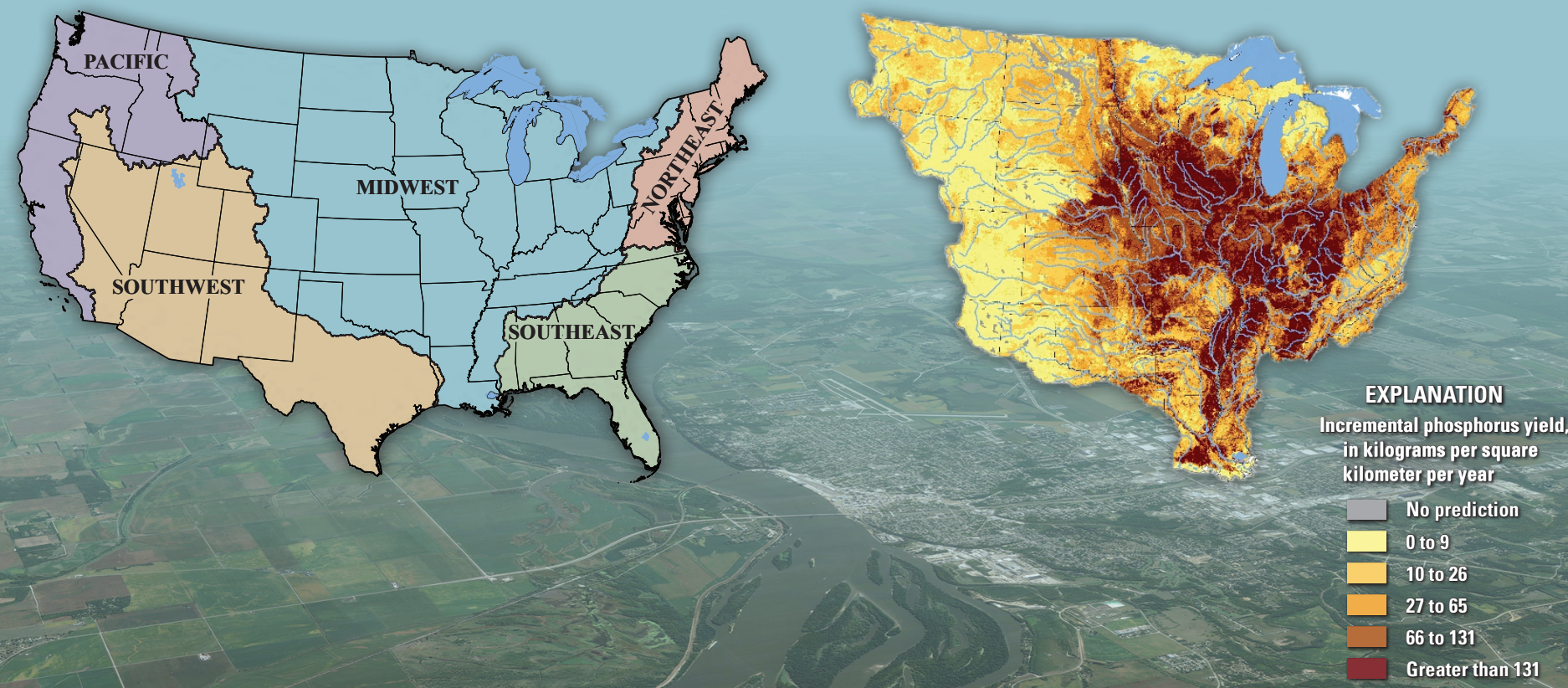

Scientific Investigations Report 2019-5114

U.S. Department of the Interior

U.S. Geological Survey 
Cover. Upper left: SPAtially Referenced Regression On Watershed attritutes (SPARROW) modeling regions of the conterminous United States. Upper right: SPARROW simulated total phosphorus incremental yield, in kilograms per square kilometer per year.

Lower center: Mississippi River near Burlington, lowa, looking south. Credit: Satellite image courtesy of Google Earth.

Back cover. Major streams of the United States in the Midwest modeling region. Credit: U.S. Geological Survey digital data, 2006-14. 


\section{Spatially Referenced Models of Streamflow and Nitrogen, Phosphorus, and Suspended- Sediment Loads in Streams of the Midwestern United States}

By Dale M. Robertson and David A. Saad

National Water-Quality Program

Scientific Investigations Report 2019-5114 


\title{
U.S. Department of the Interior DAVID BERNHARDT, Secretary
}

\author{
U.S. Geological Survey \\ James F. Reilly II, Director
}

\section{U.S. Geological Survey, Reston, Virginia: 2019}

For more information on the USGS - the Federal source for science about the Earth, its natural and living resources, natural hazards, and the environment-visit https://www.usgs.gov or call 1-888-ASK-USGS.

For an overview of USGS information products, including maps, imagery, and publications, visit https://store.usgs.gov.

Any use of trade, firm, or product names is for descriptive purposes only and does not imply endorsement by the U.S. Government.

Although this information product, for the most part, is in the public domain, it also may contain copyrighted materials as noted in the text. Permission to reproduce copyrighted items must be secured from the copyright owner.

Suggested citation:

Robertson, D.M., and Saad, D.A., 2019, Spatially referenced models of streamflow and nitrogen, phosphorus, and suspended-sediment loads in streams of the Midwestern United States: U.S. Geological Survey Scientific Investigations Report 2019-5114, 74 p. including 5 appendixes, https://doi.org/10.3133/sir20195114.

Associated data for this publication:

Saad, D.A., and Robertson, D.M., 2019, SPARROW model inputs and simulated streamflow, nutrient and suspended-sediment loads in streams of the Midwestern United States, 2012 base year:

U.S. Geological Survey data release, https://doi.org/10.5066/P930MXC9.

ISSN 2328-0328 (online) 


\section{Foreword}

Sustaining the quality of the Nation's water resources and the health of our diverse ecosystems depends on the availability of sound water-resources data and information to develop effective, science-based policies. Effective management of water resources also brings more certainty and efficiency to important economic sectors. Taken together, these actions lead to immediate and long-term economic, social, and environmental benefits that make a difference in the lives of the almost 400 million people projected to live in the United States by 2050.

In 1991, Congress established the National Water-Quality Assessment (NAWQA) to address where, when, why, and how the Nation's water quality has changed, or is likely to change in the future, in response to human activities and natural factors. Since then, NAWQA has been a leading source of scientific data and knowledge used by national, regional, State, and local agencies to develop science-based policies and management strategies to improve and protect water resources used for drinking water, recreation, irrigation, energy development, and ecosystem needs (https://water.usgs.gov/nawqa/applications/). Plans for the third decade of NAWQA (2013-21) address priority water-quality issues and science needs identified by NAWQA stakeholders, such as the Advisory Committee on Water Information and the National Research Council, and are designed to meet increasing challenges related to population growth, increasing needs for clean water, and changing land-use and weather patterns.

Federal, State, and local agencies have invested billions of dollars to reduce the amount of pollution entering rivers and streams that millions of Americans rely on for a variety of water needs and biota rely on for habitat. Understanding the sources and transport of pollution is crucial for designing strategies to improve water quality. The U.S. Geological Survey's (USGS) SPAtially Referenced Regression On Watershed attributes (SPARROW) model was developed to aid in the understanding of sources and transport of pollution across large spatial scales. The SPARROW model is calibrated by statistically relating watershed sources and transport-related properties to monitoring-based streamflow and water-quality load estimates. This report describes the methods and results of SPARROW models developed to estimate streamflow and total nitrogen, total phosphorus and suspended-sediment transport in streams of the Midwest United States, based on inputs and management practices centered on 2012. The results of the SPARROW model used to estimate streamflow are useful for understanding factors affecting the transport of water and for providing information on how the other water-quality constituents are transported down the stream network. The results of the SPARROW nutrient and sediment models are useful for understanding where nutrients and sediment originate on the landscape, how much is delivered to local streams, and how much is ultimately delivered to downstream waterbodies. The constituent models also are useful for describing the major sources of the nutrients and suspended sediment.

We hope this publication will provide you with insights and information to meet your waterresource needs and will foster increased citizen awareness and involvement in the protection and restoration of our Nation's waters. The information in this report is intended primarily for those interested or involved in resource management and protection, conservation, regulation, and policymaking at the regional and national levels.

Dr. Donald W. Cline

Associate Director for Water

U.S. Geological Survey 



\section{Contents}

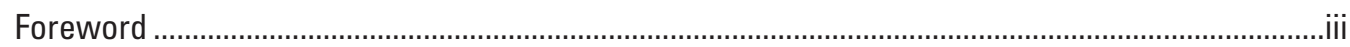

Abstract

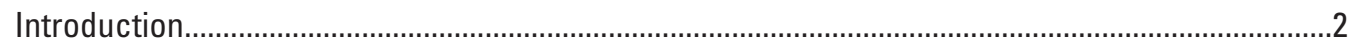

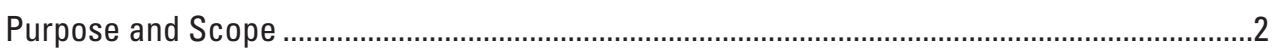

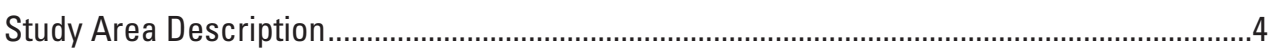

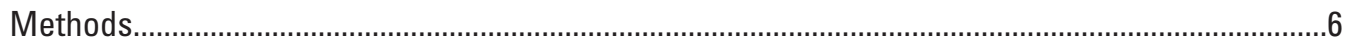

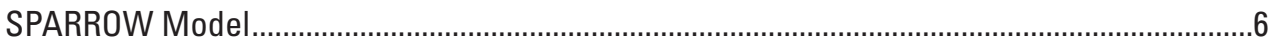

SPARROW Model Calibration ................................................................................................

Changes in the SPARROW Modeling Approach from Previous Applications ............................7

Improvements in the Resolution and Accuracy of the Explanatory and Response

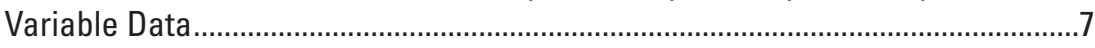

Methods to Produce Statistically Independent Model Residuals ...................................8

Reporting of a Refined Measure of SPARROW Model Performance ...............................

Expanded Monitoring Estimates of Suspended-Sediment Loads for SPARROW

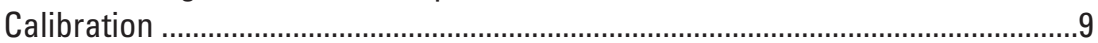

SPARROW Model Predictions ................................................................................................10

Data Used to Develop and Calibrate the SPARROW Models................................................10

Surface-Water Drainage Network...............................................................................

Long-Term Mean-Annual Streamflow and Constituent Load Information ......................11

Sources of Water, Nitrogen, Phosphorus, and Suspended Sediment.............................13

Sources of Water for the Streamflow Model............................................................13

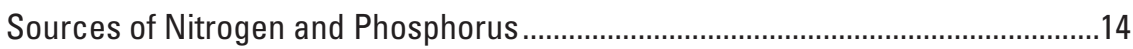

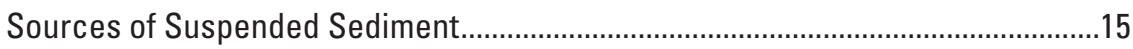

Factors Affecting Water, Nitrogen, Phosphorus, and Sediment Transport .....................16

Factors Affecting Water Transport .......................................................................16

Factors Affecting Nitrogen and Phosphorus Transport to the Stream Network ...17

Factors Affecting Sediment Transport to the Stream Network.................................18

Factors Affecting Nitrogen, Phosphorus, and Sediment Transport down the

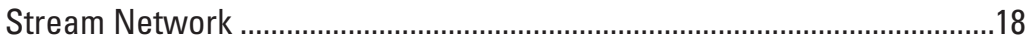

Use of SPARROW Streamflow Model Results in Other Constituent Models..........................19

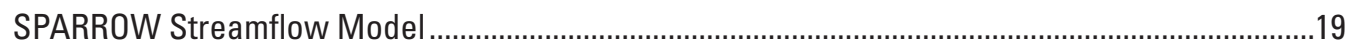

Specification of the Streamflow Model .............................................................................19

Simulated Water Transport and Streamflow throughout the Midwest ....................................24

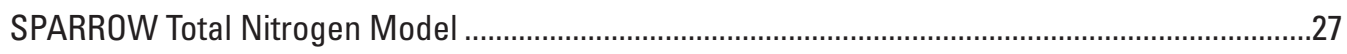

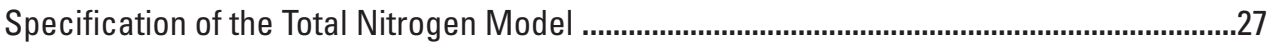

Simulated Total Nitrogen Transport throughout the Midwest...............................................32

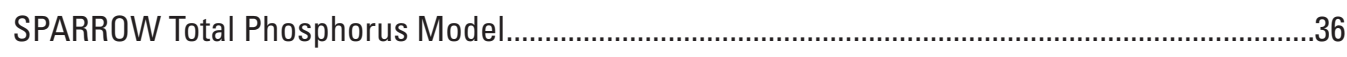

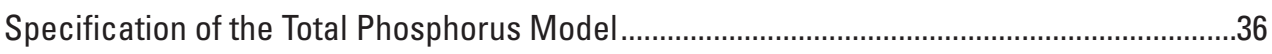

Simulated Total Phosphorus Transport throughout the Midwest..............................................37

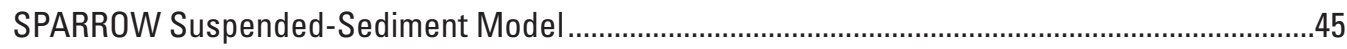

Specification of the Suspended-Sediment Model ...............................................................4

Simulated Suspended-Sediment Transport throughout the Midwest .....................................48 


\section{Contents-Continued}

Model Limitations and Future SPARROW Model Development.......................................................54

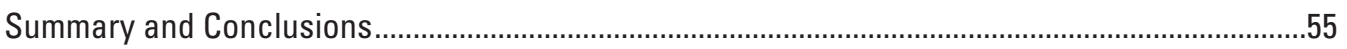

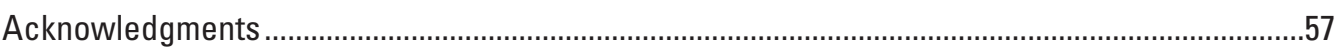

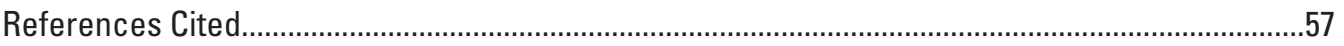

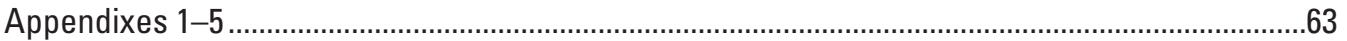

\section{Figures}

1. Map showing the spatial extent of the Midwest SPARROW model region ........................3

2. Map showing major drainage basins within the Midwest study area ...............................4

3. Map showing land cover in the Midwest region of the United States, 2011 ....................5

4. Map showing mean-annual precipitation minus actual evapotranspiration (water years 2000-14) in the Midwest region .................................................................6

5. Diagnostic plots for the Midwest SPARROW streamflow model for all calibration sites.

6. Maps showing the spatial distribution of residuals from the Midwest streamflow model.

7. Maps showing the distribution of incremental mean-annual yields of water from the Midwest SPARROW streamflow model.

8. Bar graph showing predicted mean-annual water yield, by source, for the Midwest, Great Lakes Basin, Mississippi River Basin, and selected major drainage basins in the Midwest region of the United States.

9. Diagnostic plots for the Midwest SPARROW total nitrogen model for all calibration sites

10. Maps showing the spatial distribution of residuals from the Midwest total nitrogen model

11. Maps showing the distribution of incremental mean-annual yields of total nitrogen from the Midwest SPARROW total nitrogen model

12. Bar graph showing predicted mean-annual total nitrogen yield, by source, for the Midwest, Great Lakes Basin, Mississippi River Basin, and selected major drainage basins in the Midwest region of the United States.

13. Diagnostic plots for the Midwest SPARROW total phosphorus model for all calibration sites

14. Maps showing the spatial distribution of residuals from the Midwest total phosphorus model

15. Maps showing the distribution of incremental mean-annual yields of total phosphorus from the Midwest SPARROW total phosphorus model

16. Bar graph showing the predicted mean-annual total phosphorus yields, by source, for the Midwest, Great Lakes Basin, Mississippi River Basin, and selected major drainage basins in the Midwest region of the United States.....

17. Diagnostic plots for the Midwest SPARROW suspended-sediment model for all calibration sites

18. Maps showing the spatial distribution of residuals from the Midwest suspended-sediment model. 


\section{Figures-Continued}

19. Bar graphs showing the mean-annual yields of suspended sediment by land-use/surficial-material type

20. Maps showing the distribution of incremental mean-annual yields of suspended sediment from the Midwest SPARROW suspended-sediment model ..........51

21. Bar graph showing predicted mean-annual suspended-sediment yield, by source, for the Midwest, Great Lakes Basin, Mississippi River Basin, and selected major drainage basins in the Midwest region of the United States

\section{Tables}

1. Counts of sites throughout the data compilation and selection process for 2012 Midwest SPARROW models

2. Combined land use/land cover and surficial-material-based source categories used in the 2012 Midwest SPARROW models.

3. Summary of calibration results for the 2012 Midwest SPARROW streamflow model

4. Mean-annual yields of water, by source, to streams and delivered to the downstream receiving waterbody from each of the major drainage basins in the Midwest.

5. Summary of calibration results for the 2012 Midwest SPARROW total nitrogen model

6. Mean-annual yields of total nitrogen, by source, to streams and delivered to the downstream receiving waterbody from each of the major drainage basins in the Midwest.

7. Summary of calibration results for the 2012 Midwest SPARROW total phosphorus model

8. Mean-annual yields of total phosphorus, by source, to streams and delivered to the downstream receiving waterbody from each of the major drainage basins in the Midwest.

9. Summary of calibration results for the 2012 Midwest SPARROW suspendedsediment model

10. Mean-annual yields of suspended sediment, by source, to streams and delivered to the downstream receiving waterbody from each of the major drainage basins in the Midwest

2.1. Source, land-to-water delivery, and instream and in-reservoir decay variables tested and used in the 2012 Midwest SPARROW models

3.1. Sampling agencies that collected water-quality data used to calculate total nitrogen, total phosphorus, suspended sediment, and suspended solid loads considered for use in the 2012 Midwest SPARROW models

4.1. Wastewater treatment plant effluent load for total nitrogen and total phosphorus, by State and by percentage, based on measured versus typical pollutant concentration used in the 2012 Midwest SPARROW models

5.1. Original, generalized, and final surficial-materials categories considered

for use in the 2012 Midwest SPARROW models. 


\section{Conversion Factors}

International System of Units to U.S. customary units

\begin{tabular}{|c|c|c|}
\hline Multiply & By & To obtain \\
\hline \multicolumn{3}{|c|}{ Length } \\
\hline millimeter (mm) & 0.03937 & inch (in.) \\
\hline meter $(\mathrm{m})$ & 3.281 & foot $(\mathrm{ft})$ \\
\hline kilometer $(\mathrm{km})$ & 0.6214 & mile (mi) \\
\hline \multicolumn{3}{|c|}{ Area } \\
\hline hectare (ha) & 2.471 & acre \\
\hline square kilometer $\left(\mathrm{km}^{2}\right)$ & 247.1 & acre \\
\hline square kilometer $\left(\mathrm{km}^{2}\right)$ & 0.3861 & square mile $\left(\mathrm{mi}^{2}\right)$ \\
\hline \multicolumn{3}{|c|}{ Flow rate } \\
\hline cubic meter per second $\left(\mathrm{m}^{3} / \mathrm{s}\right)$ & 70.07 & acre-foot per day (acre-ft/d) \\
\hline cubic meter per second $\left(\mathrm{m}^{3} / \mathrm{s}\right)$ & 35.31 & cubic foot per second $\left(\mathrm{ft}^{3} / \mathrm{s}\right)$ \\
\hline millimeter per year $(\mathrm{mm} / \mathrm{yr})$ & 0.03937 & inch per year (in/yr) \\
\hline \multicolumn{3}{|c|}{ Mass } \\
\hline kilogram (kg) & 2.205 & pound avoirdupois (lb) \\
\hline metric ton $(\mathrm{t})$ & 1.102 & ton, short $(2,000 \mathrm{lb})$ \\
\hline
\end{tabular}

\section{Datum}

Vertical coordinate information is referenced to the North American Vertical Datum of 1988 (NAVD 88).

Horizontal coordinate information is referenced to the North American Datum of 1983 (NAD 83).

Elevation, as used in this report, refers to distance above the vertical datum.

\section{Supplemental Information}

A water year is the period from 0 ctober 1 to September 30 and is designated by the year in which it ends. 


\section{Abbreviations}

$\begin{array}{ll}\text { AET } & \text { actual evapotranspiration } \\ \text { APEX } & \text { Agricultural Policy Environmental Extender } \\ \text { BRE } & \text { Beale ratio-estimator method to compute loads } \\ \text { BMP } & \text { best management practice } \\ \text { CEAP } & \text { Conservation Effects Assessment Program } \\ \text { CMAO } & \text { Community Multiscale Air Quality } \\ \text { CRP } & \text { Conservation Reserve Program } \\ \text { ET } & \text { evapotranspiration } \\ \text { F5K } & \text { five-parameter regression with Kalman smoothing method to compute loads } \\ \text { HSPF } & \text { Hydrologic Simulation Program-Fortran } \\ \text { HUC } & \text { hydrologic unit code } \\ \text { IF_TSS } & \text { coefficient representing the occurrence of suspended solids concentration data } \\ \text { NAWQA } & \text { National Water Quality Assessment Program } \\ \text { NHDPlusV2 } & \text { National Hydrographic Dataset Version 2 at a 1:100,000 scale } \\ \text { NRCS } & \text { U.S. Department of Agriculture, National Resources Conservation Service } \\ \text { NWIS } & \text { U.S. Geological Survey National Water Information System } \\ \text { PPT } & \text { precipitation } \\ \text { PPT-AET } & \text { precipitation minus actual evapotranspiration } \\ \text { RF1 } & \text { enhanced stream-reach file 1 } \\ \text { RMSE } & \text { root mean square error } \\ \text { SPARROW } & \text { SPAtially Referenced Regression On Watershed attributes } \\ \text { SS } & \text { suspended sediment } \\ \text { SWAT } & \text { Soil Water Assessment Tool } \\ \text { TN } & \text { total nitrogen } \\ \text { TP } & \text { total phosphorus } \\ \text { TPC } & \text { typical pollutant concentration } \\ \text { TSS } & \text { total suspended solids } \\ \text { U.S. } & \text { United States } \\ \text { USGS } & \text { U.S. Geological Survey } \\ \text { WWTP } & \text { wastewater treatment plant } \\ & \\ \text { SW } & \end{array}$





\title{
Spatially Referenced Models of Streamflow and Nitrogen, Phosphorus, and Suspended-Sediment Loads in Streams of the Midwestern United States
}

\author{
By Dale M. Robertson and David A. Saad
}

\section{Abstract}

In this report, SPAtially Referenced Regression On Watershed attributes (SPARROW) models developed to describe long-term (2000-14) mean-annual streamflow, total nitrogen (TN), total phosphorus (TP), and suspended-sediment (SS) transport in streams of the Midwestern part of the United States (the Mississippi River, Great Lakes, and Red River of the North Basins) are described. The nutrient and suspendedsediment models have a base year of 2012, which means they were developed based on source inputs and management practices similar to those existing during or near 2012 and average hydrological conditions detrended to 2012 (2000-14), whereas the streamflow model has base years of 2000-14, which means it was developed based on the average input precipitation minus actual evapotranspiration from 2000 to 2014. In developing the models, several updates and improvements were made to the data inputs and statistical approaches used to calibrate/develop the models from those used in the previous 2002 SPARROW models. The 2012 SPARROW models were constructed using a higher resolution stream network, which resulted in a mean catchment size of 2.7 square kilometers compared to 480 square kilometers in the 2002 models; more detailed and updated wastewater treatment plant contribution estimates; inputs from background phosphorus sources that were not included in the 2002 model; and more accurate loads for calibration that were computed using a modified Beale ratio-estimator technique whenever no trend in load was determined. Statistical approaches were added to compensate for the unequal effect of each monitoring site during the calibration process by adjusting for the fraction of the basin included in other upstream monitored sites (nested share) and thinning the calibration sites if a negative statistical correlation between nearby sites was determined.

Results from 2012 SPARROW models describe how much of each water, TN, TP, and SS source was delivered to the stream network, and the major landscape factors that affected their delivery. Atmospheric deposition and natural (background) sources of TN and TP, respectively, were the dominant sources in anthropogenically unaffected areas (especially in the Rocky Mountains and north-central areas of the Midwest), whereas fertilizers, manure, and fixation were dominant sources in agricultural areas, especially in the Corn Belt and near the Mississippi River. Urban sources of TN and TP were typically localized, but they were still important for some large areas, especially the Lake Erie Basin. All of the land-to-water delivery variables in the nutrient and sediment SPARROW models, such as runoff, soil erodibility, basin slope, and the amount of tile drains, are commonly included in process-driven models. In the SPARROW TN and TP models, best management practices (BMPs) reduced the delivery of these nutrients to streams.

Long-term mean-annual flows and nutrient and sediment loads were simulated in streams throughout the Midwest. The simulated flows from the SPARROW flow model were used in the SPARROW TN, TP, and SS models to help describe nutrient and sediment transport from the watershed and through the stream network. Outputs from the TN, TP, and SS models describe loads and yields of these constituents throughout the Midwest, and from major drainage basins throughout the Midwest. Highest TN, TP, and SS yields and delivered yields were from the Lake Erie, Ohio River, Upper Mississippi River, and Lower Mississippi River Basins, whereas lowest yields were spread over most other areas. Losses during downstream delivery resulted in part of the TN, TP, and SS that reach the stream network not reaching the downstream receiving bodies: 14,15 , and 28 percent of the TN, TP, and SS, respectively, are lost during delivery to the Great Lakes and 19, 23, and 52 percent of the TN, TP, and SS, respectively, are lost during delivery to the Gulf of Mexico. The largest losses of nutrients and sediments during transport were in the Missouri and Arkansas River Basins.

Information from these SPARROW models can help guide nutrient and sediment reduction strategies throughout the Midwest. Model results provide information on what may be the most appropriate general type of actions to reduce total loading by describing the relative importance of each source, and where to most efficiently place the efforts to reduce loading by describing the distribution of nutrient and sediment loading. By implementing management efforts addressing the major sources of the loads in areas contributing the highest loads, it may be possible to reduce nutrient loading throughout 
the Mississippi River Basin and thus reduce the size of the hypoxic zone in the Gulf of Mexico; reduce nutrient loading into lakes, and thus reduce the occurrence of harmful algal blooms; and reduce sediment losses, and thus improve the benthic habitat in streams and rivers throughout the Midwest.

\section{Introduction}

Excessive nutrients and sediment concentrations have been a persistent problem in streams and estuaries throughout the United States (Howarth and others, 1996; Carpenter and others, 1998; U.S. Environmental Protection Agency, 2000; Howarth and others, 2002; Bricker and others, 2008; Heimann and others, 2011; Lee and Glysson, 2013). In the "National Water Quality Inventory-1996 Report to Congress," the U.S. Environmental Protection Agency identified suspended sediment and siltation as the most common impairment to streams and rivers throughout the United States, followed by the overenrichment of nutrients (U.S. Environmental Protection Agency, 1996). Excessive input of phosphorus and nitrogen to streams and rivers from anthropogenic sources has been linked to excessive macrophyte and phytoplankton growth (U.S. Environmental Protection Agency, 1998). The downstream transport of these nutrients has been determined to cause increased eutrophication, harmful algal blooms, and hypoxia in lakes and reservoirs throughout the Midwest (Schindler and others, 2016), specific areas of the Great Lakes (Michalak and others, 2013; Watson and others, 2016), Lake Winnipeg (McCullough and others, 2012), and the Gulf of Mexico (U.S. Environmental Protection Agency, 2007; Mississippi River/Gulf of Mexico Watershed Nutrient Task Force, 2008). High suspended-sediment concentrations interfere with water-treatment processes and recreational uses of streams (Lorenz and others, 2009). Excessive siltation can bury and suffocate fish eggs and bottom-dwelling organisms. In addition to instream effects, excessive sediment loading can cause sedimentation problems in many downstream lakes and harbors and can lead to water-clarity problems in nearshore areas.

In developing management strategies to reduce nutrient and sediment export, it is important to understand where and from what sources the nutrients and sediment originate. This information is important in determining where to concentrate management efforts (in other words, identifying "hotspots" on the landscape) and deciding on what types of actions are needed to reduce export (such as, whether to focus on addressing export from point sources from wastewater treatment plants [WWTPs], or nonpoint sources from agricultural runoff).

Water-quality information is typically acquired by monitoring programs in which water samples are collected and analyzed in a laboratory; however, extensive monitoring is expensive and cannot typically be completed over large scales or in all streams. Modeling is one technique that can be used to extend the information gathered by monitoring to estimate the spatial distribution of water-quality conditions, identify linkages between those conditions and the environmental factors that affect them, and help interpret the monitoring information. SPAtially Referenced Regression On Watershed attributes (SPARROW) models (Smith and others, 1997; Schwarz and others, 2006; Alexander and others, 2008) represent one modeling technique that is specifically designed to extrapolate the information from monitoring data in selected riverine sites to all streams and rivers within a specific spatial domain.

SPARROW models offer several advantages in describing water-quality conditions over large scales compared to other modeling approaches. One advantage is that SPARROW models are developed using statistical algorithms to objectively identify the environmental factors that have significant linkages with water quality. SPARROW models can be used to identify the relative importance of various sources of a waterquality constituent, such as total nitrogen (TN) or total phosphorus (TP). A second advantage is that SPARROW models are designed to use detailed large-scale geographic information and synthesize that information in a way that it can be related to the spatial scale of available monitoring data while retaining the underlying small-scale spatial resolution for prediction purposes. In this way, SPARROW models provide a framework for integrating a wide range of data and use all that information to provide spatially detailed estimates of waterquality conditions. In SPARROW, these estimates are typically of streamflow or loading, which is the transport of a mass of a constituent over a given time interval. A third advantage is that SPARROW models provide water-quality load estimates that are fully referenced in space through a digital stream network dataset so that upstream environmental factors in the model can be related to downstream water-quality conditions (in other words, the model is spatially referenced). These characteristics result in the ability of SPARROW models to describe water-quality conditions over large areas while retaining substantial spatial detail; describe the factors that affect water-quality conditions; and relate upstream environmental factors, such as the various sources of specific constituents, to downstream water quality.

\section{Purpose and Scope}

In this report, we describe SPARROW models developed to simulate long-term (2000-14) mean-annual streamflow and TN, TP, and suspended-sediment (SS) transport in streams and rivers in the Midwestern part of the United States (fig. 1) based on inputs and management practices centered near 2012, the base year of the model (referred to as the 2012 SPARROW models). The Midwest region is one of five areas of the United States for which SPARROW models for similar constituents were developed as part of a national modeling effort by the U.S. Geological Survey (USGS). The other four areas include the Northeast (Ator, 2019), Southeast (Hoos and Roland, 2019), Southwest (Wise and others, 2019), and Pacific (Wise, 2019) regions of the United States. 


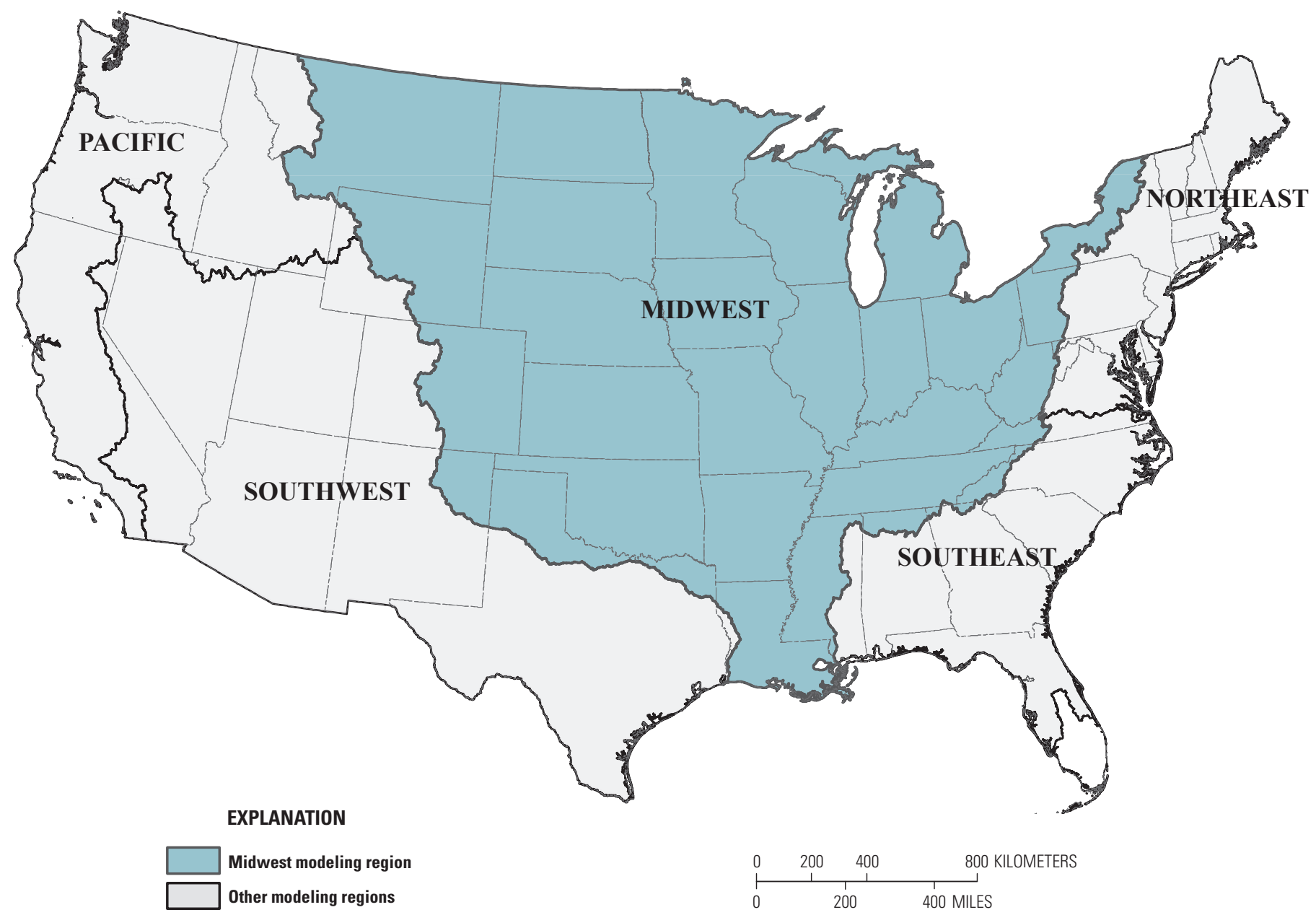

Figure 1. Spatial extent of the Midwest SPARROW (SPAtially Referenced Regression On Watershed attributes) model region. Other regions being modeled also are delineated.

SPARROW models describing TN and TP transport have been developed previously for the entire conterminous United States (Smith and others, 1997) and large regions of the conterminous United States (Preston and others, 2011) as part of the USGS National Water Quality Assessment (NAWQA) Program. These models were representative of conditions between the late 1980s and early 2000s. Three of the regional models included portions of the Midwestern United States: Upper Midwest (Robertson and Saad, 2011); Missouri River Basin (Brown and others, 2011); and Lower Mississippi, Arkansas-White-Red Rivers and Texas-Gulf Basins (Rebich and others, 2011). In addition to these efforts, SPARROW models have been developed for the Mississippi-Atchafalaya River Basin (Alexander and others, 2008; Robertson and Saad, 2013; Robertson and others, 2014) and the Red-Assiniboine River Basin (Benoy and others, 2016). The previous SPARROW models describing TN and TP transport for all or parts of the Midwest were based on inputs and management practices similar to either 1987 or 2002 and were based on models with a lower spatial resolution (subdivided into about 480-square kilometer $\left[\mathrm{km}^{2}\right]$ catchments). Since those models were developed, land uses, agricultural practices, and data availability have all changed. The 2012 Midwest SPARROW models, in this study, were developed using updated and improved datasets including a more detailed (higher resolution) spatial framework, load estimates that were derived with greater accuracy, and more detailed point-source information than were used in the previous models.

Some calculations within SPARROW models, such as instream and reservoir decay, rely on estimates of the long-term mean flow throughout the modeled area. In past SPARROW applications, long-term mean streamflows were estimated from data collected from 1971 to 2000 from streamgages throughout the United States (D. Wolock, U.S. Geological Survey, written commun., 2009). Mean flow estimates were not available for the years bracketing 2012; therefore, 2012 SPARROW streamflow models were also developed and output from the model was used in the other SPARROW models to provide more contemporaneous flow data for use in the 2012 SPARROW TN, TP, and SS models. 


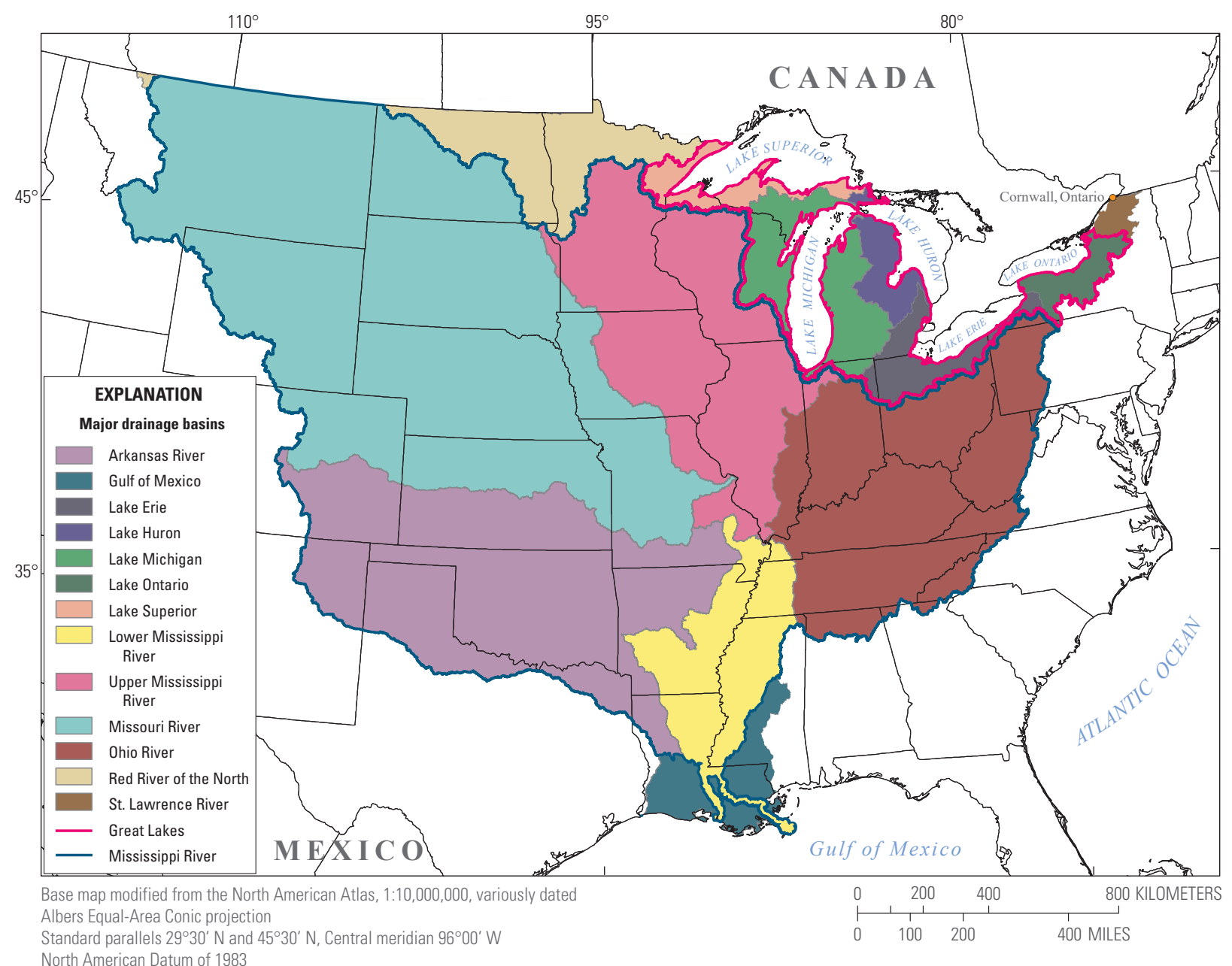

North American Datum of 1983

Figure 2. Major drainage basins within the Midwest study area.

As part of the work described here, several of the statistical approaches used in the previous SPARROW modeling studies were refined and enhanced to improve model predictions and improve the interpretability of information from the models. These updates and improvements are meant to provide water-quality information that better supports management needs such as what general type of actions are needed, by understanding the relative importance of each of the sources, and where actions should have the largest effect, by understanding where the largest yields of nutrients and sediments are.

\section{Study Area Description}

The SPARROW models developed in this study describe long-term mean-annual streamflow, and TN, TP, and SS transport throughout the Midwestern part of the United States. For this study, the Midwestern part of the United States includes four main areas: (1) basins of all U.S. tributaries draining into the Great Lakes; (2) basins of all U.S. tributaries draining into the St. Lawrence River downstream from Lake Ontario and upstream from Cornwall, Ontario; (3) the Red River of the North Basin to the Canadian border; and (4) the Mississippi River Basin and adjacent tributaries in Louisiana draining into the Gulf of Mexico (fig. 2). This area covers about 3.7 million $\mathrm{km}^{2}$ and includes all or parts of 31 States. The Great Lakes Basin was further subdivided into areas draining into each of the Great Lakes (Lakes Erie, Huron, Michigan, Ontario, and Superior). The Mississippi River Basin was further subdivided into the Upper Mississippi Basin, Missouri River Basin, Ohio River Basin, Arkansas River Basin, and Lower Mississippi River Basin that includes the Atchafalaya River. In addition, the Gulf Coast Basin includes the area draining directly to the Gulf of Mexico, but not from the Mississippi or Atchafalaya Rivers. This division results in the Midwest study area being divided into 13 major drainage basins (fig. 2). Throughout this report, model results are presented for each of the 13 major drainage basins, which were combined into the Mississippi River and Great Lakes Basins, and the entire study area. 


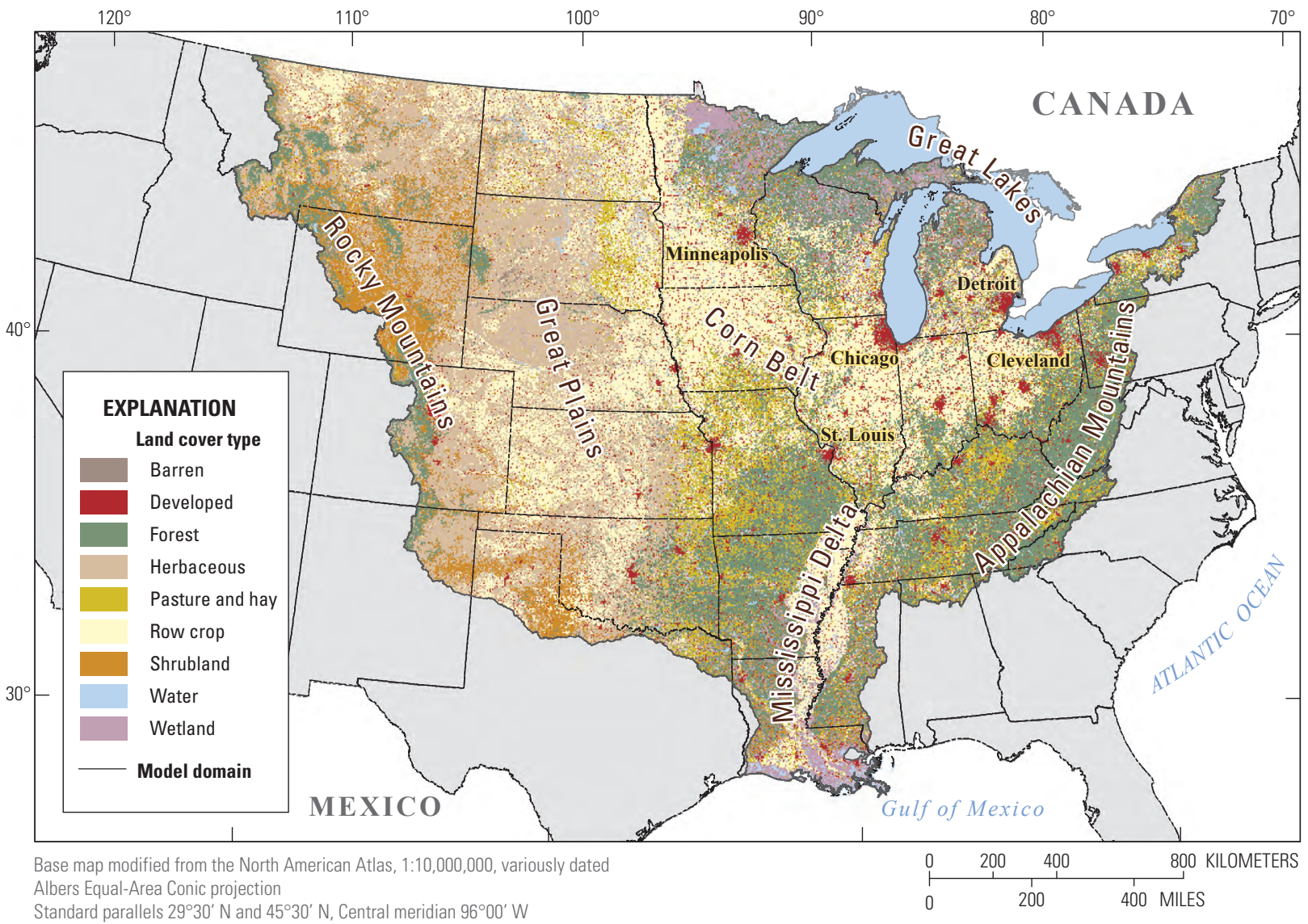

Standard parallels $29^{\circ} 30^{\prime} \mathrm{N}$ and $45^{\circ} 30^{\prime} \mathrm{N}$, Central meridian $96^{\circ} 00^{\prime} \mathrm{W}$

North American Datum of 1983

Figure 3. Land cover in the Midwest region of the United States, 2011 (Homer and others, 2015; Wieczorek and others, 2019).

Major features of the Midwest include the Rocky Mountains and Great Plains in the west, the Appalachian Mountains in the east, the Mississippi Delta in the south, and the Great Lakes in the north (fig. 3). The central part of the Midwest is dominated by an extensive agricultural area commonly referred to as the "Corn Belt." Extensive forested areas occur in the north and southeast, and extensive grasslands occur in the west. This area also includes some of the largest urban areas in the United States, including Chicago, Illinois; Minneapolis, Minnesota; Detroit, Michigan; Cleveland, Ohio; and St. Louis, Missouri. Streams and rivers in the Midwest region drain to the Gulf of Mexico to the south, the Great Lakes to the northeast, and Lake Winnipeg to the northwest (not shown).

One of the most important factors affecting streamflow and the transport of nutrients and sediment is the difference in the amount of precipitation (PPT) and actual evapotranspiration (AET). There is a strong northwest to southeast gradient in mean PPT across the Midwest. Mean-annual PPT ranges from approximately 130 millimeters per year $(\mathrm{mm} / \mathrm{yr})$ in the west to $2,400 \mathrm{~mm} / \mathrm{yr}$ in the southeast (PRISM Climate Group, 2015). There also is a strong northwest to south gradient in AET (McCabe and Wolock, 2011), which ranges from less than $130 \mathrm{~mm} / \mathrm{yr}$ in the northwest to almost $1,100 \mathrm{~mm} / \mathrm{yr}$ in southern Louisiana. The difference in PPT and AET (PPTAET) results in a strong gradient in water available to reach the stream network ranging from less than $30 \mathrm{~mm} / \mathrm{yr}$ in the west to more than $2,000 \mathrm{~mm} / \mathrm{yr}$ in the southeastern part of the Midwest (fig. 4). 


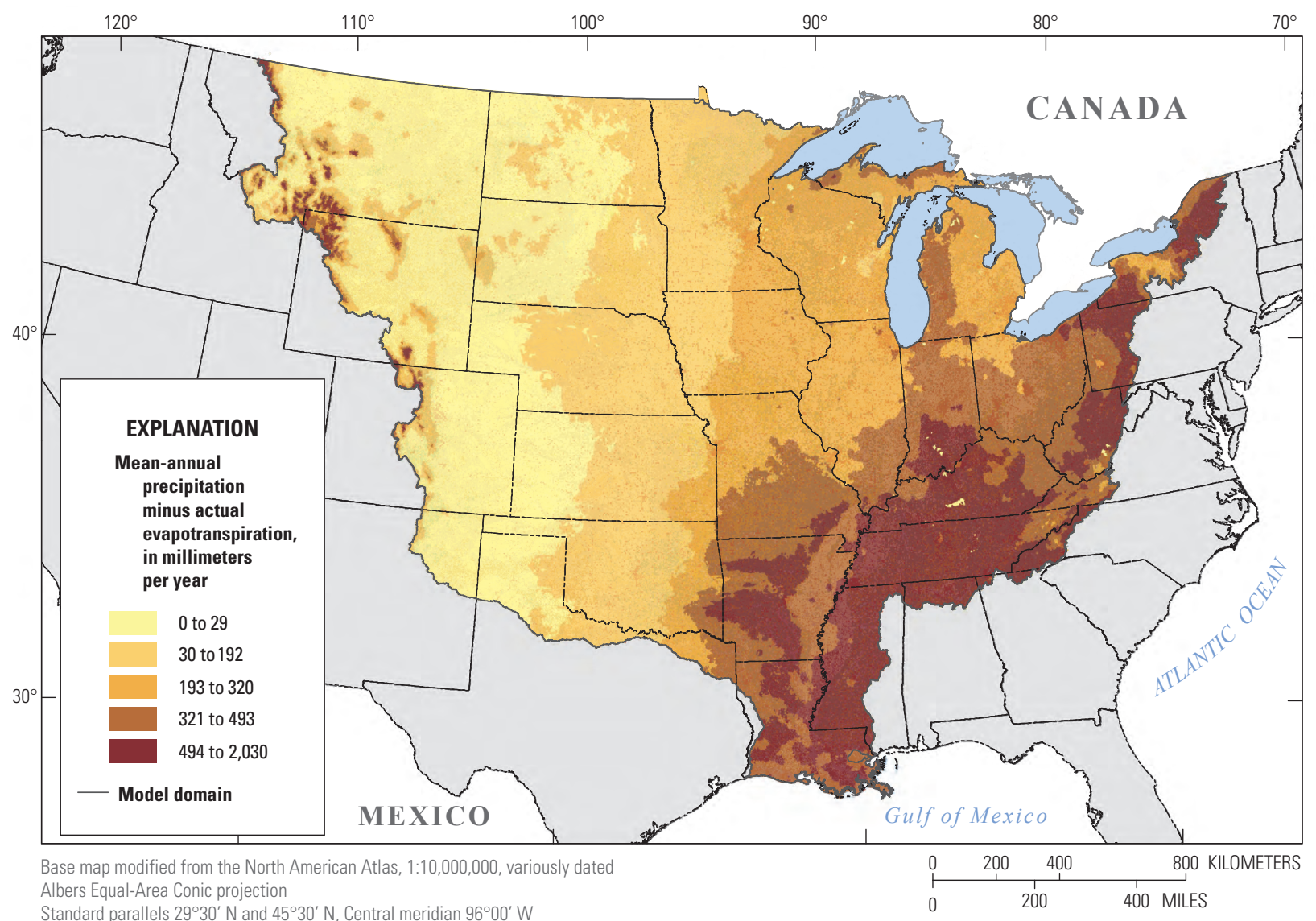

Standard parallels $29^{\circ} 30^{\prime} \mathrm{N}$ and $45^{\circ} 30^{\prime} \mathrm{N}$, Central meridian $96^{\circ} 00^{\prime} \mathrm{W}$ North American Datum of 1983

Figure 4. Mean-annual precipitation minus actual evapotranspiration (water years 2000-14) in the Midwest region (Wieczorek and others, 2019; Wolock and McCabe, 2018).

\section{Methods}

\section{SPARROW Model}

SPARROW is a spatially referenced watershed model that uses a hybrid mass-balance/statistical approach to estimate the nonconservative transport (that is, transport with losses) of a constituent throughout a study area in relation to landscape properties that include sources of a given constituent and factors describing variability in the transport of the constituent, such as climate, soils, artificial drainage, and instream/reservoir properties (Smith and others, 1997; Schwarz and others, 2006; Alexander and others, 2008). SPARROW models typically simulate the long-term (decadal) mean-annual transport (the flux or load of a given constituent) given source inputs and management practices similar to a given period (referred to as the "base year," in this study around 2012). SPARROW models simulate annual constituent transport (streamflow or constituent loading) from catchments throughout the study area to the river network (appendix 1); therefore, the model includes inputs from surface-water runoff and groundwater inputs during base-flow and high-flow events. In the SPARROW applications described in this report, the mean-annual transport is for streamflow (in cubic feet per second), TN and TP (in kilograms per year); and SS loads (in metric tons per year). Streamflow, in cubic feet per second, is directly proportional to the total flux of water per year; therefore, streamflow, in cubic feet per second, is analogous to the total mean-annual load of other constituents, in kilograms per year or metric tons per year, being transported down the stream network if all its sources are provided in the same units in each of the respective models. Spatial variability in the environmental setting, described with land-to-water delivery variables, is used to describe variability in the amount of a constituent from each source in the model that is mediated by surface and subsurface properties during transport to the stream/river network (hereafter referred to as simply "stream network"). Variability in flow and residence time in streams and reservoirs is used to describe variability in transport down the stream network. 
The coefficient reported for each source variable (appendix 1) is expressed as an estimate of how much of a given source (typically in kilograms per year, metric tons per year, or cubic feet per second) is delivered for the mean-adjusted land-to-water delivery factors; this expression standardizes each source coefficient to the mean of the delivery factors across the study area, allowing a more accurate comparison of the source coefficients within and between models. The amount of a constituent ultimately transported or delivered to a downstream location incorporates the fraction of the inputs mediated by climatic and landscape properties and delivered to the stream and the fraction of the water or constituent load removed during downstream transport through the river network, both of which are estimated during model calibration. The magnitude of the coefficient for a land-to-water delivery variable indicates the sensitivity of the modeled constituent to changes in that delivery variable. For delivery variables that are logarithmically transformed, the interpretation of sensitivity can be quantified as follows: a coefficient value of $X$ means that a 1-percent difference between catchments in the value of the delivery variable causes an $X$-percent difference between catchments in the delivery ratio. If all delivery variables are logarithmically transformed, the variables with the larger (positive or negative) coefficient are those to which the delivery of the constituent is most sensitive. Calibrated SPARROW models can be used to simulate streamflow and water-quality loading throughout the surface-water network, including areas where no measured streamflow or water-quality data exist. See appendix 1 for more details on the SPARROW model.

\section{SPARROW Model Calibration}

In SPARROW model development/calibration, various model specifications are evaluated to determine which constituent sources, landscape characteristics, and stream/reservoir decay variables are statistically associated with constituent transport. In other words, various forms of the regression equations (different variables) are evaluated in equation 1.2 in appendix 1. In some cases, variables specified in the model may serve as surrogates for other factors that are spatially correlated with those specified in the models. For example, although the amount of agricultural land may be included as an input source in the SPARROW TN model, it also may represent nitrogen from natural sources and other agricultural sources that are not included in the model. Variables identified as statistically significant, typically probability values less than $0.05(p<0.05)$ based on one-sided (source variables and instream and reservoir decay variables) or two-sided (land-to-water delivery variables) $t$-tests, in explaining the distribution in measured loads are typically retained in the model. If source variables are not statistically significant, they are typically combined with other sources in a series of model calibrations until an acceptable specification is obtained in terms of model fit (based on root mean square error [RMSE], model-estimated coefficients, variance inflation factors, and residual plots). If the land-to-water variables or reservoir decay variables are not statistically significant, they are typically not included in the model. Coefficients in the models reported here were estimated using nonlinear least-squares regression (Schwarz and others, 2006) or weighted nonlinear least-squares regression (described below). Other calibration techniques have been developed (such as Bayesian techniques; Wellen and others, 2015) but were not used in developing the models described in this report.

The mechanistic mass-balance framework of SPARROW (appendix 1) enables a fairly complete accounting of the constituent sources, implying the overall delivery of these sources to monitoring locations in streams is reasonably estimated. Coefficients for the source terms have a physical interpretation that depends upon the form by which each source is expressed in the model. Coefficients estimated for source terms with units of volume or mass per unit time represent a scaling factor (fraction of the input source delivered to the stream) for that source, whereas coefficients estimated for source terms with units of area represent the mean yield (typically kilograms per unit area) of that source. The coefficients for the stream and impoundment decay terms can be used to determine the fraction of the water, sediment, or nutrients entering the stream network that is transported to any point downstream on the network. The individual land-to-water delivery factors included in a final calibrated SPARROW model may not represent all the factors operating in an actual ecosystem, complicating the determination of their causative effect. Therefore, we caution the interpretation of the coefficients of each of the individual land-to-water delivery factors, similar to the caution that should be used when interpreting individual coefficients obtained with simple multiple regression approaches (Box, 1966).

\section{Changes in the SPARROW Modeling Approach from Previous Applications}

The 2012 Midwest SPARROW models developed in this study are different from those previously developed for all or parts of the Midwest by Smith and others (1997), Alexander and others (2008), Brown and others (2011), Rebich and others (2011), Robertson and Saad (2011), Robertson and Saad (2013), and Benoy and others (2016) in many important ways as described in the following subsections.

\section{Improvements in the Resolution and Accuracy of the Explanatory and Response Variable Data}

First, the new models described here are based on inputs and management practices similar to 2012 (at least 10 years more recent than the data used in the previous models); therefore, the results are more representative of recent conditions. The constituents for which models were developed were expanded from TN and TP to include water volume 
(streamflow) and SS. These additional constituents are not only of value in themselves but also are related to TN and TP transport and the factors affecting their transport. For a few constituent sources, primarily inputs from WWTPs (described in the "Sources of Water, Nitrogen, Phosphorus, and Suspended Sediment" section), more effort was put into obtaining measured effluent concentration data rather than relying on extrapolated (regional average) concentration data (Skinner and Maupin, 2019). The new models have a higher spatial resolution than most of the previous models. The spatial framework for the new models (described below in the "Surface-Water Drainage Network" section) is based on the National Hydrographic Dataset Version 2 at a 1:100,000 scale (hereafter referred to as "NHDPlusV2"; Horizon Systems, 2013) and provides a much greater spatial resolution compared to previous SPARROW models.

Several studies have been critical of the data used to calibrate previous SPARROW models (Stenback and others, 2011; Richards and others, 2013), including the data used to develop the previous models for the Midwest. Previous SPARROW models were calibrated with long-term mean-annual TN and TP loads estimated using regression techniques, which were later determined to be potentially biased, potentially underestimating TP loads (Stenback and others, 2011; Richards and others, 2013). To minimize this problem, long-term meanannual loads used in calibrating the models in this study were computed with both a modified Beale ratio-estimator (BRE) technique (Beale, 1962) and a regression-based five-variable water-quality model that was a function of flow, seasonality (sine and cosine terms), trend, and an intercept with Kalman smoothing (F5K; Saad and others, 2019). The modified BRE method was implemented in stratified form as described in Cochran (1977) and used to estimate long-term mean-annual loads. The BRE method is typically used to compute annual loads; however, the modified BRE method was used to estimate the long-term mean-annual load using 8 strata formed by subdividing daily average flows from all years into 2 classes (delineated by the 80th percentile of flow) and 4 seasons. Whenever there was no trend in the loads based on the F5K method, the BRE load was used because it was determined to have little bias and provided more accurate estimates of longterm mean-annual loads for less conservatively transported constituents, such as TP and sediment, than most regression approaches (Lee and others, 2016). When there was a statistically significant trend $(p<0.05)$ in the F5K loads between 2000 and 2014 for a site, the long-term mean-annual load, detrended to 2012, was used to calibrate the models. Before use as calibration targets in SPARROW models, all loads were evaluated for accuracy and bias. Load relations with standard errors greater than 50 percent of the mean load estimate were considered unacceptable, which is consistent with the accuracy level used in previous SPARROW studies (Saad and others, 2011), and dropped from consideration. The approaches used to estimate loading using BRE and F5K methods, and assess their accuracy, are described in detail by Saad and others (2019).

\section{Methods to Produce Statistically Independent Model Residuals}

There also have been criticisms of how the monitoring data have previously been used to calibrate the SPARROW models (Qian and others, 2005; Wellen and others, 2014). Previous SPARROW models were developed under the assumption that the residuals from the monitoring sites are statistically independent and that errors in the measured loads are relatively small; however, proximity of some of the monitoring sites and the possibility of large errors incorporated into the mean-annual loads (for example, related to imprecision in the monitoring load estimates) can potentially contribute to less precise estimates of the SPARROW coefficients and the model errors. Possible site density and spatial bias problems were evaluated using statistical tests that were developed to identify significant spatial correlation in the model residuals in tight clusters of closely spaced calibration sites (those within 5 kilometers $[\mathrm{km}]$ of each other). In these tests, two Pearson correlation coefficients are computed for all combinations of the residuals from sites within $5 \mathrm{~km}$ of each other: one for calibration sites on the same stream (nested sites) and one for calibration sites on different streams and nested calibration sites with dissimilar drainage areas, a ratio greater than a factor of 2 (collectively referred to as nonnested sites). A significant positive correlation $(p<0.05)$ for either of these two groups may indicate that closely spaced sites are both affected by similar environmental factors that are not well specified in the model. A negative correlation for either of these groups may indicate errors in the source variables, meaning that the spatial scale of a source variable was coarser than the spatial scale of the catchments and the sources may be overallocated to one site and underallocated to a neighboring site. There is no systematic way to remove the effects of a significant positive coefficient other than to try to improve the model specification. However, to address significant negative spatial correlation, we thinned the closely spaced nested monitoring sites by only including the most downstream site for further model calibration and thinned the closely spaced nonnested sites by randomly selecting one site in each pair and removing it from the calibration dataset.

In addition to sites being too closely spaced, calibration sites are commonly nested within the basin of downstream sites (in other words, some calibration sites are upstream from other calibration sites). When this placement exists during typical SPARROW calibration, the model-simulated load at each upstream calibration site is replaced with its measured load to eliminate errors from propagating down the stream network and to reduce the correlation across the subbasin error terms (Smith and others, 1997). The resulting downstream load that is simulated using the upstream measured load is referred to as the "conditioned" predicted load used in model calibration, whereas the load exclusively predicted by the model is referred to as the "unconditioned" predicted load or simply the "simulated load." This use of conditioned loads during calibration 
can result in an underestimation of the residuals compared to when the model is used to simulate loads throughout the basin, especially for sites with many upstream hydrologically nested sites. The net effect of sites being nested and the use of conditioned loads in model calibration is a potential reduction in the effect the downstream sites have on the coefficients in the SPARROW model (Wellen and others, 2014), and can result in a relation among the residuals (Qian and others, 2005). Because the sites with larger drainage basins are more likely to be affected by this reduction in the magnitude of the residuals, it can result in a heteroscedastic distribution in the residuals.

To address the potential unequal effect of the nested basins during model calibration and reduce the heteroscedastic distribution of the residuals, a statistical algorithm was developed to compute weights for each of the residuals. The weights are computed as being proportional to the fraction of the upstream drainage area that is downstream from other monitored sites (the nested share). These weights are then used in a subsequent reestimation of the model using weighted nonlinear least-squares regression (Schwarz and others, 2006, eq. 1.55). To obtain the weights for each site, the SPARROW model is first estimated with nonlinear least-squares regression using equal weights applied to all monitoring sites to obtain an estimate of the model residuals. The squared values of these residuals are then regressed on the fraction of each monitored basin that is not included in upstream monitored sites (sites with no upstream monitoring locations are assigned a value of 1.0), and if there is a significant relation, then the inverses of the predicted values from this regression serve as weights in a subsequent reestimation (recalibration) of the SPARROW model. Because the coefficient associated with the squared residual and nested share regression relation has a positive sign, the result is a second SPARROW model calibration that uses larger residual weights for the load observations associated with sites that have small areas downstream from the other monitoring sites. During this process, the model specification (final variables included in the model and their coefficients) was again evaluated in an iterative manner. For a further description of the methodology to remove the effects of nested monitoring sites see Robertson and others (2019). Because of these changes, slight changes were needed to demonstrate the robustness of the final models compared to those used for previous models. Confidence intervals were determined for each coefficient using the standard errors from the weighted nonlinear least-squares regression and the quantile from the standard $t$-statistic distribution. Confidence intervals in SPARROW predictions were computed in the conventional manner using bootstrap methods (parametric) with 200 iterations, which included correcting for potential bias caused by logarithmic retransformations. For a full description of bootstrap methodology see Schwarz and others (2006).

In spatial regression models, it is preferred that the residuals are spatially independent. To determine if there was a spatial correlation among the model residuals, the Moran's $I$ statistic (Cliff and Ord, 1973) was used to identify significant spatial correlation among loose clusters of calibration sites.
A significant positive test statistic indicates that there is spatial clustering of residuals with the same sign; in these cases, the model might be improved by adding additional explanatory variables (beyond those tested in our study) that enhance model performance in regions where the model consistently overpredicts or underpredicts mean-annual load.

\section{Reporting of a Refined Measure of SPARROW Model Performance}

In most SPARROW applications, the RMSE of the model is one of the primary statistical evaluation criteria. The RMSE from a SPARROW model is typically based on the difference in the measured loads and the conditioned predicted loads (both in logarithmic space) computed during calibration (in other words, where the predicted loads at each upstream monitoring site are replaced with the measured values). This replacement can result in an underestimation of the model error compared to when the model is used to simulate loads throughout the basin, using the unconditioned predictions (Qian and others, 2005; Wellen and others, 2014). Therefore, an unconditioned RMSE also is reported for each final model, which was based on the differences in the measured loads and the unconditioned loads predicted with the final SPARROW model. The unconditioned RMSE provides the best representation of the predictive skill of a calibrated SPARROW model and is well suited for comparing the prediction accuracy of different models because conditioning effects on the predicted loads are removed.

\section{Expanded Monitoring Estimates of Suspended- Sediment Loads for SPARROW Calibration}

Water-quality data used to calibrate SPARROW models are typically assembled from various agencies that may have used different techniques for collecting and processing waterquality samples. For example, for most samples collected by the USGS, cross-sectionally integrated and flow-integrated techniques have been used (U.S. Geological Survey, 2018a), whereas surface-grab sampling methods have been used by most other agencies. In addition, for some constituents, different analytical techniques have been used in the laboratory. For sediment in the water column, two analytical techniques have been commonly used: the suspended-sediment method (American Society for Testing and Materials, 2006) was typically used by the USGS, and the total suspended solids method (American Public Health Association, American Water Works Association, and Water Pollution Control Federation, 2012) was typically used by most other agencies. The suspended-sediment concentration is the mass of all the sediment within a known volume of a water-sediment mixture collected directly in the water sample (Guy, 1969). In contrast, the total suspended solids (TSS) concentration is the mass of suspended material within a subsample of a water-sediment mixture collected directly from the water sample. Such subsampling 
can introduce negative bias and more variability, especially when the percentage of sandsize sediment is high because of sediment settling before subsampling (Gray and others, 2000). Values determined by both methods should not generally be used interchangeably (Gray and others, 2000). Most of the available sediment data for the Midwest area were TSS data; however, development of a SPARROW suspended-sediment (SS) model is preferred because suspended sediment provides a better representation of the total mass of sediment in the water column than TSS.

The number of calibration stations where suspended sediment was measured was not sufficient for satisfactory SPARROW model development; therefore, to enable a SPARROW SS model that uses loads based on both suspended-sediment and TSS concentrations to be developed, an approach was developed to account for the potentially systemic differences between the two groups of calibration loads. In this approach, a statistical difference in the two groups was evaluated by including an additional variable in SPARROW (If_Tss) with a value of 1.0 when the calibration load was based on TSS data and a value of 0.0 when the calibration load was based on suspended-sediment data. Then an additional coefficient for this variable was evaluated during model calibration. Because this coefficient only applies to reaches associated with TSS, it can be interpreted as a scaling factor for converting between the two types of loads. Because the SPARROW SS model was calibrated in logarithmic space, the coefficient for the If_TsS variable can be converted to a scaling factor using equation 1. A similar approach could be used to evaluate differences in the loads in other constituents estimated by different agencies, but it was not used in this study.

$$
\text { SS load }=T S S \text { load } \times\left(1 / e^{I f-T s s}\right)
$$

where

SS load is the suspended-sediment load,

TSS load is the total suspended solids load, and

If_TsS is the coefficient used to compute the scaling

factor between suspended solids loads and suspended-sediment loads.

\section{SPARROW Model Predictions}

SPARROW models provide predictions of incremental (originating in the immediate catchment area) and accumulated (originating in the immediate catchment area and all upstream catchments) loads and yields, volumetrically weighted concentrations, and source-share contributions for each stream reach. In addition, the delivered incremental and delivered accumulated load and accumulated yield from any location are computed as that part of the load and yield (delivery fraction) ultimately transported downstream to a specific location, in this case the Gulf of Mexico, each of the Great Lakes, and the Red River of the North at the Canadian border, after accounting for downstream removal/attenuation in streams and reservoirs. Loads and yields (with upper and lower confidence limits) were simulated from each of the major drainage basins in the modeled area, from the Mississippi/Atchafalaya River Basin, from the U.S. part of the Great Lakes Basin, and from the U.S. part of the Red River of the North Basin. The upper and lower confidence limits for flow and loads at the end of each catchment and summary area are provided in Saad and others (2019).

\section{Data Used to Develop and Calibrate the SPARROW Models}

Four types of data are used to build or calibrate SPARROW models: (1) a routed, digital surface-water stream network that consists of a series of stream reaches that extend between nodes in the stream network. The incremental drainage area associated with each stream reach is referred to as a catchment. Each stream reach has attributes that are used to define instream/reservoir losses and gains (delivery fraction); (2) long-term mean-annual loads (including long-term mean flow for the streamflow models) for many sites throughout the study area; (3) information describing all the main sources of the constituent being modeled (in this case water, TN, TP, and SS); and (4) information describing factors affecting the delivery of the constituent from the land (catchment) to the stream (land-to-water delivery variables). Mean-annual loads represent the dependent variables used in the models. The stream network, source, and land-to-water delivery data represent the independent variables. Most network and catchment/ watershed attributes used in the Midwest SPARROW models were compiled by NAWQA as part of a national effort (Wieczorek and others, 2019; Brakebill and others, in press) and are briefly described here, but some watershed attributes were created specifically for the Midwest SPARROW models and are described in more detail. All network and watershed attributes used in the Midwest SPARROW models are described and included in an associated USGS data release (Saad and Robertson, 2019). During SPARROW model calibration, many model specifications were evaluated to determine which constituent sources, landscape characteristics, and stream/reservoir decay variables were statistically significant in controlling the transport of constituents. All the variables examined, and the final variables included in the models are summarized in appendix 2 .

\section{Surface-Water Drainage Network}

The surface-water drainage network for the Midwest models was constructed from a modified version of NHDPlusV2 that includes attributes for surface-water features, such as streams (identified as perennial or intermittent), lakes, ponds, and artificial reservoirs (Simley and Carswell, 2009; Horizon Systems, 2013; Brakebill and others, in press). These surface-water features correspond to features identified on 1:100,000-scale USGS topographic maps. Each stream 
reach in NHDPlusV2 starts at a point of channel initiation or tributary junction. Most reaches represent streams or inland waterbodies, such as lakes and reservoirs; however, some reaches represent coastlines or closed basins that do not have a surface-water connection to other reaches. In addition to the reservoir information in NHDPlusV2, reservoir information from the U.S. Army Corps of Engineers National Inventory of Dams dataset for the United States (U.S. Army Corps of Engineers, 2016) was incorporated into the network. In the process of building the hydrologic framework for the SPARROW models, most reaches (associated with closed basins) that do not drain to the Gulf of Mexico, Great Lakes, or Canadian border were eliminated. In NHDPlusV2, the incremental watershed draining into each stream reach without passing through another reach is referred to as a catchment and is identified in the dataset. Not all stream reaches were large enough to delineate a catchment and were simply used to connect nearby catchments. Although NHDPlusV2 contains minimal information for stream reaches and watersheds in Canada and Mexico, it did provide sufficient information to properly route surface water into the United States.

The Midwest SPARROW modeling domain (fig. 2) has about 1.38 million reaches, which vary in size from small, intermittent streams that can go years without flow to the Mississippi River near to where it enters the Gulf of Mexico, with an average streamflow greater than 660,000 cubic feet per second $\left(\mathrm{ft}^{3} / \mathrm{s}\right)$. The domain has about 1.36 million catchments, with a median catchment size of $1.4 \mathrm{~km}^{2}$ (mean size of $2.7 \mathrm{~km}^{2}$ ), compared to catchments with a median size of $480 \mathrm{~km}^{2}$ in the original Robertson and Saad (2011 and 2013) models based on the enhanced stream-reach file 1 (RF1; 1:500,000 scale; Nolan and others, 2003). About 52 percent of the free-flowing stream length within the model domain was identified as having perennial streamflow, and 48 percent was identified as having intermittent streamflow.

\section{Long-Term Mean-Annual Streamflow and Constituent Load Information}

SPARROW is a steady-state, mass-balance model that relies on the assumption that the dependent and explanatory variables reflect conditions for comparable periods of time (Schwarz and others, 2006). Use of a uniform period of record (or closely comparable periods of record) to estimate all variables removes the confounding effect of temporal variability from the SPARROW spatial analysis. For the SPARROW streamflow model, comparability among estimates of the dependent variable was achieved by using the mean-annual value for a common 15-year period (October 1, 1999, through September 30, 2014; water years 2000 through 2014) for all stations and based on continuous daily mean streamflow records. Average flow rates based on 15 years of data enables the model to represent the typical variability in flow throughout the study area, rather than variability caused by weather conditions that may occur in any one year. Sites missing more than 2 years of streamflow record during this period were excluded from the calibration dataset. Comparability between the dependent variable (streamflow) and explanatory variables for the SPARROW streamflow model was achieved by using mean-annual precipitation minus actual evapotranspiration (PPT-AET) for 2000-14, which was expected to be the primary source of streamflow throughout the study domain.

For the SPARROW TN, TP, and SS models, estimated loads used for calibration sites with trends in loads were normalized (detrended) to the selected base year, rather than using the BRE-estimated long-term mean-annual loads. In other words, the estimated loads represent the loads that would have been observed during 2000-14 if the dynamic factors causing trends in loads were held constant throughout that period, equal to their values in the base year. The loads were normalized to a specific base year because comparability of conditions could not be guaranteed using mean values for 2000-14 because the water-quality monitoring data used to estimate loads may represent different periods of record, sample size, and hydrologic conditions at different sites, or may be affected by long-term trends in water quality (Schwarz and others, 2006). The explanatory variables for these models also were normalized (detrended) to the same base year. For monitoring sites for which no significant trends in water quality were observed during 2000-14, the BRE-estimated mean-annual load for the period was used in the analysis. For monitoring sites with significant trends during 2000-14, the base year loads were estimated by detrending the estimated loads to 2012 (described later in this section). The watershed attributes used as explanatory variables (for example, source inputs, climatic data, and land management practices) in these models were also meant to represent 2012 conditions or conditions as close to 2012 as possible (described in the "Sources of Water, Nitrogen, Phosphorus, and Suspended Sediment" section and the "Factors Affecting Water, Nitrogen, Phosphorus, and Suspended-Sediment Transport" section). The predictions from the SPARROW TN, TP, and SS models, therefore, represent loads and yields that would have been observed between 2000 and 2014 given the hydrologic conditions throughout that period and given source inputs and management practices that were similar to those occurring in 2012.

The dependent variables in Midwest SPARROW models were long-term mean streamflow (in cubic feet per second) and long-term mean-annual TN, TP, and suspended-sediment/ suspended solids loads (in kilograms per year) that were detrended when necessary to the 2012 base year. A brief summary of the methods used to estimate the long-term meanannual streamflow, and TN, TP, and suspended-sediment/ suspended solids loads is included here; additional details are in Saad and others (2019). Streamflow data for the 15-year period from October 1, 1999, to September 30, 2014, were compiled from 11,575 monitoring sites in the Midwest study area (fig. 2). These data were primarily obtained from the USGS National Water Information System (NWIS) database (U.S. Geological Survey, 2015), but data also were obtained from the U.S. Army Corps of Engineers (2019), Colorado 
Division of Water Resources (2019), and a cooperative streamgaging network operated by the Minnesota Department of Natural Resources (2019) and the Minnesota Pollution Control Agency (2019). Mean-annual streamflow was computed from monitoring sites with continuous (daily mean) streamflow for a minimum record length of 13 years (with no missing data) and a record that included 2012 (the base year).

To estimate long-term mean-annual TN and TP loads, various forms of nitrogen and phosphorus concentration data were compiled from nearly 94,000 stream monitoring sites, and to estimate SS and TSS loads, concentration data were compiled from more than 60,000 sites from October 1, 1999, to September 30, 2014. Most water-quality data were obtained from the USGS NWIS (U.S. Geological Survey, 2019) and U.S. Environmental Protection Agency databases (U.S. Environmental Protection Agency, 2018a); however, additional data from several water-resources agencies were obtained to help fill in temporal and spatial data gaps (Saad and others, 2019). Water-quality data from 71 Federal, State, regional, local, Tribal, university, and private sampling agencies and organizations were used to estimate TN, TP, SS, and TSS loads throughout the Midwest area (appendix 3). It was assumed that data from each of these sources provided comparable concentration information.

Once the streamflow and water-quality concentration datasets were compiled, the data were screened to identify sites with sufficient data to compute long-term mean-annual TN, TP, SS, and TSS loads. For a site to be considered for use in the models, it had to have sufficient streamflow and waterquality data, have its location indexed to the digital stream network used in the models, and have a paired nearby streamgage to estimate the loads. For a streamgage to be considered for use in load computations, it had to have a minimum record length of 10 years of daily mean values (with no data gaps) and the streamflow record had to include 2012 (the base year). For a water-quality site to be considered for use in load computations, it had to have a minimum record length of 3 years, have at least 24 samples, and have at least 3 samples in each of the four 3-month seasons (January-March, April-June, JulySeptember, and October-December). The water-quality period of record also had to be within 3 years of the 2012 base year.

Matching a water-quality site with a flow site involved initially selecting the flow site with characteristics that best represented those at the water-quality site. Loads are ideally calculated for sites with colocated water-quality and streamflow data; however, the use of a nearby streamflow site (streamgage) is a common approach when the data are not colocated. Where water-quality sites were not colocated with a streamgage, specific criteria were used to identify suitable nearby streamgages for a water-quality site. First, nearby streamgages used for load computation had to be within $40 \mathrm{~km}$ and had to have a ratio of watershed area between that of the water-quality site and the streamgage between 0.75 and 1.33 , and if the watershed area of the water-quality site was greater than $260 \mathrm{~km}^{2}$, then the streamgage had to be on the same stream. If a potential water-quality site had multiple nearby suitable streamgages, priority for selection was given to flow sites with a longer period of data overlap, watershed area ratios closer to 1 , and a shorter distance to the water-quality site (the screening and matching processes are described in more detail by Saad and others [2019]).

Long-term mean-annual loads for each water-quality site and constituent were estimated using both the BRE method and F5K method (described in detail by Saad and others [2019]). The Fluxmaster program (Schwarz and others, 2006; Lee and others, 2016) was used to generate the BRE and F5K load estimates. The BRE method was implemented in stratified form as described in Cochran (1977) using 8 strata formed by subdividing daily average flows from all years into 2 classes (delineated by the 80th percentile of flow) and four 3-month seasons. For water-quality sites with a significant trend in load determined using the F5K method, the F5K long-term meanannual load estimates were detrended to 2012 .

Load estimates were evaluated for trend, accuracy, and bias prior to being considered for inclusion as calibration targets in the Midwest SPARROW models. In general, the decision of whether to use the BRE or F5K load estimate for a site was based on whether or not there was a significant trend in the loads determined using the F5K method. If there was no significant trend in the loads, the long-term, mean-annual BRE load was selected as the final load. If there was a significant $(p<0.05)$ trend in the loads, the F5K estimate detrended to 2012 was generally selected as the final load. Only sites with standard errors in the load-computation model and potential biases in the estimated load less than 50 percent of the meanannual load estimate were considered acceptable and included for consideration in SPARROW model calibration (for more detail, see Saad and others [2019]).

The number of sites considered for inclusion in calibration of the Midwest SPARROW models was much fewer than the number of sites with water-quality data (table 1). For the Midwest SPARROW streamflow model, only 17 percent of the original streamgages $(2,057$ of 11,575$)$ were considered for use as calibration targets. Less than 2 percent $(1,346$ and $1,344$ of 93,994$)$ of original water-quality sites with TN and TP data, respectively, and about 2 percent $(1,262$ of 60,360$)$ of the original sites with suspended-sediment/suspended solids data were considered for use as calibration targets in the Midwest nutrient and sediment models, respectively. In addition to the large number of sites eliminated for consideration as calibration targets because of site selection protocols (table 1), a few additional sites were eliminated because they had streamflow routing issues associated with the digital stream network, the contributing areas from Canada could not be represented properly, or an evaluation of spatial correlation of residuals required that the site be removed because of thinning. Even with the elimination of many sites, the distribution of the final calibration sites generally covered most of the Midwest area for the SPARROW streamflow, TN, TP, and SS models. Site density, for all models, was generally lower in the west and higher in the eastern parts of the Midwest area (Saad and others, 2019). 
Table 1. Counts of sites throughout the data compilation and selection process for 2012 Midwest SPARROW models.

[SPARROW, SPAtially Referenced Regression On Watershed attributes; --, not computed separately]

\begin{tabular}{lccc}
\hline \multicolumn{1}{c}{ SPARROW model } & Original sites & $\begin{array}{c}\text { Sites considered for use in } \\
\text { SPARROW models }\end{array}$ & $\begin{array}{c}\text { Sites used in final } \\
\text { SPARROW models }\end{array}$ \\
\hline Streamflow & 11,575 & 2,057 & 2,012 \\
Nutrients & 93,994 & -- & -- \\
$\quad$ Total nitrogen & -- & 1,344 & 1,335 \\
Total phosphorus & -- & 1,346 & 1,273 \\
Sediment & 60,360 & -- & -- \\
$\quad$ Suspended solids & -- & 1,085 & 1,082 \\
Suspended sediment & -- & 177 & 107 \\
\hline
\end{tabular}

\section{Sources of Water, Nitrogen, Phosphorus, and Suspended Sediment}

Inputs to the Midwest SPARROW models include data that attempt to describe or quantify all the major sources of water, nitrogen, phosphorus, and suspended sediment for as close to 2012 as possible. Most inputs have been updated and refined from those used in previous SPARROW models developed for this area. In this section, all sources considered for use in the models are described, with special attention to the sources included in the final models, especially those for which new techniques have been developed.

\section{Sources of Water for the Streamflow Model}

The primary source of water in the Midwest was believed to be the difference between inputs from PPT and losses from AET, referred to as PPT-AET. Total annual PPT and AET for the Midwest for water years 2000 through 2014, which were estimated using the water-balance modeling approach of McCabe and Wolock (2011), were obtained from Wieczorek and others (2019). From the total annual PPT and AET, the mean-annual PPT-AET for 2000-14 (units of cubic feet per second) were computed and used in the model.

In addition to inputs of water from PPT-AET, water can be added to or removed from streams by municipal use (input to study area by water supplies and exported to stream network by WWTPs), added by springs, added from outside the study area or exported from the study area by diversions, and diverted within the network. NHDPlusV2 does not account for all the hydrologic manipulations that can occur in a stream network. To facilitate the use of this type of information in SPARROW models, additional reach attributes were created to represent the diversion and transfer of water within the surfacewater drainage network (Brakebill and others, in press).
WWTP discharge was considered as a source in the Midwest SPARROW streamflow model in locations where the discharge was believed to originate from an external source of water, which included WWTPs in areas where the primary source of drinking water originated from the Great Lakes or deep groundwater. Deep groundwater can supply water to streams; however, it typically takes years to decades or more for water to move through the groundwater system before being discharged to a stream (Heath, 1983). For this reason, WWTP discharge originating from deep groundwater sources was considered to represent a potential additional input of streamflow. In areas where streams were the primary source of drinking water, WWTP discharge comes from water derived from recent PPT that was already included as a separate source in the model (PPT-AET); therefore, these WWTP discharges were not added to the model.

WWTP discharge data, for 2012, were compiled from the Integrated Compliance Information System database (Skinner and Maupin, 2019). The part of the discharge from each WWTP facility considered to be a new source of water was estimated based on the fraction of drinking water from groundwater, or surface water from the Great Lakes, for the county the facility was in. Drinking-water amounts and the fraction of drinking water originating from groundwater were obtained from 2010 county-level water-use estimates (Maupin and others, 2014). For all facilities in the Great Lakes Basin, all drinking water from surface-water sources was assumed to originate from the Great Lakes. All the WWTP discharge flow from external sources was summed for each catchment and included as a source (in units of cubic feet per second) in the model.

Water originating from springs was compiled for 90 springs in the Midwest area from the USGS NWIS database (U.S. Geological Survey, 2018b). For most springs, intermittent measurements of flow from 1970 to 2014 were used to 
compute the mean-annual flow. For four sites (Big, Cleghorn, Greer, and Mammoth Springs [not shown]), daily mean flows from 2000 through 2014 were used to compute mean-annual flow. Estimated flows from the springs (units of cubic feet per second) were summed for each catchment and included as a source in the model.

Diversions of water from outside the study area or associated with withdrawals for public supply and representing returns to the stream network at some location farther downstream, are described by Brakebill and others (in press). Most water diversions originating from outside the Midwest study area occur near the Rocky Mountains. Several water diversions associated with withdrawals for public supply also occur in Arkansas, Missouri, Nebraska, and Oklahoma. Water diversion amounts (units of cubic feet per second) were identified for specific stream reaches and were directly included in the model.

A small part of the Midwest SPARROW study area originates in Canada where detailed source information was not available. To account for the flow that originates in Canada, the cumulative watershed area in Canada was assigned as a source, using a flow yield based on the nearest USGS streamgage. Streamgages used for streamflow yields from Canadian areas included the Souris River (USGS station 05114000), the Pembina River (05100000) and the Roseau River (05112000) (not shown; U.S. Geological Survey, 2018b). Because the yields from these areas were directly provided to the model, these streamgages were excluded from the streamflow model calibration process.

\section{Sources of Nitrogen and Phosphorus}

Nitrogen and phosphorus in surface water originate from natural/background and anthropogenic sources. Most natural/background nitrogen in surface water originates from the fixation of atmospheric nitrogen by soil bacteria that is transported through groundwater to streams. Some nitrogen, however, comes from the weathering of nitrogen-containing minerals, fixation by aquatic bacteria, and lightning strikes. Natural/background nitrogen sources have been difficult to express in SPARROW models because it is difficult to separate natural/background input from the inputs from atmospheric deposition (typically a major source of nitrogen) that occur throughout the modeled area and are affected by various urban and agricultural sources. Alexander and others (2008) tried to describe the inputs from natural/background sources by quantifying nitrogen inputs from forest, barren lands, and shrublands, but stated that these inputs may include inputs from atmospheric deposition affected by anthropogenic factors; therefore, natural/background sources were not included in the Midwest TN model. The major natural source of phosphorus in surface water is from the weathering of phosphoruscontaining minerals. Typically, natural/background inputs of phosphorus from atmospheric deposition are not considered a major source and were not included in SPARROW phosphorus models (Smith and others, 1997; Robertson and Saad, 2011).
Natural/background phosphorus sources have been expressed in previous SPARROW models in different ways: as runoff from land-cover types with minimal human effect (Moore and others, 2004; Wise and Johnson, 2013), as a function of the natural phosphorus content of local rock (Domagalski, and Saleh, 2015; García and others, 2011), and as weathering of specific geologic units that were expected to be important contributors to instream phosphorus (Ator and others, 2011). In the Midwest SPARROW TP model, the phosphorus content of the geologic material was used to represent the natural/background source (Nardi, 2014). Natural/background phosphorus was based on geochemical soils data collected from about 5,000 sites sampled across the country (Smith and others, 2013). Those data were extrapolated to soil concentrations for unsampled locations using predefined geologic mapping units and methods described by Nardi (2014) and Terziotti and others (2010). The natural/background phosphorus in the soil was included in the SPARROW model as the mass of phosphorus computed from the phosphorus concentration, catchment area, soil bulk density, and soil thickness. Soil bulk density and soil thickness were obtained from the STATSGO soils database (Schwarz and Alexander, 1995; Wieczorek and others, 2019). The soil thickness was assumed to be the top 1 meter (m) of soil, unless there was less than $1 \mathrm{~m}$ present. Natural/background phosphorus was included in the model using units of metric tons of phosphorus in the upper $1 \mathrm{~m}$ of soil in the catchment.

Previous SPARROW modeling has indicated that a major contributor to surface-water TN and TP loads is point-source facilities, such as WWTPs and commercial and industrial point sources, that discharge directly to streams (Preston and others, 2011). As part of a nationwide effort, Skinner and Maupin (2019) compiled effluent discharge volumes and effluent phosphorus and nitrogen concentration data and estimated TN and TP loads for water year 2012. For the Midwest area, there were 1,934 major National Pollutant Discharge Elimination System WWTPs and 7,511 nonmajor National Pollutant Discharge Elimination System WWTPs.

Skinner and Maupin (2019) provide detailed descriptions of the methods used to estimate the 2012 point-source nutrient loads, their quality-assurance and quality-control procedures, and the ways that their approach differed from previous efforts to estimate point-source nutrient loads. To estimate outfall from each facility, the effluent flow for each month was multiplied by either a measured or surrogate nitrogen or phosphorus effluent concentration. A surrogate concentration was used in the monthly load estimate when a measured value was not available. The surrogate concentration was either a seasonal median value for the facility (when sufficient facility-specific measurements were available for 2012) or a typical pollutant concentration (TPC) that represented similar facilities within the same State, adjacent States, or the conterminous United States (in order of preference). The monthly load estimates were then summed to estimate TN and TP loads for water year 2012. When a facility had less than 12 months of flow data for the year but had flow for at least three seasons in 2012, 
the seasonal nutrient loads were extrapolated to estimate the annual TN and TP loads (based on the assumption that the facility likely discharged throughout the year and the flow data were simply missing). If a facility had fewer than three seasons of effluent flow, however, it was assumed to discharge only intermittently, and the annual loads were equal to the sum of the available monthly loads.

For the Midwest study area, it was estimated that WWTPs discharged about 222,000,000 kilograms $(\mathrm{kg})$ of nitrogen and 28,400,000 kg of phosphorus to the stream network in 2012 (Skinner and Maupin, 2019). Of the TN input, 25.3 percent of the nitrogen was monitored and 74.5 percent was based on TPCs (ranging from 0.1 percent being monitored in Pennsylvania to 94.7 percent being monitored in Montana). Of the TP input from WWTPs, 61.4 percent of the phosphorus input was monitored, and 38.6 percent was based on TPCs (ranging from 3.0 percent being monitored in Virginia to 99.1 percent being monitored in Minnesota). More detailed information on inputs from WWTPs is available in appendix 4. Inputs from commercial and industrial facilities were assumed to be incorporated in the other defined sources, such as WWTPs or urban sources, or represented in model error.

The 2012 farm fertilizer input data used in the models was estimated by Stewart and others (2018), who related countylevel commercial fertilizer sales data to spatially referenced data on incremental catchment attributes to estimate elemental fertilizer use on agricultural lands for the conterminous United States. The approach built upon earlier efforts that used Association of American Plant Food Control Officials data on fertilizer sales to provide county-level estimates of nitrogen and phosphorus fertilizer use (Ruddy and others, 2006). The spatially referenced method improved on these previous efforts by allowing for varying nitrogen to phosphorus ratios at the catchment scale and expanding the set of variables used to allocate county-level sales data to the catchment scale. The spatially referenced fertilizer models included catchment-level factors that were either primary determinants of fertilizer use, such as the acreage of different crop types, or measures that reflected the intensity of use, such as climate.

Inputs of nitrogen and phosphorus from manure were estimated from county-level estimates of animal wastes from Gronberg and Arnold (2017). Manure inputs were derived from 2012 county livestock population data from the U.S. Census of Agriculture using species specific rates. The county data were then allocated to each SPARROW catchment by the amount of agricultural land and grassland in the catchment compared to the total agricultural and grassland in the county.

Nitrogen from fixation was represented by the land area of nitrogen-fixing crops from the 2012 Cropland Data Layer produced by the U.S. Department of Agriculture (U.S. Department of Agriculture National Agriculture Statistics Service, 2018). Nitrogen-fixing crops included alfalfa, chickpea, clover, lentil, peanuts, peas, soybeans, vetch, wild flower, and winter wheat. The input of nitrogen from fixation per unit of land with nitrogen-fixing crops was determined during model calibration.
Atmospheric deposition of nitrogen from 2012 was based on data from the U.S. Environmental Protection Agency Community Multiscale Air Quality (CMAQ) modeling system (U.S. Environmental Protection Agency, 2018b; Wieczorek and others, 2019). The estimates of total atmospheric nitrogen deposition were equal to the sum of each of the individual parameters in CMAQ: bias and PPT-adjusted wet deposition of oxidized nitrogen, bias and PPT-adjusted wet deposition of reduced nitrogen, mean dry deposition of total oxidized nitrogen, mean dry deposition of total reduced nitrogen, mean total deposition of total reduced nitrogen, and mean total deposition of total oxidized nitrogen. CMAQ data include volatilized losses from natural/background, agricultural sources, and urban sources. Atmospheric deposition of phosphorus was not available. Typically, phosphorus from atmospheric deposition is not considered a major source of phosphorus and not included in SPARROW phosphorus models (Smith and others, 1997; Robertson and Saad, 2011); therefore, this source was assumed to be insignificant and was not included in the SPARROW TP model. Phosphorus inputs from atmospheric deposition were assumed to be incorporated in other defined sources or represented in model error.

To account for the TN and TP that originated from Canada, the cumulative watershed area originating in Canada was assigned as a source using TN and TP yields based on information from the nearest TN and TP load site. Sites used for Canada area TN and TP yields included the Souris River (USGS station 05114000) and the Pembina River (05100000) (not shown). These sites were excluded from the model calibration process.

\section{Sources of Suspended Sediment}

Suspended sediment in streams comes from two general processes: erosion of upland areas (from surface erosion, soil creep, debris avalanches, and slump and earth flow) and erosion within stream corridors (Swanson and others, 1982). Upland sediment sources include runoff from various landuse/land-cover types, whereas stream corridor sources include erosion of stream banks (including valley sides and terrace walls) and resuspension of sediment from channel beds (Gellis and others, 2016). Two datasets were used to represent upland sediment sources: one based on land use/land cover and the other based on surficial geology. Surficial geology represents natural sources and land use/land cover represents sources that are associated with human activities. The Midwest consisted of 9 National Land Cover database land-cover categories (fig. 3; Homer and others, 2015) and 50 surficial geology classes (appendix 4; Soller and others, 2009). To facilitate model development, surficial geology classes were generalized into 19 categories that generally represented the texture and type of surficial material (appendix 4). To further facilitate the use of surficial geology and land use/land cover in a single model, these generalized surficial materials and land-use/ land-cover characteristics were intersected using a geographic information system. The result of this intersection was a single 
dataset with 171 categories of surficial geology and land-use/ land-cover combinations of upland sources (Wieczorek and others, 2019). Some of these combination sources represented small areas in the Midwest, so this dataset was further generalized and aggregated to represent 10 upland sources in the Midwest SS model (table 2). A total of 3 urban, 3 agricultural, and 3 "other" (nonurban/nonagricultural) land-use sources were included in the Midwest SS model. The other land-use category primarily represents natural/background sources (referred to as "background sources"). Each of these land-use sources had a corresponding set of surficial-material component sources that represent medium- and coarse-grained surficial materials, fine-grained and silt surficial materials, and colluvium-residuum-carbonate surficial-material categories. The categories were aggregated to make the final surficialmaterial groups considered for use in the Midwest SPARROW SS model (described in detail in appendix 5). Even with the generalizations and aggregations noted previously, there were still some additional surficial geology-based categories that represented small areas of the Midwest. These small areas were combined into a single upland source category that represents all land uses for all remaining surficial geology categories (referred to as all land uses on "other" surficial material). Data for the 10 upland source variables used in the Midwest SS model are provided for all SPARROW catchments are included in an associated USGS data release (Saad and Robertson, 2019).

Table 2. Combined land use/land cover and surficialmaterial-based source categories used in the 2012 Midwest SPARROW suspended-sediment model.

[SPARROW, SPAtially Referenced Regression On Watershed attributes]

\begin{tabular}{l} 
Combined land cover and \\
\multicolumn{1}{c}{$\begin{array}{c}c \\
\text { Surficial-material source category }\end{array}$} \\
\hline Alluvial, medium-coarse sediments. \\
Colluvial, residual, carbonate materials. \\
Fine-grained and silty sediments. \\
\hline Agriculture \\
\hline Alluvial, medium-coarse sediments. \\
Colluvial, residual, carbonate materials. \\
Fine-grained and silty sediments. \\
\hline Other/background \\
\hline Alluvial, medium-coarse sediments. \\
Colluvial, residual, carbonate materials. \\
Fine-grained and silty sediments. \\
\hline All land uses \\
\hline All other surficial-material sources.
\end{tabular}

In addition to the upland sources, the Midwest SS model included source variables to represent watershed contributing areas in Canada and stream corridor channel sources. To account for the sediment that originated in Canada, the cumulative watershed area originating in Canada was assigned as a source, using SS yields based on information from the nearest sediment load sites. Sites used for Canada area SS yields included the Souris River (USGS station 05114000) and the Pembina River (05100000). These sites were then excluded from the SPARROW SS model calibration process.

Sediment also originates from erosion from streambanks and bottom sediments within the stream corridors. Reach length was used as a surrogate for these types of erosion. Reach length was only used as a source term for catchments where mean streamflow was between 50 and 3,000 ft $3 / \mathrm{s}$. During calibration of the SPARROW SS model, sediment losses from channels with other flow rates were found to be negative or insignificant. The sediment generated within stream corridors was modeled as a function of reach length within each catchment.

\section{Factors Affecting Water, Nitrogen, Phosphorus, and Sediment Transport}

Inputs to the Midwest SPARROW models include information that attempts to describe the major factors affecting the transport of water, TN, TP, and sediment to the streams and down the stream network. These factors are subdivided into land-to-water delivery variables and instream decay variables within SPARROW (appendix 2). Here, special attention is given to the variables included in the final models, especially those for which new techniques were developed.

\section{Factors Affecting Water Transport}

Many environmental factors were examined to determine which factors significantly explained variability in the delivery of PPT-AET to the stream network (appendix 2). Air temperature directly affects the amount of ET; therefore, although it was included in the original computations of ET, it was also examined as a potential land-to-water delivery variable. Annual mean air temperatures from 2000 to 2014 were obtained from Wolock and McCabe (2018). The intensity of rainfall events could affect the efficiency that PPT-AET is delivered to streams; therefore, an indicator of rainfall intensity was computed as the natural logarithim of the meanannual precipitation divided by the average number of days with precipitation (Wieczorek and others, 2019). The elevation of the catchment (logarithmically transformed) (Wieczorek and others, 2019) was also considered as a potential land-towater delivery factor.

It was believed that the estimated AET may underestimate true evapotranspiration, especially in western areas of the Midwest; therefore, aridity, computed as mean-annual PPT minus mean-annual potential evapotranspiration (PET, McCabe and Wolock, 2011) was examined as a possible 
instream decay variable, and referred to as PPT-PET. This variable was examined as an instream decay variable, so that it would not interact with the dominant source variable (PPT-AET). Aridity was only considered as an instream decay variable in the Midwest model where this value was negative (mainly in the western half of the Midwest area). Excess aridity values less than zero were multiplied by -1 prior to including it as a decay variable.

Groundwater pumping near a stream has been shown to reduce streamflow (Barlow and Leake, 2012). Groundwater pumping for irrigation was examined in the SPARROW streamflow model as a potential instream removal variable. Groundwater pumping for irrigation was based on 2012 irrigated areas within each catchment (Wieczorek and others, 2019) and groundwater irrigation amounts from 2010 countylevel water-use estimates (Maupin and others, 2014). Groundwater irrigation in each catchment was computed assuming that the total amount of groundwater irrigation for each county was evenly distributed over all irrigated areas of the county. Groundwater irrigation was reported in units of cubic feet per second, which were then converted to a removal variable computed as the negative logarithim of (1 minus the fraction of streamflow not removed for groundwater irrigation). The groundwater irrigation removal fraction was limited to 80 percent of the total streamflow in each catchment. This limitation was placed on groundwater irrigation removal because the flows in the model represent long-term average conditions and irrigation would never take more flow than what was available in the stream.

Evaporation from streams, lakes, and reservoirs reduces the amount of water transported in the stream network. To determine whether evaporation from streams was important, the lengths of intermittent and continual flowing streams were examined. To determine if evaporation from lakes and reservoirs was important, wetted area evaporation was computed as mean-annual potential evaporation multiplied by waterbody surface area. Lake and reservoir waterbody surface areas were obtained from NHDPlusV2 (Brakebill and others, in press), supplemented with information from the National Inventory of Dams dataset (U.S. Army Corp of Engineers, 2018). Evaporation from lakes and reservoirs for each stream reach was reported in units of cubic feet per second and then converted to a removal variable, computed as the negative logarithim of (1 minus the fraction of streamflow not removed by evaporation). The lake and reservoir evaporation removal fractions were limited to 80 percent of total stream flow. This limitation was placed on lake and reservoir evaporation because flows in the model represent long-term average conditions and it was felt that evaporation should not exceed the major source of water to the waterbody.

Direct water removal from streams was included in the model in locations where water was not returned to the stream in the vicinity of the removal location. These types of withdrawals occur at several locations throughout the Midwest area (Brakebill and others, in press) and typically are associated with water used for public supply. The locations where water was returned were also represented in the model as part of the diversion source term described above. Water removal for water supply was directly included in the SPARROW streamflow model, without calibration, as a stream decay function for the stream reach with the removal, computed as the negative natural logarithim of (1 minus the fraction of streamflow not removed for public supply).

\section{Factors Affecting Nitrogen and Phosphorus Transport to the Stream Network}

Six watershed properties and processes were found to be significant factors affecting the delivery of nitrogen from upland areas to streams: natural logarithim of runoff, detrended mean-annual air temperature, natural logarithim of the percent of catchment underlain by agricultural tiles, natural logarithim of soil clay content, natural logarithim of percent of catchment using no-till farm practices, and the ratio of Conservation Reserve Program (CRP) area to total farmland area (CRP/farm-acre ratio). Other potential factors affecting nitrogen delivery to streams, including factors describing the drier conditions in the western part of the study area, were evaluated but found not to be significant are provided in appendix 2 .

Five watershed properties and processes were found to be significant factors affecting the delivery of phosphorus from upland areas to streams: natural logarithim of runoff, natural logarithim of soil erodibility, natural logarithim of the percent of catchment underlain by agricultural tiles, natural logarithim of drainage density, and the natural logarithim of the U.S. Department of Agriculture-National Resources Conservation Service (NRCS)-estimated reduction in phosphorus loss due to best management practices (BMPs). Other potential factors affecting phosphorus delivery to streams, including factors describing the drier conditions in the western part of the study area, were evaluated but found not to be significant are provided in appendix 2 .

Runoff included in the SPARROW TN and TP models was obtained from the nondecayed, incremental flow predictions of the Midwest SPARROW streamflow model described in this report. Because runoff was used as a land-to-water delivery variable, the total incremental flows were converted to runoff yields by dividing the runoff values by the incremental areas of the catchments. Nondecayed incremental flow represents the overland runoff and base flow (streamflow derived mainly from groundwater) delivered from the catchment to the stream channel and does not include losses from instream or in-reservoir decay in the incremental reach.

Annual mean air temperatures, for the period from 2000 through 2014, were obtained from McCabe and Wolock (2011) and Wolock and McCabe (2018), and detrended to 2012. Detrending was done using annual mean air temperature data for each 4-km $\times 4-\mathrm{km}$ grid cell represented in the Wolock and McCabe (2018) dataset. For a given grid cell, a regression equation was developed using air temperature as the dependent variable and year as the independent variable. Detrended air temperature values were based on predictions 
for each regression relation using year set equal to 2012 (the SPARROW model base year). The detrended air temperature dataset was based on detrended predictions where the regression coefficient for year was significant $(p<0.05)$. Where the coefficient was not significant, the mean of the 15 -year dataset was used. Detrended data from the $4-\mathrm{km} \times 4-\mathrm{km}$ gridded data were processed to the NHDPlusV2 catchments using methods described by Wieczorek and others (2019).

Previous SPARROW models (Robertson and Saad, 2011, 2013) demonstrated that agricultural tile drains can be an important term for describing delivery of nitrogen and phosphorus from the land to streams. Nakagaki and Wieczorek (2016) estimated the extent of subsurface tile drainage for 12 Midwest States. This information was extrapolated to NHDPlusV2 catchments following the methods of Wieczorek and others (2019). Recent data for North Dakota and South Dakota were used to supplement and fill in areas of the Midwest for which the Nakagaki and Wieczorek (2016) information was limited or missing (Finocchiaro, 2014 and 2016). The North Dakota and South Dakota tile drain data were presented as polygons that represent tile permit locations as of 2016 and 2012, respectively. Tile polygons for North and South Dakota were intersected with NHDPlusV2 catchments to calculate the percentage of each catchment underlain by tiles. The recent data for North and South Dakota replaced the information from Nakagaki and Wieczorek (2016) data for these areas.

Soil erodibility was represented by the $K$ factor from STATSGO (Schwarz and Alexander, 1995; Wieczorek and others, 2019). Drainage density was computed as reach length in the catchment divided by the catchment area using NHDPlusV2 attributes.

The no-till and CRP variables included in the SPARROW TN model represent BMPs associated with agricultural activities. The percentage of catchment with no-till farming practices was based on the 2012 Conservation Practices dataset from the U.S. Department of Agriculture National Agricultural Statistical Service (U.S. Department of Agriculture National Agriculture Statistics Service, 2018; Wieczorek and others, 2019). The $\mathrm{CRP} /$ farm-area ratio for each catchment was based on countylevel data reported on an annual basis (Farm Service Agency, 2012; LaMotte, 2015).

The potential benefits of agricultural management practices included in the SPARROW TP model were quantified using NRCS-estimates of reductions in the loss of nutrients and sediment from fields caused by the implementation of a suite of BMPs (U.S. Department of Agriculture National Resources Conservation Service, 2016; García and others, 2016). Reductions in the nutrient and sediment loss were estimated by the NRCS Conservation Effects Assessment Program (CEAP) using a combined sampling and modeling approach. Data collected by the National Resources Inventory Program were used to characterize representative agricultural areas for features such as soils, climate, and topography. Additional information was collected from each of those representative areas through the CEAP Program to characterize current farming practices.
The effects of specific agricultural management practices were simulated using the Agricultural Policy Environmental Extender (APEX) model applied on a location-by-location basis. Those effects were then extrapolated to watershed scales using the Soil and Water Assessment Tool (SWAT). The output from this procedure provided estimates of phosphorus loss under three scenarios: (1) a baseline defined by the conditions observed by the CEAP survey, (2) the loss if no BMPs had been implemented, and (3) the loss if enhanced nutrient management had been implemented. These estimates were available at a large watershed scale (hydrologic unit code 4; HUC4; Seaber and others, 1987) but were further processed using geospatial techniques and land characteristics to extend the information to the NHDPlusV2 catchments following the methods of Wieczorek and others (2019). For use in the SPARROW models, an index, representing change in loss rate, was computed as the difference between the baseline (simulated loss rates for conservation practices for the period 2003 through 2006) and the "no implementation" scenarios (García and others, 2016). This index was intended to provide an indication of the expected aggregate benefits of the implementation of a suite of management practices: The larger the values in the change in loss rate variable, the larger the effect of the BMPs.

\section{Factors Affecting Sediment Transport to the Stream Network}

Four land-to-water delivery variables were included in the SPARROW SS model: the natural logarithm of runoff, the natural logarithm of soil clay content, the natural logarithm of soil erodibility, and the natural logarithm of basin slope in areas where mean catchment elevation is less than $1,500 \mathrm{~m}$ (appendix 2). Other potential factors affecting sediment delivery to streams were evaluated but determined not to be significant and are provided in appendix 2. Descriptions of the first three variables were included in the previous section "Factors Affecting Nitrogen and Phosphorus Transport to the Stream Network" for the Midwest SPARROW TN and TP models. Basin slope and catchment elevation are attributes of the NHDPlusV2 dataset. Sediment loss typically increases as basin slope increases (Wischmeier and Smith, 1978); however, this attribute was not statistically significant in the Midwest SS model when catchments with elevation greater than $1,500 \mathrm{~m}$ were included. These higher elevations correspond mostly to areas in the Rocky Mountains where stream sediment yields were low (Saad and others, 2019). Eliminating these high mountain areas (not including this variable for catchments with elevations greater than $1,500 \mathrm{~m}$ ) allowed this variable to better explain sediment transport in the rest of the study area.

\section{Factors Affecting Nitrogen, Phosphorus, and Sediment Transport down the Stream Network}

The Midwest TN, TP, and SS models used the time of travel through a stream reach and settling velocity in lakes and reservoirs to estimate how much of the TN, TP, and $\mathrm{SS}$ is permanently removed through particle settling and 
denitrification (for TN) by bacteria. When modeling longterm mean-annual conditions in free-flowing streams and impoundments, it was assumed that there was no net gain or net loss of TN and TP associated with the growth and decay of aquatic plants (Schwarz and others, 2006). Permanent loss of TN and TP in free-flowing streams was evaluated by estimating a first-order decay rate (in inverse days) that, when multiplied by the time of travel (in days) through the reach, represented the fraction of the load that either settled to the bottom of the reach or was taken up by benthic bacteria. Permanent loss of TN and TP in impoundments was evaluated by estimating a hypothetical settling velocity (in meters per year) that, when multiplied by reciprocal areal hydraulic load (in years per meter) represented the fraction of the incoming load that either settled to the bottom of the impoundment or was taken up by benthic bacteria.

The time of travel through a reach was included in both the SPARROW TN and TP models and applied to stream reaches where mean streamflow was less than 1.4 cubic meters per second $\left(\mathrm{m}^{3} / \mathrm{s} ; 50 \mathrm{ft}^{3} / \mathrm{s}\right)$. Stream reaches in other streamflow categories were evaluated in the calibration process but were determined to be statistically insignificant or determined to be a source (negative sign in the calibration) of TN or TP. The time of travel (in days) was based on mean stream velocity estimated using drainage area, reach slope, and mean streamflow (Jobson, 1996). The reciprocal areal hydraulic load was computed as lake and reservoir surface area divided by the mean streamflow of the corresponding reach. Drainage area and slope were obtained from NHDPlusV2. Mean streamflows for all reaches were from the Midwest SPARROW streamflow model (described in the following section).

Three decay variables were included in the SPARROW SS model to represent loss of suspended sediment through loss of water or settling in streams and reservoirs: pumping or diversion from the stream and reservoirs, time of travel in streams, and settling velocity in reservoirs (appendix 2). These variables are the same as the decay variables included in the Midwest SPARROW TN and TP models.

\section{Use of SPARROW Streamflow Model Results in Other Constituent Models}

Some computations within SPARROW models, such as instream and reservoir decay, rely on estimates of the longterm mean streamflow in each stream reach. In past SPARROW applications, the long-term mean flows throughout the stream network were estimated from data from streamgages throughout the United States collected during 1971-2000 (D. Wolock, U.S. Geological Survey, written commun., 2009). Long-term mean streamflow has been estimated at a finer scale as part of NHDPlusV2 (Horizon Systems, 2013) based on streamflow data during 1971-2000; however, more recent estimates of long-term mean streamflow for all NHDPlusV2 stream reaches are not currently available. To provide more contemporaneous mean streamflow data for use in the 2012
SPARROW TN, TP, and SS models, output from the 2012 SPARROW streamflow model (incremental flows) was used to describe runoff from the catchments, and reach-level predictions of long-term mean streamflow were used to describe instream and reservoir losses.

\section{SPARROW Streamflow Model}

\section{Specification of the Streamflow Model}

The long-term average streamflow through a stream network represents the net result of the balance between inputs of water from PPT and water diversions into the basin and losses of water from evapotranspiration (ET) both on the landscape and in the river network and from diversions out of the basin. Water primarily reaches streams from relatively rapid (minutes to days) surface runoff and relatively slow (days to decades or more) groundwater inflow. A wide variety of potential sources and losses of water was considered for inclusion in the Midwest SPARROW streamflow model, and only those for which a statistical relation with measured streamflow could be demonstrated were retained in the model (appendix 2). Surface runoff and groundwater inputs are derived from PPT-AET; therefore, PPT-AET was used as the primary source variable in the model; water diversions also were included in the model (table 3). During calibration, the model was evaluated to determine if the full set of potential monitoring sites should be thinned and if many of the sites being nested may affect the model as described above. Results of preliminary model evaluations indicated thinning was not necessary (in other words, there was no significant negative spatial correlation for nested or nonnested sites within $5 \mathrm{~km}$ ); therefore, the model was calibrated with mean streamflows from the 2,012 monitoring sites. Additional model evaluations indicated that the nested monitoring sites may have unequal effect during model calibration $\left(p=6.3 \times 10^{-5}\right)$; therefore, weights were applied to all monitoring sites based on the percentage of the basin area that was nested during the final calibration of the SPARROW streamflow model. Adjusting for the effects of nested monitoring sites had little effect on the summary statistics of the model (RMSE, standard errors, and $p$-values), but it did result in modifications to the coefficients for several variables.

The 2012 Midwest SPARROW streamflow model has 14 variables (table 3 ). The model has five sources of water: PPT-AET, wastewater treatment plant discharge (WWTP) from facilities in areas where the primary drinking-water source was from outside of the basin (water from the Great Lakes or deep groundwater), springs, diversions into the study area, and streamflow originating in Canada (Canada flow). Estimated diversions into the Midwest area and Canada flow were directly included in the model without calibration (coefficients set to 1.0). The model has four land-to-water delivery variables that represent factors that collectively enhance or reduce water delivery to streams: mean daily air 
Table 3. Summary of calibration results for the 2012 Midwest SPARROW streamflow model. Calibration incorporated adjustments for the amount of the upstream watershed that was included in watersheds of other calibration sites.

[SPARROW, SPAtially Referenced Regression On Watershed attributes; $p$-value, probability value; $t$-value, $t$-statistic; AET, actual evapotranspiration; f $\mathrm{ft}^{3} / \mathrm{s}$, cubic foot per second; $<$, less than; --, not computed; ${ }^{\circ} \mathrm{C}$, degrees Celsius; $\mathrm{m}$, meter; In, natural logarithm; mm/days, millimeter per day; PET, potential evapotranspiration; km, kilometer; RMSE, root mean square error; Moran's $I$, measure of spatial autocorrelation; $R^{2}$, coefficient of determination]

\begin{tabular}{|c|c|c|c|c|c|c|c|c|c|c|}
\hline \multirow[t]{2}{*}{ Variable } & \multirow[t]{2}{*}{ Variable unit } & \multirow{2}{*}{\multicolumn{2}{|c|}{ Coefficient unit }} & \multirow[t]{2}{*}{$\begin{array}{l}\text { Model } \\
\text { coefficient } \\
\text { value }\end{array}$} & \multicolumn{2}{|c|}{$\begin{array}{c}\text { 90-percent confidence } \\
\text { interval for the model } \\
\text { coefficient }\end{array}$} & \multirow{2}{*}{$\begin{array}{l}\text { Standard } \\
\text { error of the } \\
\text { model } \\
\text { coefficient }\end{array}$} & \multirow[t]{2}{*}{$p$-value } & \multirow[t]{2}{*}{$t$-value } & \multirow[t]{2}{*}{$\begin{array}{c}\text { Variance } \\
\text { inflation } \\
\text { factor }\end{array}$} \\
\hline & & & & & Low & High & & & & \\
\hline \multicolumn{11}{|c|}{ Source } \\
\hline Precipitation minus AET & $\mathrm{ft}^{3} / \mathrm{s}$ & \multicolumn{2}{|c|}{ Fraction, dimensionless } & 0.968 & 0.940 & 0.997 & 0.017 & $<0.0001$ & 56.2 & 2.3 \\
\hline Wastewater treatment plants, external & $\mathrm{ft}^{3} / \mathrm{s}$ & \multicolumn{2}{|c|}{ Fraction, dimensionless } & 1.374 & 0.935 & 1.813 & 0.267 & $<0.0001$ & 5.1 & 1.0 \\
\hline Springs & $\mathrm{ft}^{3} / \mathrm{s}$ & \multicolumn{2}{|c|}{ Fraction, dimensionless } & 0.622 & 0.378 & 0.866 & 0.148 & $<0.0001$ & 4.2 & 1.0 \\
\hline Diversion into model area & $\mathrm{ft}^{3} / \mathrm{s}$ & \multicolumn{2}{|c|}{ Fraction, dimensionless } & 1.0 & -- & -- & -- & -- & -- & -- \\
\hline Canada flow & $\mathrm{ft}^{3} / \mathrm{s}$ & \multicolumn{2}{|c|}{ Fraction, dimensionless } & 1.0 & -- & -- & -- & -- & -- & -- \\
\hline \multicolumn{11}{|c|}{ Land-to-water delivery } \\
\hline Air temperature & ${ }^{\circ} \mathrm{C}$ & \multicolumn{2}{|l|}{${ }^{\circ} \mathrm{C}^{-1}$} & -0.068 & -0.079 & -0.058 & 0.006 & $<0.0001-$ & -10.8 & 4.4 \\
\hline Catchment elevation & $\mathrm{m}$ & \multicolumn{2}{|l|}{$\mathrm{m}^{-1}$} & $-3.82 \times 10^{-4}$ & $-4.2 \times 10^{-4}$ & $-3.4 \times 10^{-4}$ & $2.3 \times 10^{-5}$ & $<0.0001-$ & -16.4 & 1.5 \\
\hline Soil clay content & Percent & \multicolumn{2}{|l|}{ Percent $^{-1}$} & $3.01 \times 10^{-3}$ & $3.5 \times 10^{-4}$ & $5.7 \times 10^{-3}$ & $1.6 \times 10^{-3}$ & 0.0632 & 1.9 & 1.5 \\
\hline Ln (precipitation intensity, in mm/days) & Unitless & \multicolumn{2}{|l|}{ Unitless } & 0.424 & 0.254 & 0.594 & 0.104 & $<0.0001$ & 4.1 & 4.3 \\
\hline \multicolumn{11}{|c|}{ Aquatic loss } \\
\hline Precipitation minus PET (aridity) & $\mathrm{ft}^{3} / \mathrm{s}$ & \multicolumn{2}{|l|}{$\left(\mathrm{ft}^{3} / \mathrm{s}\right)^{-1}$} & $1.35 \times 10^{-3}$ & $1.0 \times 10^{-3}$ & $1.7 \times 10^{-3}$ & $1.9 \times 10^{-4}$ & $<0.0001$ & 7.2 & 1.2 \\
\hline Stream loss from groundwater pumping for irrigation ${ }^{\mathrm{a}}$ & Unitless & \multicolumn{2}{|l|}{ Unitless } & 1.221 & 1.008 & 1.434 & 0.129 & $<0.0001$ & 9.4 & 1.2 \\
\hline Length of nonperennial streams & $\mathrm{km}$ & \multicolumn{2}{|l|}{$\mathrm{km}^{-1}$} & 0.016 & 0.013 & 0.018 & 0.002 & $<0.0001$ & 9.5 & 1.5 \\
\hline Evaporation from surface-water bodies ${ }^{a}$ & Unitless & \multicolumn{2}{|l|}{ Unitless } & 1.485 & 1.210 & 1.759 & 0.167 & $<0.0001$ & 8.9 & 1.1 \\
\hline Surface-water withdrawal for public supply ${ }^{\mathrm{a}}$ & Unitless & \multicolumn{2}{|l|}{ Unitless } & 1.0 & -- & -- & -- & -- & -- & -- \\
\hline \multicolumn{2}{|l|}{ Spatial test } & Number & $\begin{array}{l}\text { Correlation/ } \\
\text { value }\end{array}$ & $p$-value & \multicolumn{4}{|c|}{ Model summary statistic } & \multicolumn{2}{|c|}{$\begin{array}{l}\text { Model summary } \\
\text { statistic value }\end{array}$} \\
\hline \multicolumn{2}{|l|}{ Tight clusters - pairs of nested sites within $5 \mathrm{~km}$} & 22 & 0.894 & 0.030 & Conditioned & $\mathrm{RMSE}^{\mathrm{b}}$, in $\mathrm{n}$ & tural logarithn & aic units & & .373 \\
\hline Tight clusters - pairs of nonnested sites and dissimilarly & ized nested sites within $5 \mathrm{~km}$ & 123 & 0.168 & 0.063 & Conditioned & $\mathrm{RMSE}^{\mathrm{b}}$, perc & entage in real & space units ${ }^{c}$ & 38 & .6 \\
\hline Nested sites (weighting) - coefficient for ln (nested sha & & 2,012 & 0.150 & $6.3 \times 10^{-5}$ & Uncondition & ed RMSEd, in & natural logarit & hmic units & & .425 \\
\hline Loose clusters-Moran's $I$ & & 2,012 & 0.056 & 0.129 & Uncondition & ed RMSEd, $p$ & ercentage in re & al space units ${ }^{c}$ & 44 & .5 \\
\hline & & & & & Mean expon & entiated weigl & ted error & & & .084 \\
\hline & & & & & $R^{2}$ & & & & & .965 \\
\hline & & & & & Yield $R^{2}$ & & & & & .936 \\
\hline & & & & & Number of si & & & & 2,012 & \\
\hline
\end{tabular}

${ }^{a}$ Expressed in $-\ln (1-$ fraction of unremoved streamflow)

${ }^{b}$ Conditioned RMSE is the root mean square error of the difference between the natural logarithm of measured calibration streamflows and the natural logarithm of predicted accumulated streamflows that were reset to the measured streamflows at the calibration sites upstream in the basin.

'RMSE in terms of percentage in real space units was computed as $100 \times\left(\exp \left[\mathrm{RMSE}^{2}\right]-1\right)^{0.5} ;$ RMSE in this equation is in natural logarithmic units (Hoos and Roland, 2019).

${ }^{d}$ Unconditioned RMSE is similar to the conditioned RMSE except the predicted accumulated streamflows were not reset to the measured streamflows at the calibration sites upstream in the basin. 
temperature, catchment elevation, soil clay content, and the natural logarithm of PPT intensity. The model has five aquatic loss (decay) variables that describe the loss of water from free-flowing streams and impoundments. Three of the decay variables represent naturally occurring processes: excess aridity, loss from nonperennial streams, and evaporation from lakes and reservoirs. Nonperennial streams were identified in NHDPlusV2 and included as a decay variable based on their reach length (in kilometers). This variable was only applied to nonreservoir reaches. Two of the decay variables represent effects of human activities: direct withdrawals for public supply and losses associated with irrigation from groundwater pumping. Withdrawals for public supply were directly measured; therefore, they were included in the model without calibration (coefficient set to 1.0). Several variables that enhance water removal were included in the model to reduce the simulated streamflow in the western part of the study area where predictions were consistently too high.

The coefficients for all the variables in the streamflow model were statistically significant at $p<1.0 \times 10^{-4}$, except for the coefficient for the soil clay content $(p=0.0632)$, implying that each variable was important in describing streamflow in the Midwest. Soil clay content is often considered an important factor for describing water delivery, so it was retained in the final model. Coefficients included in the streamflow model generally had small standard errors, with an average coefficient of variation (computed as the standard error of the coefficient divided by its mean value) for the source variables of 0.15 and average coefficient of variation for the land-to-water delivery variables of 0.23 .

Analysis of the residuals for the streamflow model indicated that the weighted residuals for streamflow and water yield (figs. $5 A$ and $B$ were relatively homoscedastic (that is, the distribution of the residuals was similar throughout the range of predicted values); however, there was a slight decrease in the range of the residuals for the highest predicted values. It should be noted that the three highest yields were from small catchments that included springs. There was slight improvement in the homoscedasticity of the residuals (observed visually) when weighting of the sites for nesting was considered. Comparisons of measured streamflows with model predictions during the calibration process (conditioned) and during full model simulation (unconditioned) are shown in figures $5 C$ and $D$, respectively. The model explained 96 percent of the variance in flows and 94 percent of the variances in yields (not shown), respectively. The RMSE during model calibration (conditioned RMSE) was 0.373 and when the model was used for full prediction (unconditioned RMSE) was 0.425 (both in natural logarithmic units). These values equate to an RMSE of 38.6 percent for conditioned predictions and an RMSE of 44.5 percent for unconditioned predictions in real (cubic feet per second) space. In general, the model results fit the measured streamflow data during calibration and full prediction well; however, the model did not predict the lower streamflows as well: the unconditioned RMSE was 0.60 for streamflows of less than 5 logarithmic units compared to 0.26 for streamflows greater than 5 logarithmic units.

The evaluation of the spatial correlation of the weighted residuals throughout the study area indicated that the residuals had no significant regional patterns (Moran's $I$ value of 0.056 with $p=0.129$ ). However, flow predictions in the western part of the study area were less precise (as evidenced by larger residuals in fig. 6): flows were slightly overpredicted in the southwestern part of the study area and underpredicted in the areas surrounding the overpredictions. The distribution of the unconditioned residuals was similar to the distribution obtained during model calibration, and this pattern also was demonstrated in the residuals (fig. $6 B$ ). The southwestern part of the study area is a more arid region where variations in the relatively low flows are presumably sensitive to processes that are not included in the model such as natural climatic processes or various anthropogenic processes that remove and divert water in this area, mainly for agriculture. Although these residuals in the southwestern part of the study area appear to be large in logarithmic space, they are actually quite small in real space and, in general, only represent an error of a few cubic feet per second. Predicting flows in these arid regions also has been determined to be difficult for other hydrological models (McCabe and Wolock, 2011).

The coefficient for PPT-AET $(0.968$, table 3$)$ indicates that for every $1 \mathrm{ft}^{3} / \mathrm{s}$ of PPT-AET applied to the catchment, there is $0.968 \mathrm{ft}^{3} / \mathrm{s}$ of water delivered to the stream; therefore, PPT-AET was the primary source of streamflow, and the calculated input values were a good estimate of this source. The coefficient for the external point sources was 1.374, which is greater than 1.0, and suggests the input data for this source may have been underestimated. The coefficient for flows from springs was less than 1.0, which suggests the input data for this source may be overrepresented.

Based on the signs of coefficients for the land-to-water delivery variables, the magnitude of streamflow was inversely related to air temperature and catchment elevation; therefore, as air temperature and elevation increase, streamflow decreases. Soil clay content and PPT intensity had positive relations with streamflow; therefore, as these variables increase, streamflow increases. Instream decay and removal variables reflect additional reductions in streamflow during downstream transport. Inclusion of the aridity variable (PPTPET, precipitation minus potential evaporation) represents enhanced ET beyond that represented in AET in the western parts of the study area, and inclusions of the nonperennial stream variable may represent additional losses through the streambed in western parts of the study area. The coefficients for removal through evaporation from reservoirs and loss because of groundwater pumping for irrigation were greater than 1.0, which indicates the original input estimates for these losses underrepresented their full effect. For example, the coefficient for evaporation from reservoirs (1.485) implies a 1 -percent increase in the share of unevaporated flow causes a 1.485 -percent decrease in delivery. 

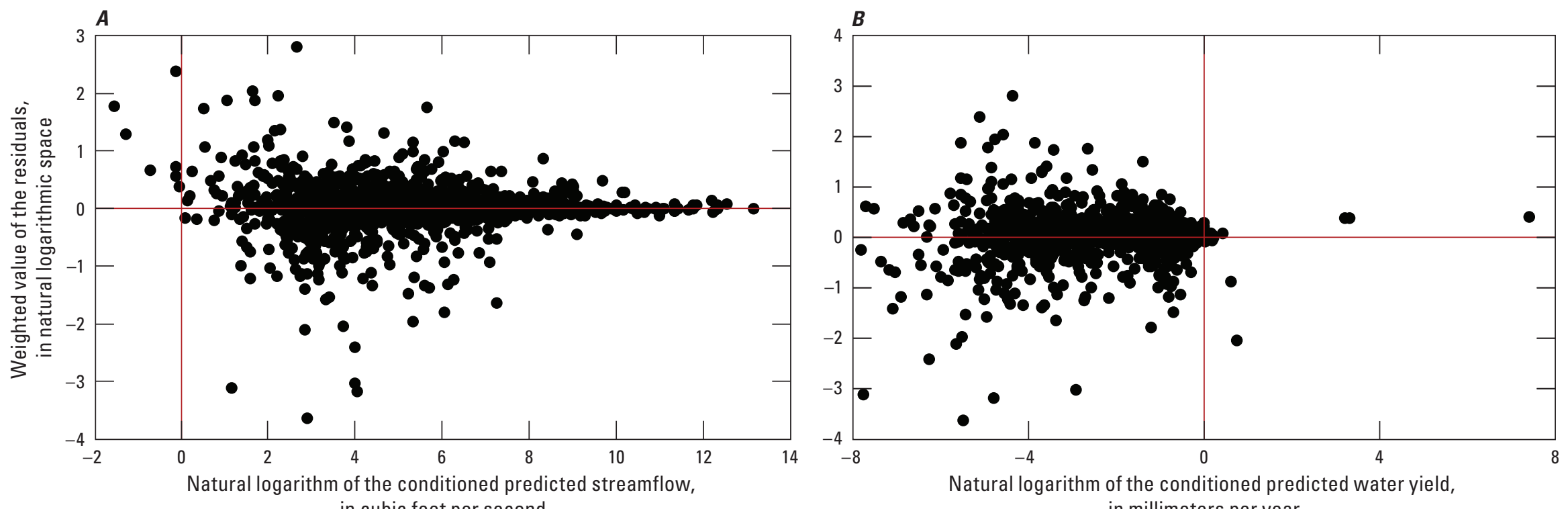
in cubic feet per second

Natural logarithm of the conditioned predicted water yield, in millimeters per year
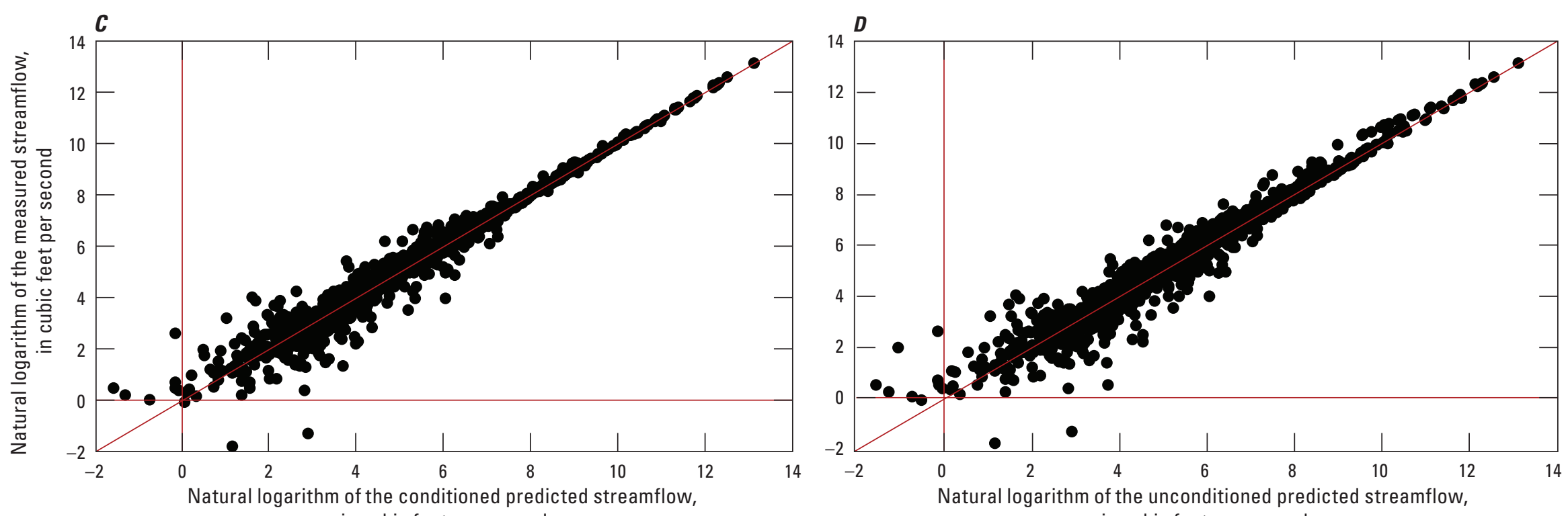

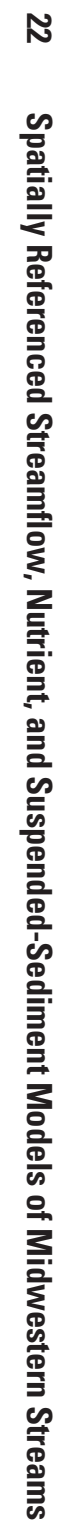

Figure 5. Diagnostic plots for the Midwest SPARROW (SPAtially Referenced Regression On Watershed attributes) streamflow model for all calibration sites. A, weighted residuals versus conditioned predicted streamflows; $B$, weighted residuals versus conditioned predicted yields; $C$, measured streamflows versus conditioned predicted streamflows (model calibration); $D$, measured streamflows versus unconditioned predicted streamflows (full simulation). Conditioned predicted streamflows and water yields are based on the upstream streamflows at the calibration sites reset to the measured streamflows. Unconditioned predicted streamflows are based on the upstream streamflows at the calibration sites not reset to the measured streamflows. 

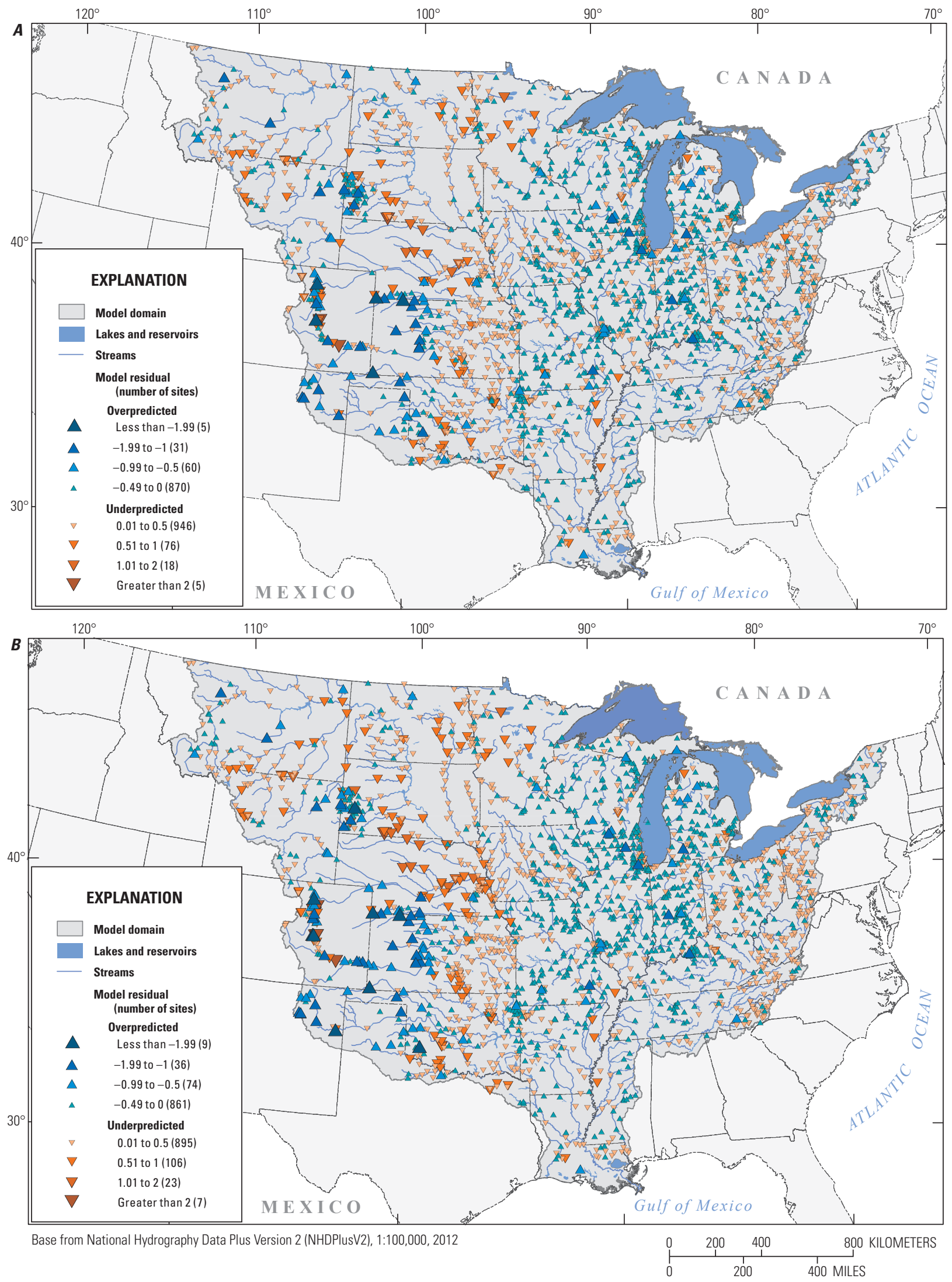

Figure 6. Spatial distribution of residuals, in natural logarithmic units, from the Midwest streamflow model. $A$, conditioned residuals (calibration); $B$, unconditioned residuals (full simulation). 


\section{Simulated Water Transport and Streamflow throughout the Midwest}

Incremental water yields throughout the Midwest are shown in figure 7 . Incremental yields of water reaching the streams (in millimeters per year) were computed by dividing the incremental flow from each catchment by its incremental area. The incremental yields are mediated by the land-to-water delivery factors. Mean and median incremental annual water yields were 334 and $321 \mathrm{~mm} / \mathrm{yr}$, respectively. A few catchments, primarily those dominated by sources other than PPTAET, had high-water yields. In general, the highest annual incremental yields (greater than $482 \mathrm{~mm} / \mathrm{yr}$ ) were from areas in the eastern part of the study area, and the lowest yields (less than $18 \mathrm{~mm} / \mathrm{yr}$ ) were from the areas just east of the Rocky Mountains.

The areally weighted aggregated water yields from each major drainage basin in the Midwest ranged from $76.3 \mathrm{~mm}$ from the Missouri River Basin to $682 \mathrm{~mm}$ from the St. Lawrence River Basin (fig. 8 and table 4). For all these areas, the major source of water was from PPT-AET (fig. 8). A few areas had a small percentage of their water coming from WWTP effluent (Lake Erie and Lake Ontario). The areally weighted water yield from catchments in the Great Lakes and Mississippi River Basins were 417 and $232 \mathrm{~mm}$, respectively. The areally weighted water yield to streams for the Midwest area was $249 \mathrm{~mm}$.

Not all the water reaching the end of the SPARROW catchments is delivered to its downstream receiving waterbody; some water was lost through evaporation or from the bottom of the stream to deep groundwater. Mean and median delivered incremental annual water yields to the downstream receiving waterbody were 299 and $291 \mathrm{~mm} / \mathrm{yr}$, respectively. The highest incremental yields were again from areas in the eastern part of the study area, and the lowest yields were from areas just east of the Rocky Mountains (fig. 7B). The major difference in the distributions in the incremental and the delivered incremental yields was that delivered incremental yields were lower than the incremental yields in the western part of the study area. These differences were primarily caused by high evaporation from streams and reservoirs in the western part of the Midwest.

The delivered aggregated yield of water to either the Great Lakes, the Gulf of Mexico, or Canada from each major drainage basin ranged from $49.3 \mathrm{~mm}$ from the Missouri River Basin to $666 \mathrm{~mm}$ from the St. Lawrence River Basin (table 4).
The delivered aggregated yield of water from catchments in the Great Lakes and Mississippi River Basins were $401 \mathrm{~mm}$ and $206 \mathrm{~mm}$, respectively. The delivered aggregated yield of water from streams throughout the Midwest area was $223 \mathrm{~mm}$; therefore, about 10 percent of the water that reaches the stream network is lost during transport to the downstream receiving waterbody.

In past SPARROW applications in the study area, the long-term mean streamflows used in constituent models were estimated from data collected from 1971 to 2000 from streamgages throughout the United States and were similar to the streamflows in NHDPlusV2. To determine if the Midwest SPARROW model was a more accurate predictor of the longterm mean streamflow for 2000 to 2014 (the years used in the other constituent models) and more appropriate to use in the SPARROW TN, TP, and SS models than the streamflows from NHDPlusV2, the RMSE from the Midwest streamflow model (unconditioned predictions) was compared with the RMSE computed using NHDPlusV2 data to predict the streamflows at the monitoring sites used in the SPARROW streamflow model calibration. The unconditioned RMSE from the SPARROW streamflow model was 0.425 compared to an RMSE of 0.456 from NHDPlusV2 data; therefore, the direct results from the Midwest SPARROW streamflow model are considered be more appropriate to use in the SPARROW TN, TP, and SS models than the NHDPlusV2 data. However, rather than using the direct results of the SPARROW streamflow models in the SPARROW TN, TP, and SS models, the SPARROW-simulated streamflows were adjusted (conditioned) to the measured streamflows where they were available. This conditioning should further improve the flow simulated throughout the modeled area. SPARROW-simulated streamflows were used in the SPARROW TN, TP, and SS models to compute the mean stream velocities, reach time of travels, and reciprocal areal hydraulic loads that are used in estimating losses during downstream delivery. SPARROW-simulated, nondecayed incremental streamflows, which represent streamflows generated within specific catchments, also were used to compute runoff used as a land-to-water delivery variable in the constituent models. The nondecayed incremental streamflow represents overland runoff and base flow (streamflow derived mainly from groundwater) delivered from the catchment to the stream channel and does not account for losses from instream or in-reservoir decay in the incremental reach. The simulated mean streamflow and nondecayed incremental streamflow are available in an associated USGS data release (Saad and Robertson, 2019). 

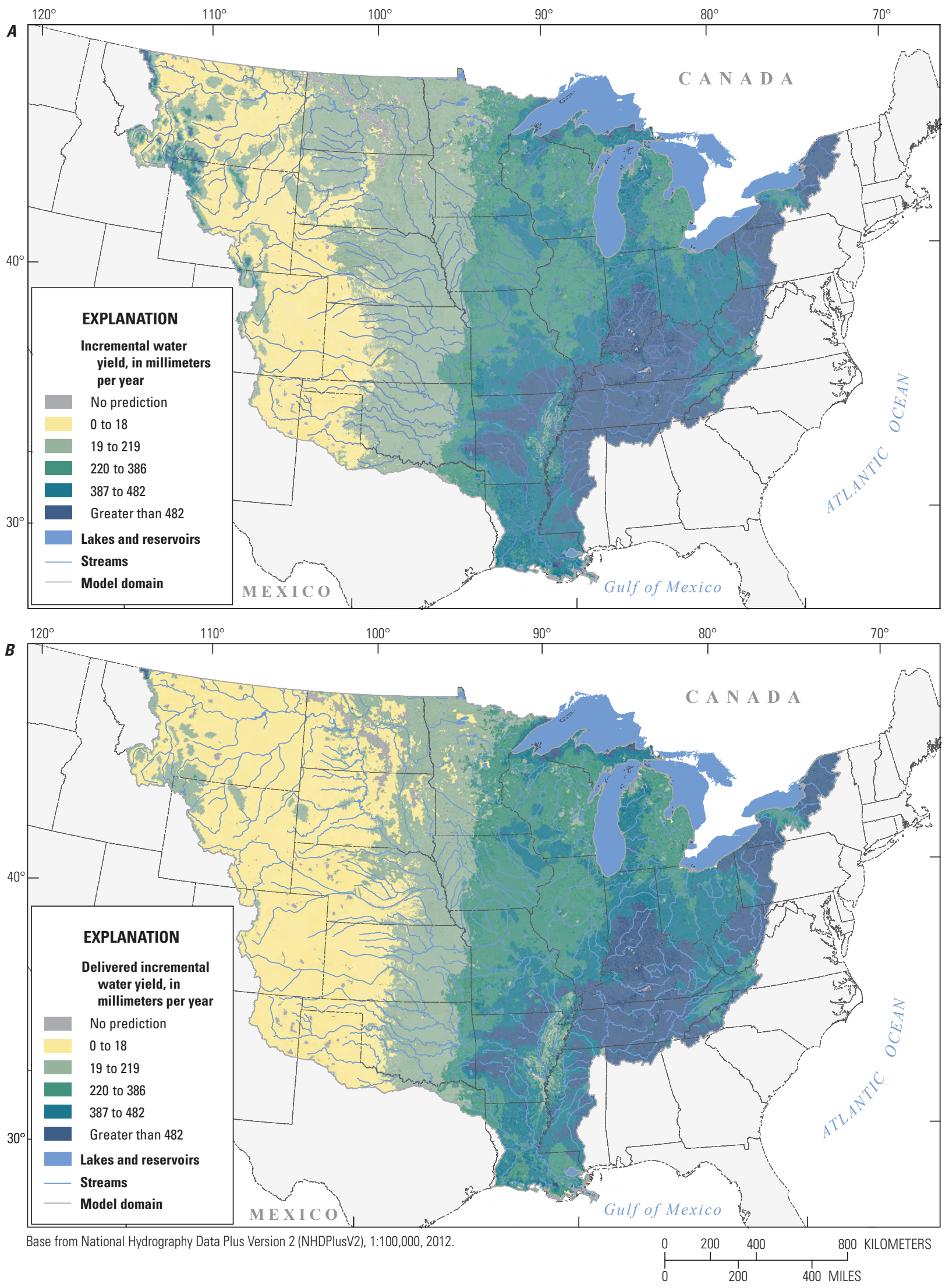

Figure 7. Distribution of incremental mean-annual yields of water, in millimeters per year, from the Midwest SPARROW (SPAtially Referenced Regression On Watershed attributes) streamflow model. $A$, incremental mean-annual yields from each catchment; $B$, delivered incremental mean-annual yields to the final receiving waterbody. 


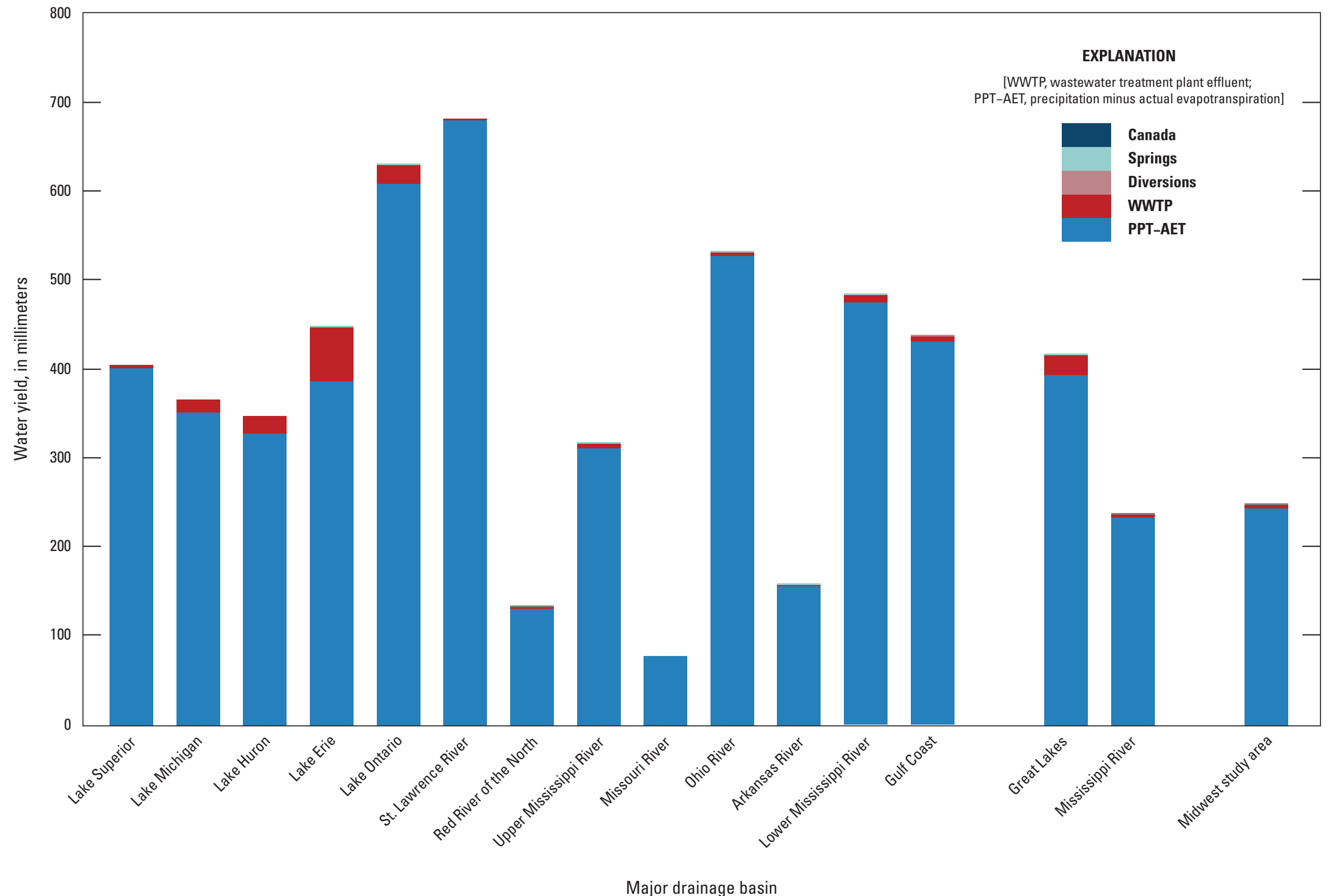

๙ั

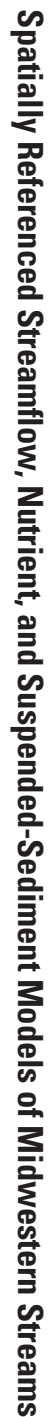

Figure 8. Predicted mean-annual water yield, by source, for the Midwest, Great Lakes Basin, Mississippi River Basin, and selected major drainage basins in the Midwest region of the United States. 
Table 4. Mean-annual yields of water, in millimeters, by source, to streams and delivered to the downstream receiving waterbody from each of the major drainage basins in the Midwest. Aggregated yields also are summarized for the Great Lakes and Mississippi River Basins and the Midwest area.

[PPT-AET, precipitation minus actual evapotranspiration; WWTP, wastewater treatment plants]

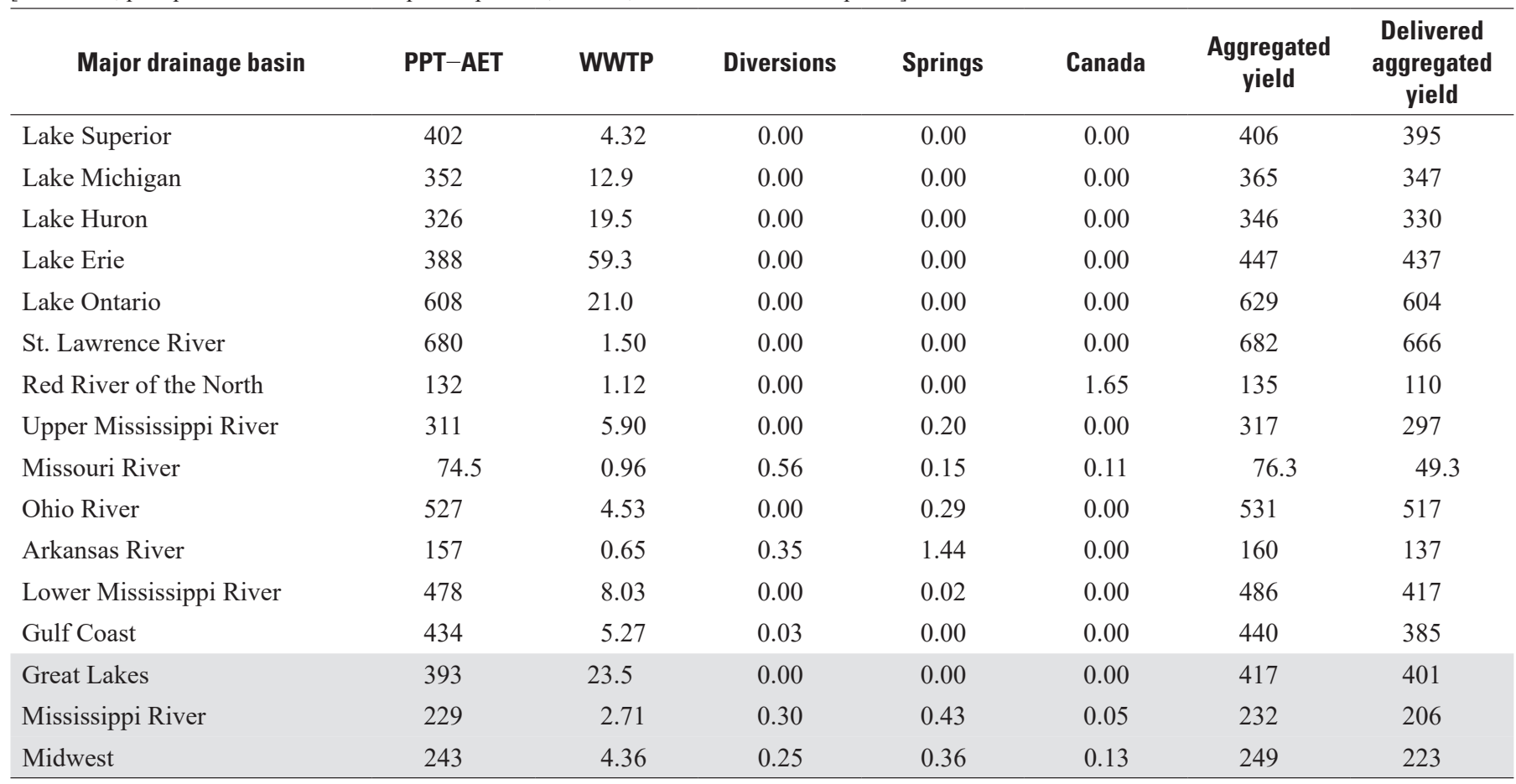

\section{SPARROW Total Nitrogen Model}

\section{Specification of the Total Nitrogen Model}

Long-term mean-annual TN loads throughout a stream network represent the net result of the balance between nitrogen inputs from natural and anthropogenic sources and nitrogen losses from removal from crops and animals, volatilization to the atmosphere, accumulation in the soil, and losses during transport down the river network. Typically, the amount of nitrogen transported down the river network, which is represented by the loads, is only a small fraction of the nitrogen applied to the land surface. Most of the typical main sources and factors affecting the loss of nitrogen were considered for inclusion in the Midwest SPARROW TN model (appendix 2); however, data describing natural/background sources of nitrogen were not available. Therefore, nitrogen from natural/background sources should be incorporated in other input sources to which they were most correlated. During calibration, the model was evaluated to determine if the monitoring sites should be thinned and if many of the monitored sites being nested may affect the model. Results of preliminary model evaluations indicated thinning was not necessary (in other words, there was no significant negative spatial correlation for nested or nonnested sites within $5 \mathrm{~km}$ ); therefore, the model was calibrated with TN loads from 1,334 monitoring sites. Additional model evaluations indicated that the nested monitoring sites may have unequal effect during model calibration $\left(p=3.3 \times 10^{-6}\right.$; table 5$)$; therefore, weights were applied to residuals from all the monitoring sites based on the percentage of the basin area that was nested during the final calibration of the TN model. Adjusting for the effects of nested monitoring sites had little effect on the summary statistics of the model (RMSE, standard errors, and $p$-values), but it did result in modifications to coefficients for several variables.

The 2012 Midwest SPARROW TN model has 17 variables (table 5). The model has seven sources of nitrogen: effluent from WWTPs, urban and open areas, fertilizers applied to cultivated crops, manure from livestock used as fertilizer on cultivated crops and pastures, fixation, atmospheric deposition, and stream loads from Canada (Canada load). Nitrogen inputs from Canada were directly included in the model without calibration (coefficient set to 1.0). The model has six land-towater delivery variables that represent factors that collectively enhance or reduce the nitrogen delivery to streams: detrended mean daily air temperature, the natural logarithm of runoff, the natural logarithm of the percentage of the catchment with tile drains, the natural logarithm of soil clay content, the CRP acres relative to total farmland ( $\mathrm{CRP} /$ farm-acre ratio), and the natural logarithm of the percentage of the catchment using notill farm practices (a specific type of BMP). The land-to-water delivery variables of $\mathrm{CRP} /$ farm-acre ratio and the percentage of the catchment using no-till practices were allowed to only interact with agricultural sources in the model. The model 
Table 5. Summary of calibration results for the 2012 Midwest SPARROW total nitrogen model. Calibration incorporated adjustments for the amount of upstream watershed that was included in

watersheds of other calibration sites.

[SPARROW, SPAtially Referenced Regression On Watershed attributes; $p$-value, probability value; $t$-value, $t$-statistic; $\mathrm{kg}$, kilogram; $<$ less than; $\mathrm{km}^{2}$, square kilometer; $\mathrm{kg} / \mathrm{km}^{2} / \mathrm{yr}$, kilogram per square kilometer per year; --, not computed; In, natural logarithm; ${ }^{\circ} \mathrm{C}$, degrees Celsius; CRP, Conservation Reserve Program; $\mathrm{m}^{3} / \mathrm{s}$, cubic meter per second; yr $/ \mathrm{m}$, year per meter; $\mathrm{m} / \mathrm{yr}$, meter per year; $\mathrm{km}$, kilometer; RMSE, root mean square error; Moran's $I$, measure of spatial autocorrelation; $R^{2}$, coefficient of determination]

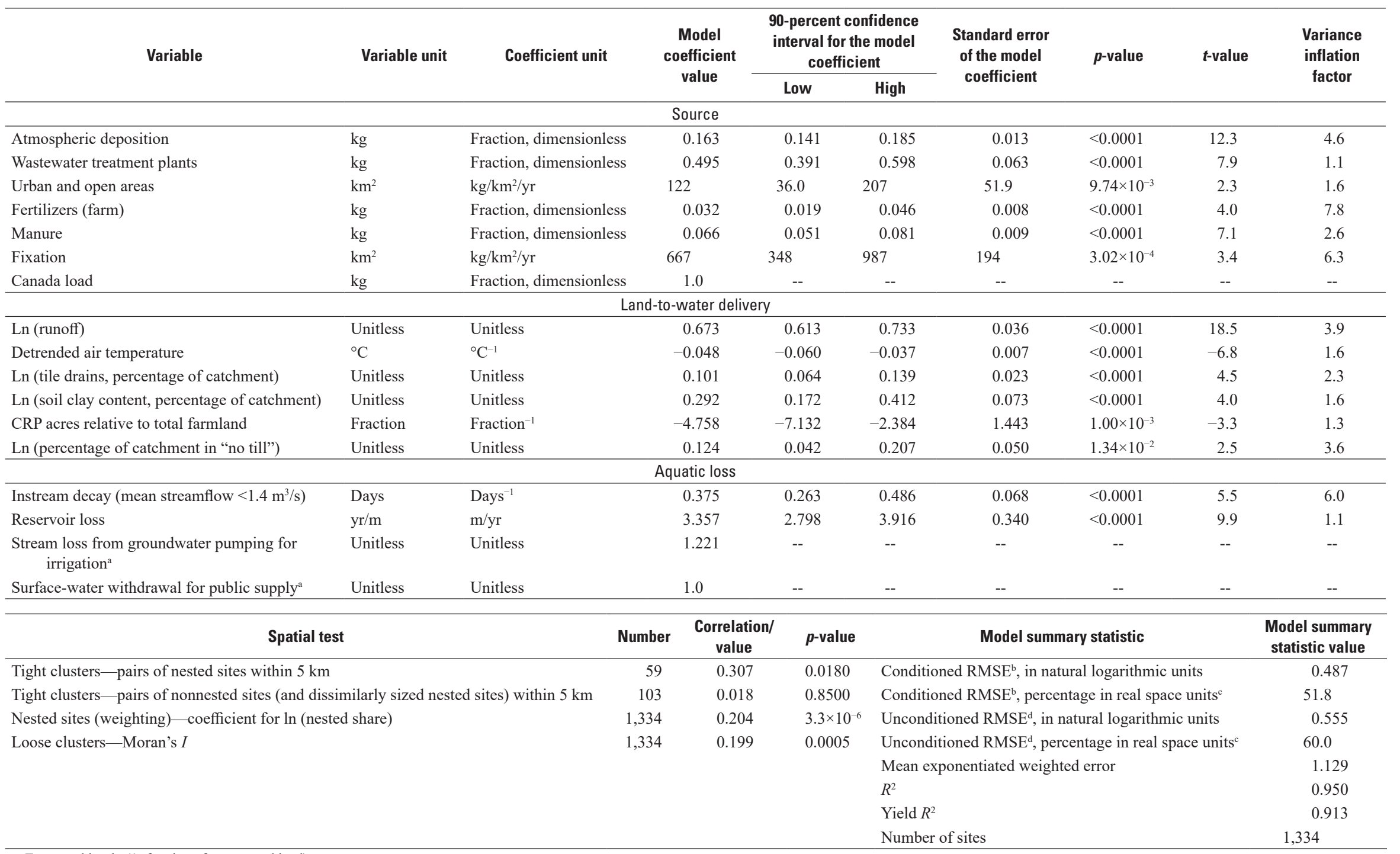

axpressed in $-\ln (1-$ fraction of unremoved load):

${ }^{b}$ Conditioned RMSE is the root mean square error of the difference between the natural logarithm of measured calibration loads and the natural logarithm of predicted accumulated loads that were reset to the measured loads at the calibration sites upstream in the basin.

${ }^{\mathrm{C}} \mathrm{RMSE}$ in terms of percentage in real space units was computed as $100 \times\left(\exp \left[\mathrm{RMSE}^{2}\right]-1\right)^{0.5} ;$ RMSE in this equation is in natural logarithmic units (Hoos and Roland, 2019).

${ }^{d}$ Unconditioned RMSE is similar to the conditioned RMSE except the predicted accumulated loads were not reset to the measured loads at the calibration sites upstream in the basin. 
has four aquatic loss (decay) variables that describe losses of nitrogen from free-flowing streams and impoundments. Two of the decay variables represent naturally occurring processes, assuming that the cultural processes were accurately accounted for: losses in streams with flows less than $1.4 \mathrm{~m}^{3} / \mathrm{s}$ $\left(50 \mathrm{ft}^{3} / \mathrm{s}\right)$, and losses in lakes and reservoirs. The specific breakpoint in streamflow for the loss in streams was determined during the calibration process by iteratively modifying the streamflow rate breakpoint and examining the model statistics. Two of the decay variables represent human activities: withdrawals for public supply and losses associated with irrigation from groundwater pumping. Withdrawals for public supply were directly included in the model without calibration (coefficient set to 1.0). It was assumed that groundwater irrigation removed nitrogen at the same rate as it removed water; therefore, the coefficient for groundwater irrigation was set to the same value as the coefficient in the SPARROW streamflow model (1.221; tables 3 and 5).

The coefficients associated with all the variables in the TN model were statistically significant at $p<0.05$, which indicates that each variable was important in describing TN loads in Midwest streams. Coefficients for sources and land-to-water delivery variables included in the TN model generally had small standard errors, with an average coefficient of variation for the source variables of 0.22 , and average coefficient of variation for the land-to-water delivery variables of 0.23 .

An analysis of the residuals for the TN model indicated that the weighted residuals for TN loads and yields (figs. $9 \mathrm{~A}$ and $B$ ) were relatively homoscedastic; however, there was a slight decrease in the range of residuals for the highest predicted values. There was slight improvement in the homoscedasticity of the residuals (observed visually) when weighting of the sites for nesting was considered. Comparisons of measured TN loads with model predictions during the calibration process (conditioned) and during full model simulation (unconditioned) are shown in figures $9 C$ and $D$, respectively. The model explained 95 percent of the variance in TN loads and 91 percent of the variances in yields (not shown), respectively. The RMSE obtained during model calibration (conditioned RMSE) was 0.487 and when the model was used for full prediction (unconditioned RMSE) was 0.555 (both in natural logarithmic units). These values equate to an RMSE of 51.8 percent for conditioned predictions and an RMSE of 60.0 percent for unconditioned predictions in real (kilograms per year) space. In general, the model results fit the measured TN loads during calibration and prediction well. However, similar to the SPARROW streamflow model, the SPARROW TN model had patterns of overpredictions and underpredictions in the western parts of the watershed (fig. 10), and the model did not predict the loads and yields as well for sites with relatively small loads. The unconditioned RMSE was 0.65 for TN loads less than 14 logarithmic units compared to 0.39 for loads greater than 14 logarithmic units.

The evaluation of spatial correlation of the weighted residuals throughout the study area indicated that the residuals had some regional patterns (Moran's I value of 0.199 with $p=0005$ ) - mainly overpredictions in the southwestern part of the study area and in eastern parts of North and South Dakota and underpredictions in the areas adjacent to the overpredictions in the central part of the study area (fig. 10A). The distribution of the unconditioned residuals was relatively similar to that determined during model calibration and demonstrated a relatively similar pattern in residuals; however, the unconditioned predictions for much of the eastern one-half of the modeled area were slightly overpredicted (fig. 10B). The unconditioned residuals also were a little larger than the conditioned residuals, and residuals of similar signs often propagated down several of the larger rivers. The western part of the study area is a more arid region where variations in the relatively smaller loads are presumably sensitive to processes that are not included in the model, such as natural climatic processes or various anthropogenic processes that remove and divert water in this area, mainly for agriculture. Although most of the large residuals in the western part the of the study area appear large in logarithmic space, they are actually quite small in terms of kilograms per year. Predicting loads in these arid regions also has been determined to be difficult for other watershed models (Robertson and Saad, 2013); however, because this area has fewer monitoring sites, it was not as obvious as that determined here.

The coefficient for WWTPs (0.495 in table 5) indicates that for every $1 \mathrm{~kg}$ of nitrogen estimated to be input from WWTPs, $0.495 \mathrm{~kg}$ is delivered to the stream; therefore, this suggests that the nitrogen input from WWTPs was probably overestimated. Much of the nitrogen concentration data that were used to estimate TN loads from WWTPs were based on regional-averaged values (TPCs, appendix 4), so it is reasonable to expect that such estimates could be less than those measured and reported. Coefficients for fertilizers, manure, and atmospheric deposition represent the fraction of their input mass that is delivered to streams. For fertilizers, only about 3.2 percent of the nitrogen applied to agricultural lands was estimated to be transported to streams. For manure, about 6.6 percent of the nitrogen excreted from agricultural animals was estimated to be transported to streams. For atmospheric deposition, about 16.3 percent of the nitrogen deposited on land was estimated to be transported to streams. Most of the nitrogen applied to the land is lost to plant uptake and harvesting, volatilization, and possibly accumulation in the soil. Area-based source coefficients for the land-area variables indicate that about 667 kilograms per square kilometer per year $\left(\mathrm{kg} / \mathrm{km}^{2} / \mathrm{yr}\right)$ originate from nitrogen-fixing crops and $122 \mathrm{~kg} / \mathrm{km}^{2} / \mathrm{yr}$ originate from urban areas.

The coefficients associated with the land-to-water delivery variables suggest how each of these characteristics affect TN transport to streams. Runoff, as represented by nondecayed incremental flows from the SPARROW streamflow model, was the most significant variable in the model as indicated by the $t$-statistic. Runoff had a positive coefficient, which suggests that as runoff increases, nitrogen delivery to streams increases. As with the streamflow model, the air temperature coefficient was negative. 

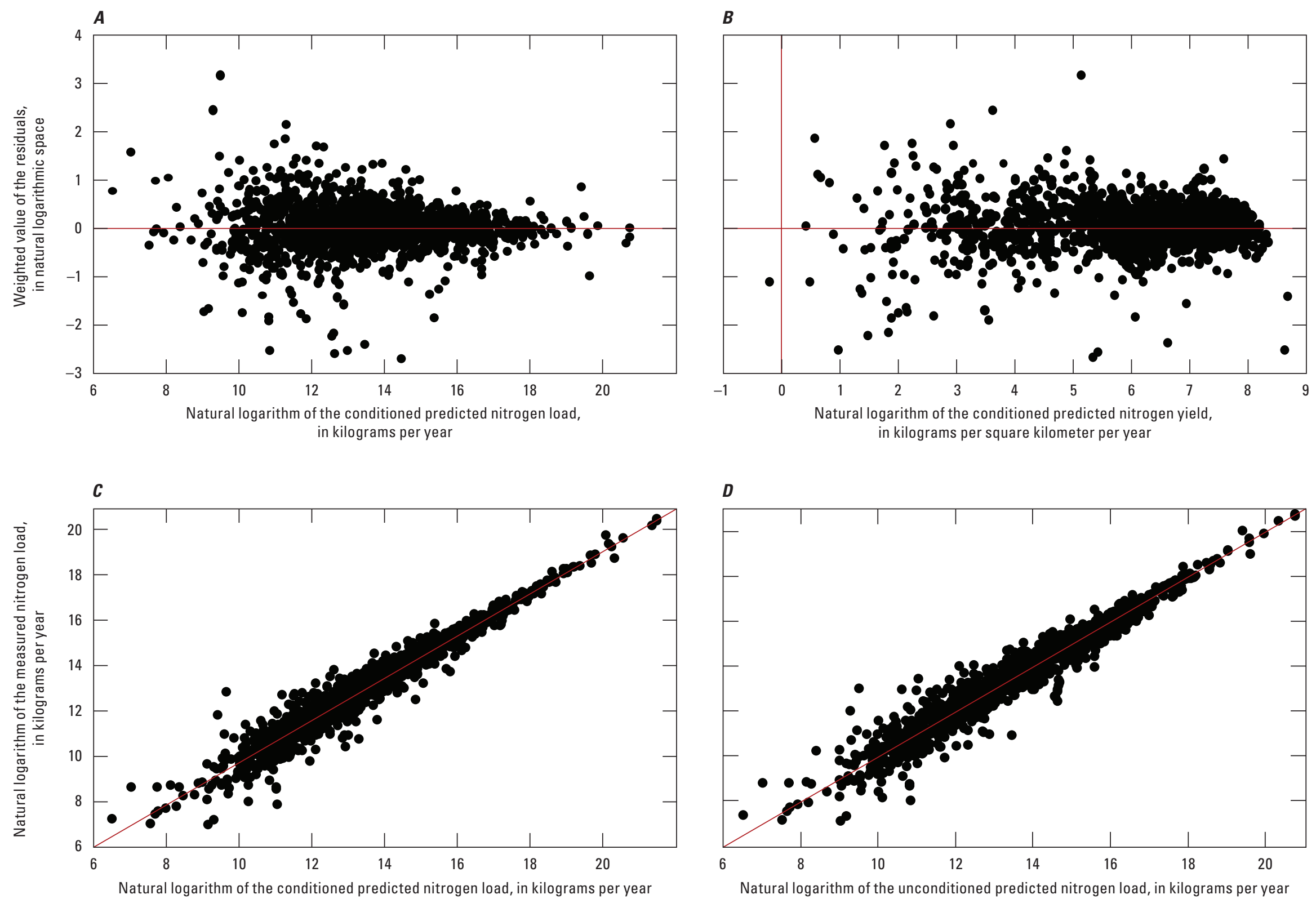

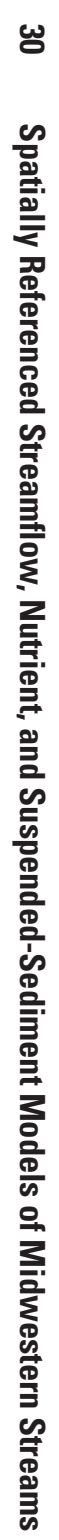

Figure 9. Diagnostic plots for the Midwest SPARROW (SPAtially Referenced Regression On Watershed attributes) total nitrogen model for all calibration sites. $A$, weighted residuals versus conditioned predicted loads; $B$, weighted residuals versus conditioned predicted yields; $C$, measured loads versus conditioned predicted loads (model calibration); $D$, measured loads versus unconditioned predicted loads (full simulation). Conditioned predicted loads and yields are based on the upstream loads at the calibration sites reset to the measured loads. Unconditioned predicted loads are based on the upstream loads at the calibration sites not reset to the measured loads. 

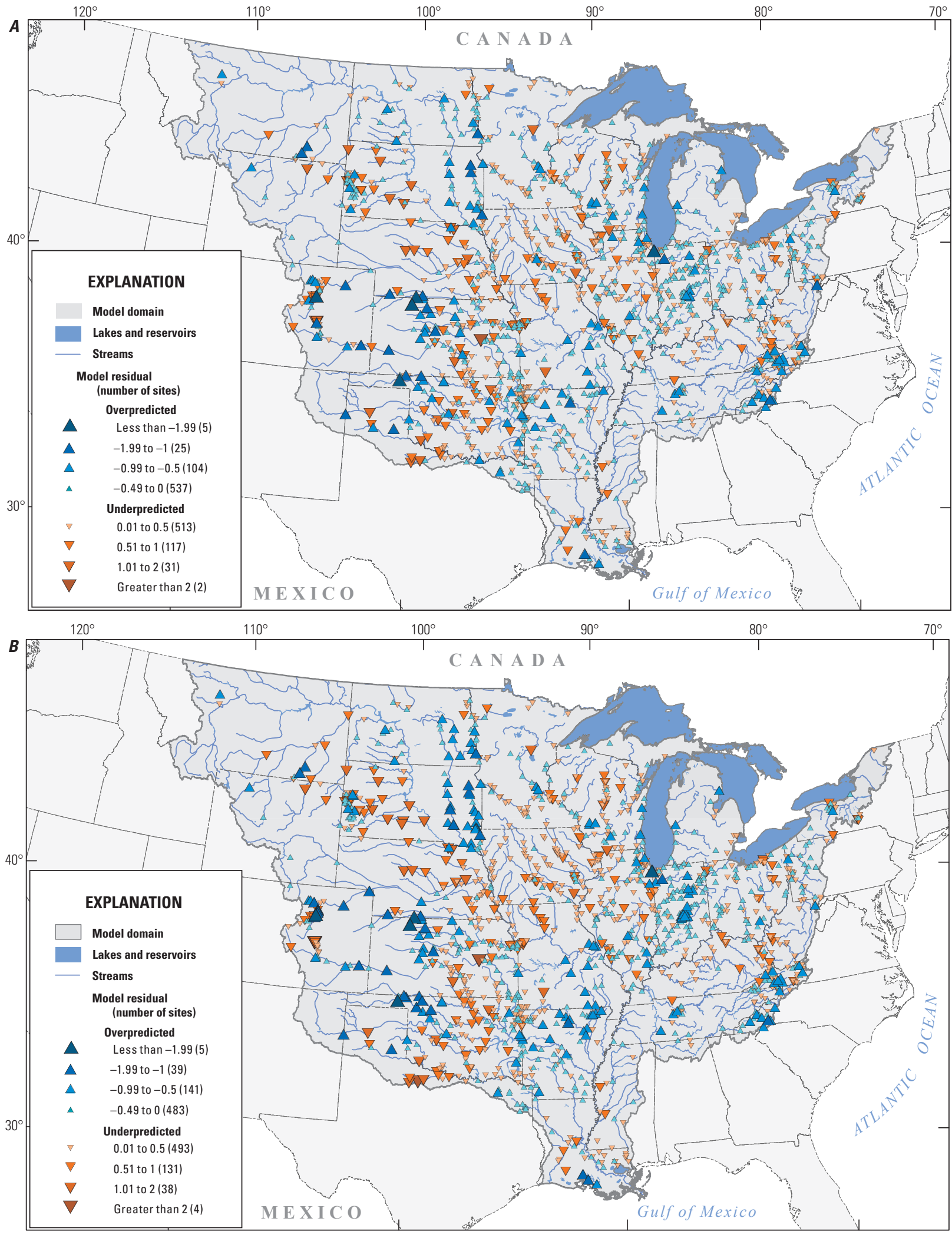

Base from National Hydrography Data Plus Version 2 (NHDPlusV2), 1:100,000, 2012

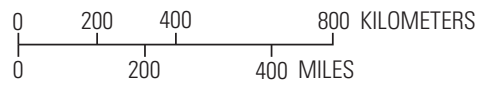

Figure 10. Spatial distribution of residuals, in natural logarithmic units, from the Midwest total nitrogen model. $A$, conditioned residuals; $B$, unconditioned residuals. 
Warmer temperatures likely enhance plant uptake and volatilization, reducing the mass delivered to streams, and increase evaporation that decreases the volume of water being transported. Also like in the streamflow model, the coefficient for soil clay content was positive. Because much of the TN load is in dissolved forms, TN behaves similar to water, which has enhanced delivery to streams in areas with higher soil clay content. The positive coefficient for tile drains suggests that these agricultural features increase nitrogen delivery to streams. The two land-to-water delivery variables that represented BMPs had opposite signs, indicating opposite effects on nitrogen delivery. The CRP/farm-acres ratio variable had a positive sign, which suggests that increases in the amount of CRP land were associated with lower nitrogen delivery to streams. The coefficient for the no-till BMP variable was positive, suggesting that this type of BMP may increase nitrogen delivery to streams. Other studies also have indicated this relation with no-till practices (Daryanto and others, 2017). The increased delivery of nitrogen may be caused by increased infiltration in areas of no-till farming practices. The increased infiltration in areas of nitrogen application can lead to increases in nitrogen concentrations in groundwater and eventually increases in the importance of nitrogen from base flow (streamflow derived mainly from groundwater) to the TN load in streams.

\section{Simulated Total Nitrogen Transport throughout the Midwest}

Incremental $\mathrm{TN}$ yields from catchments throughout the Midwest are shown in figure 11. Incremental yields of $\mathrm{TN}$ to streams (in kilograms per square kilometer per year) were computed by dividing the incremental loads from each catchment by their incremental areas. Mean and median incremental annual TN yields were 686 and $371 \mathrm{~kg} / \mathrm{km}^{2} / \mathrm{yr}$, respectively. A few catchments, primarily those dominated by WWTPs, had high TN yields. The highest annual incremental yields (greater than $825 \mathrm{~kg} / \mathrm{km}^{2} / \mathrm{yr}$ ) were generally from the Corn Belt and along the lower Mississippi River, and the lowest yields (less than $42 \mathrm{~kg} / \mathrm{km}^{2} / \mathrm{yr}$ ) were from areas just east of the Rocky Mountains.

The areally weighted aggregated $\mathrm{TN}$ yields from each major drainage basin in the Midwest ranged from $245 \mathrm{~kg} / \mathrm{km}^{2} / \mathrm{yr}$ from the Missouri River Basin to $1,830 \mathrm{~kg} / \mathrm{km}^{2} / \mathrm{yr}$ from the Lake Erie Basin (fig. 12 and table 6). For all areas, the major source of TN was from either the atmosphere (for areas with limited agriculture, such as the Lake Superior Basin) or from agricultural sources (fig. 12). Typically, fertilizers or fixation was the dominant agricultural source of nitrogen. Urban sources (urban areas and WWTPs) of nitrogen were typically not very important (less than 10 percent of the total yield), except for the Lake Erie Basin, for which they represented about 15 percent of the total yield. The aggregated TN yields from the Great Lakes Basin and Mississippi River Basin were 961 and $605 \mathrm{~kg} / \mathrm{km}^{2} / \mathrm{yr}$, respectively. The aggregated TN yield from the Midwest area was $611 \mathrm{~kg} / \mathrm{km}^{2} / \mathrm{yr}$.

Not all the nitrogen reaching the end of the SPARROW catchments is delivered to its downstream receiving waterbody because some nitrogen is lost through settling or volatilization in streams and reservoirs. Mean and median delivered incremental annual TN yields from catchments throughout the Midwest area to the downstream receiving waterbody were 556 and $288 \mathrm{~kg} / \mathrm{km}^{2} / \mathrm{yr}$, respectively. The highest annual incremental yields, similar to streamflow, were from the Corn Belt, and the lowest yields were from areas just east of the Rocky Mountains (fig. 11B). The major differences in the distribution of the incremental and delivered incremental yields were that delivered yields were lower in the western part of the study area and in areas away from the Mississippi River. These differences in the incremental yields and delivered incremental yields were primarily caused by the losses in small streams and reservoirs in the western part of the Midwest.

The delivered aggregated $\mathrm{TN}$ yields to either the Great Lakes, Gulf of Mexico, or Canada from each major drainage basin ranged from $163 \mathrm{~kg} / \mathrm{km}^{2} / \mathrm{yr}$ from the Missouri River Basin to $1,640 \mathrm{~kg} / \mathrm{km}^{2} / \mathrm{yr}$ from the Lake Erie Basin (table 6). The delivered aggregated TN yield from catchments in the Great Lakes and Mississippi River Basins were 827 and $488 \mathrm{~kg} / \mathrm{km}^{2} / \mathrm{yr}$, respectively. The aggregated delivered TN yield from the Midwest area was $494 \mathrm{~kg} / \mathrm{km}^{2} / \mathrm{yr}$. About 14 percent of the nitrogen that reaches the stream network was lost during transport to the Great Lakes, compared to 19 percent lost during transport to the Gulf of Mexico. The larger percentage lost during transport to the Gulf of Mexico was because of the longer transport distance and more large reservoirs in the Mississippi River Basin than in the Great Lakes Basin. The difference in incremental yields and delivered incremental yields means that actions upstream in the watershed will not have as large of an effect on the downstream receiving waterbody as actions near the receiving waterbodies. 

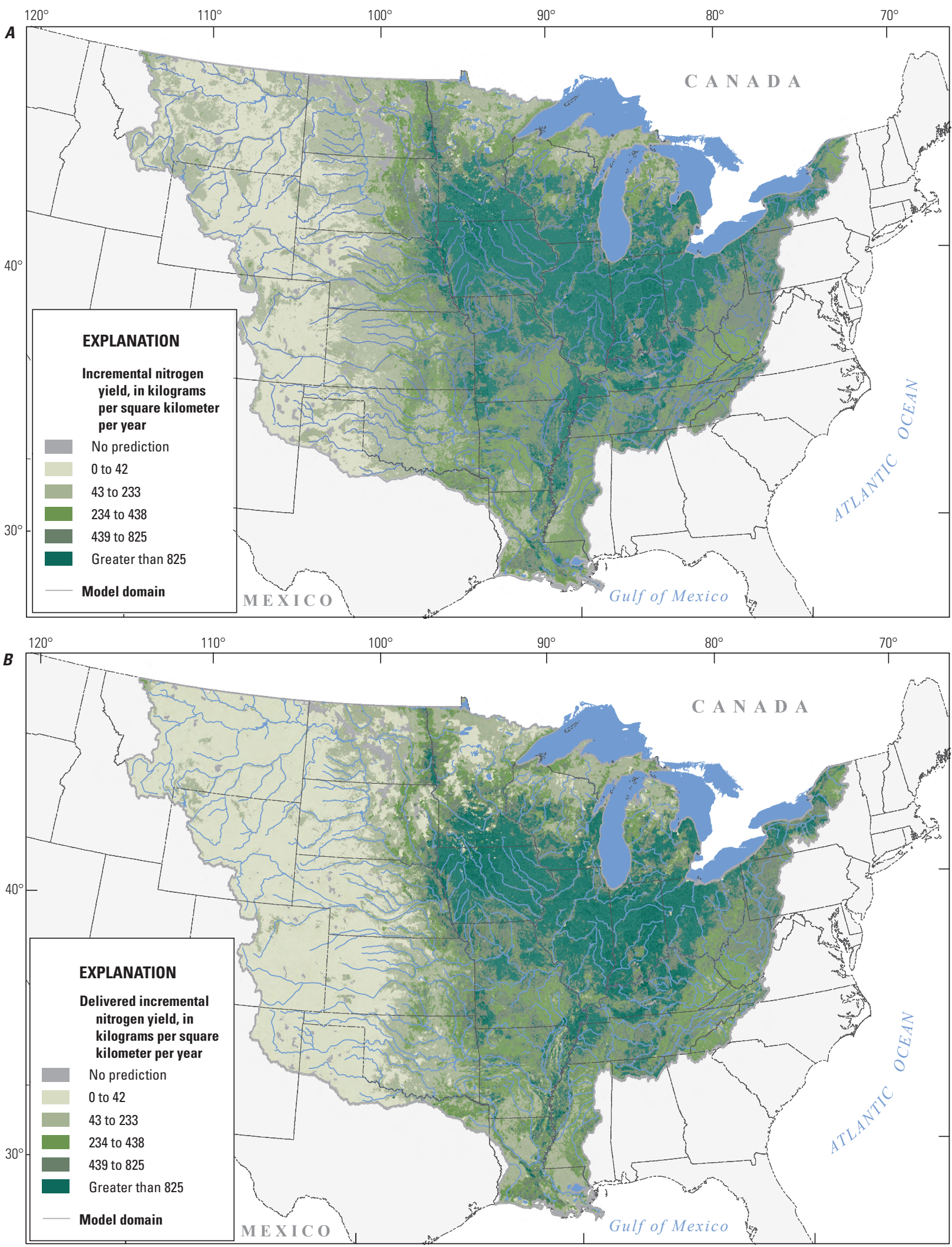

Base from National Hydrography Data Plus Version 2 (NHDPlusV2), 1:100,000, 2012

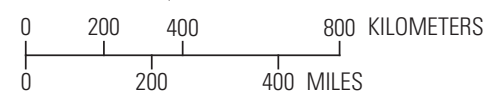

Figure 11. Distribution of incremental mean-annual yields of total nitrogen, in kilograms per square kilometer per year, from the Midwest SPARROW (SPAtially Referenced Regression On Watershed attributes) total nitrogen model. $A$, incremental mean-annual yields from each catchment; $B$, delivered incremental mean-annual yields to the final receiving waterbody. 


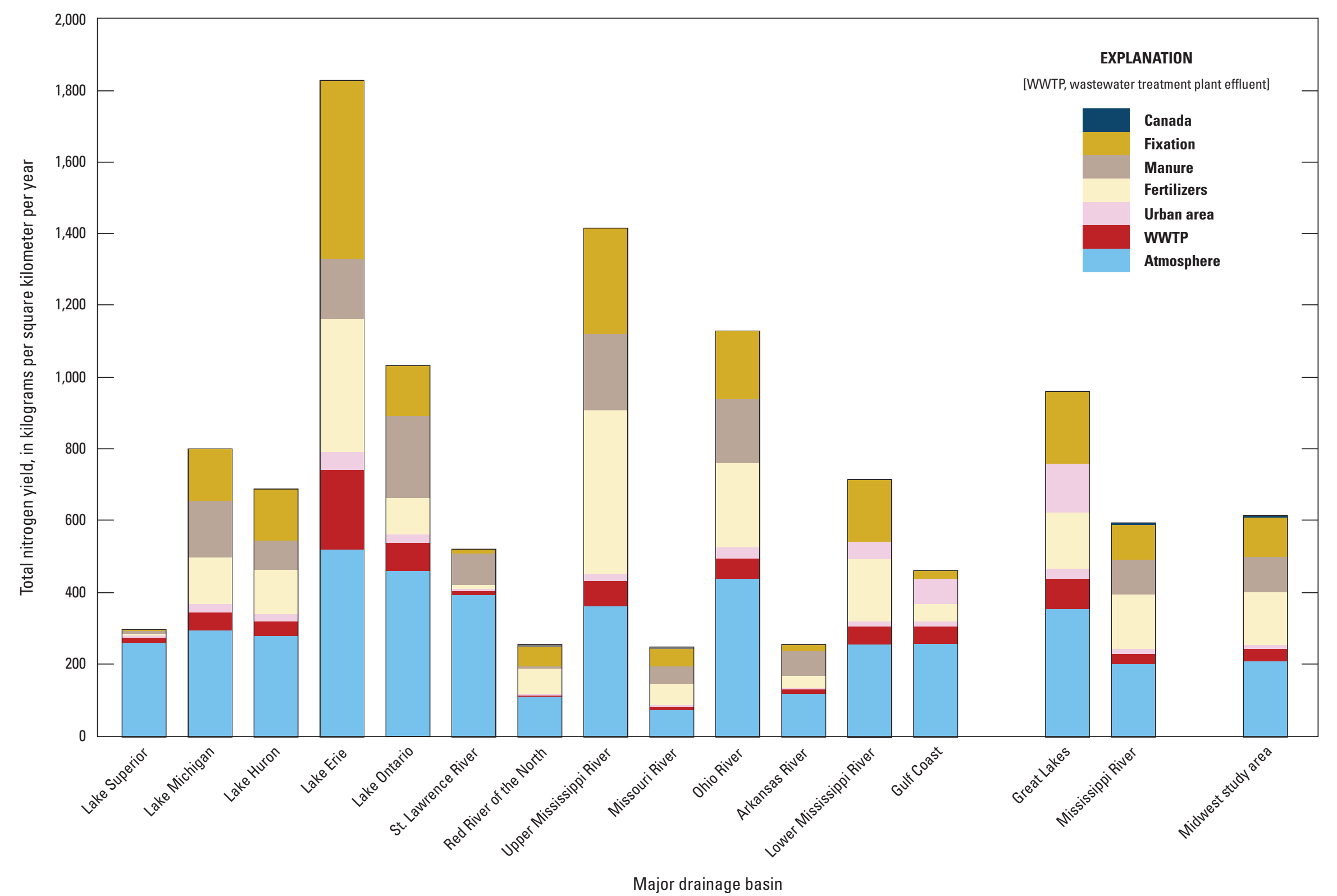

Figure 12. Predicted mean-annual total nitrogen yield, by source, for the Midwest, Great Lakes Basin, Mississippi River Basin, and selected major drainage basins in the Midwest region of the United States. 
Table 6. Mean-annual yields of total nitrogen, in kilograms per square kilometer per year, by source, to streams and delivered yield and total delivered load, in kilograms per year, to the downstream receiving waterbody from each of the major drainage basins in the Midwest. Aggregated yields also are summarized for the Great Lakes and Mississippi River Basins, and the Midwest area.

[WWTP, wastewater treatment plants]

\begin{tabular}{|c|c|c|c|c|c|c|c|c|c|c|}
\hline Major drainage basin & WWTP & Fertilizers & Manure & Fixation & Atmosphere & $\begin{array}{l}\text { Urban } \\
\text { area }\end{array}$ & Canada & $\begin{array}{l}\text { Aggregated } \\
\text { yield }\end{array}$ & $\begin{array}{c}\text { Delivered } \\
\text { aggregated } \\
\text { yield }\end{array}$ & $\begin{array}{c}\text { Total } \\
\text { delivered } \\
\text { load }\end{array}$ \\
\hline Lake Superior & 10.9 & 1.0 & 8.9 & 2.1 & 264 & 10.3 & 0.0 & 297 & 258 & $1.14 \times 10^{7}$ \\
\hline Lake Michigan & 50.7 & 128 & 159 & 144 & 296 & 24.1 & 0.0 & 802 & 657 & $7.62 \times 10^{7}$ \\
\hline Lake Huron & 44.0 & 122 & 83.6 & 143 & 280 & 20.8 & 0.0 & 693 & 594 & $2.62 \times 10^{7}$ \\
\hline Lake Erie & 223 & 370 & 168 & 495 & 521 & 50.4 & 0.0 & 1,830 & 1,640 & $1.08 \times 10^{8}$ \\
\hline Lake Ontario & 75.0 & 101 & 227 & 140 & 463 & 25.0 & 0.0 & 1,030 & 866 & $3.11 \times 10^{7}$ \\
\hline St. Lawrence River & 8.4 & 12.2 & 86.5 & 11.0 & 396 & 7.7 & 0.0 & 521 & 470 & $8.54 \times 10^{6}$ \\
\hline Red River of the North & 2.9 & 70.6 & 8.8 & 55.4 & 111 & 3.6 & 3.2 & 256 & 169 & $3.46 \times 10^{7}$ \\
\hline Upper Mississippi River & 68.5 & 455 & 212 & 294 & 365 & 22.1 & 0.0 & 1,420 & 1,160 & $5.71 \times 10^{8}$ \\
\hline Missouri River & 8.5 & 61.6 & 48.3 & 47.9 & 74.9 & 3.1 & 0.3 & 245 & 163 & $2.14 \times 10^{8}$ \\
\hline Ohio River & 56.5 & 236 & 177 & 190 & 441 & 28.3 & 0.0 & 1,130 & 1,010 & $5.30 \times 10^{8}$ \\
\hline Arkansas River & 11.7 & 29.2 & 72.4 & 15.6 & 120 & 5.7 & 0.0 & 255 & 180 & $1.15 \times 10^{8}$ \\
\hline Lower Mississippi River & 49.7 & 176 & 46.4 & 174 & 258 & 13.4 & 0.0 & 718 & 576 & $1.16 \times 10^{8}$ \\
\hline Gulf Coast & 48.7 & 47.6 & 69.1 & 23.3 & 259 & 14.1 & 0.0 & 462 & 320 & $2.68 \times 10^{7}$ \\
\hline Great Lakes & 83.9 & 158 & 136 & 199 & 357 & 27.4 & 0.0 & 961 & 827 & $2.53 \times 10^{8}$ \\
\hline Mississippi River & 29.0 & 152 & 99.9 & 111 & 201 & 11.4 & 0.1 & 605 & 488 & $1.55 \times 10^{9}$ \\
\hline Midwest & 32.4 & 145 & 97.1 & 113 & 211 & 12.3 & 0.3 & 611 & 494 & $1.87 \times 10^{9}$ \\
\hline
\end{tabular}




\section{SPARROW Total Phosphorus Model}

\section{Specification of the Total Phosphorus Model}

Long-term mean-annual TP loads throughout a stream network represent the net result of the balance between phosphorus inputs from natural and anthropogenic sources and phosphorus losses from the removal by crops and animals, accumulation in the soils, and losses during transport down the river network. Typically, the amount of phosphorus transported down the river network, which is represented by the loads, is only a small fraction of the phosphorus applied to the land surface. Most of the typical main sources and factors affecting the losses of phosphorus were considered for inclusion in the Midwest SPARROW TP model (appendix 2). Atmospheric deposition of phosphorus, which is generally considered to be small source except in predominantly pristine areas, was not available; therefore, phosphorus inputs from atmospheric deposition should be incorporated into the other inputs to which it was most correlated (most likely natural natural/background sources). During calibration, the model was evaluated to determine if the phosphorus monitoring sites should be thinned and if many of the sites being nested may affect the model. Results of preliminary model evaluations indicated thinning was necessary for the nested sites (negative correlation and $p=0.054$; table 7); therefore, each site that was within $5 \mathrm{~km}$ of the next downstream site was removed. This eliminated 62 sites and resulted in the model being calibrated with TP loads from 1,271 monitoring sites. Further model evaluations indicated that the nested monitoring sites may have unequal effect during model calibration $\left(p=4.3 \times 10^{-9}\right)$; therefore, weights were applied to all monitoring sites based on the percentage of the basin area that was nested during the final calibration of the TP model. Adjusting for the effects of nested monitoring sites had little effect on the summary statistics of the model (RMSE, standard errors, and $p$-values), but it did result in modifications to coefficients for several variables.

The 2012 Midwest SPARROW TP model has 14 variables (table 7). The model has six sources of phosphorus: inputs from natural/background sources, WWTPs, urban and open areas, fertilizers applied to cultivated crops, manure from livestock used as fertilizer on cultivated crops and pasture, and stream loads from Canada (Canada load). The model has five land-to-water delivery variables that represent factors that collectively enhance or reduce phosphorus delivery to streams: natural logarithm of runoff, the natural logarithm of the $K$ factor of the soil (soil erodibility), the natural logarithm of the percentage of the catchment with tile drains, the natural logarithm of drainage density of streams, and the natural logarithm of the NRCS-estimated reduction in phosphorus loss associated with the application of various BMPs. The NRCS-estimated reduction in the phosphorus loss variable was allowed to only interact with agricultural sources in the model. The model has three aquatic loss (decay) variables that describe losses of phosphorus in free-flowing streams and impoundments. Two of the decay variables represent naturally occurring processes, assuming that the cultural processes were accurately accounted for: loss in streams with flows less than $1.4 \mathrm{~m}^{3} / \mathrm{s}\left(50 \mathrm{ft}^{3} / \mathrm{s}\right)$ and loss in lakes and reservoirs. The specific breakpoint in streamflow for the loss in streams was determined during the calibration process by iteratively modifying the flow rate breakpoint and examining the model summary statistics. One of the decay variables represents human activities: surface-water withdrawals for public supply. Withdrawals for public supply were directly included in the model without calibration (coefficient set to 1.0).

The coefficients for all the variables in the TP model were statistically significant at $p<0.05$, which indicates that each variable was an important factor in describing TP loads in Midwest streams. Coefficients for sources and land-to-water delivery variables included in the TP model generally had small standard errors, with an average coefficient of variation for the source variables of 0.19 and average coefficient of variation for the land-to-water delivery variables of 0.24 .

Analysis of the residuals for the TP model indicated that the weighted residuals for TP loads and yields (figs. 13A and $B$ ) were both relatively homoscedastic; however, there was a slight decrease in the range of residuals at the highest predicted TP loads. There was slight improvement in the homoscedasticity of the residuals (observed visually) when weighting of the sites was considered. Comparisons of measured TP loads with model predictions during the calibration process (conditioned) and during full model simulation (unconditioned) are shown in figures $13 C$ and $D$, respectively. The model explained 88 percent of the variance in TP loads and 74 percent of the variances in TP yields (not shown), respectively. The RMSE error during model calibration (conditioned RMSE) was 0.773, and the RMSE when the model was used for full prediction (unconditioned RMSE) was 0.885 (both in natural logarithmic units). These values equate to an RMSE of 90.5 percent for conditioned predictions and an RMSE of 109 percent for unconditioned predictions in real (kilograms per year) space. This model did not predict the TP loads as well as the TN model predicted TN loads. Similar to the SPARROW streamflow and TN models, the SPARROW TP model had patterns of larger overpredictions and underpredictions in the western parts of the watershed, where loads were relatively small. The model did not predict loads and yields as well of for sites with relatively small loads. The unconditioned RMSE was 0.92 for TN loads of less than 12 logarithmic units compared to 0.81 for loads greater than 12 logarithmic units.

The evaluation of the spatial correlation of the weighted residuals throughout the study area indicated that the residuals had some regional patterns (Moran's $I$ value of 0.199 with $p=0.0004$ ) - mainly overpredictions in the southwestern part of the study area, and underpredictions in the areas surrounding the overpredicted sites in the central part of the study area (fig. 14A). The inclusion of various additional variables in the model attempted to reduce these spatial patterns, but no additional variables were determined to be statistically significant. The distribution in the unconditioned residuals was relatively 
similar to that determined during model calibration and demonstrated a relatively similar pattern in residuals; however, the unconditioned predictions for much of the eastern onehalf of the study area were overpredicted (fig. 14B). Also, the unconditioned residuals were a little larger than the conditioned residuals and often had residuals of similar signs that propagated down several of the large rivers. The western part of the study area is a more arid region, where variations in the relatively smaller loads are presumably sensitive to processes that are not included in the model, such as natural climatic processes or various anthropogenic processes that remove and divert water in this area, mainly for agriculture. Although most of the large residuals in the western part of the study area are large in logarithmic space, they are actually quite small in terms of kilograms per year. Predicting TP loads in these arid regions has also been found to be difficult for other watershed models (Robertson and Saad, 2013); however, because this area has fewer monitoring sites, it was not as obvious as that determined here.

The coefficient for WWTPs ( 0.817 in table 7$)$ indicates that for every $1 \mathrm{~kg}$ of TP estimated to be input from WWTPs, about $0.817 \mathrm{~kg}$ is delivered to the stream. Coefficients for natural/background sources, fertilizers, and manure represent the fraction of the input mass that was delivered to streams. For natural/background soils, about 1.4 percent of the available phosphorus in the soils was transported to streams (this was based on the assumption that all phosphorus in the upper $1 \mathrm{~m}$ of soil was available). For fertilizers, about 7.8 percent of phosphorus applied to agricultural lands was transported to streams. For manure, about 4.9 percent of the phosphorus excreted from agricultural animals was transported to streams. Most of the phosphorus applied to the land was lost to plant uptake and harvesting, and possibly increasing the phosphorus content of the soils in agricultural areas. The area-based source coefficient indicates about $64 \mathrm{~kg} / \mathrm{km}^{2} / \mathrm{yr}$ of phosphorus originated from urban areas.

The coefficients associated with the land-to-water delivery variables suggest how each of these characteristics affect TP transport to streams. Runoff, as represented by nondecayed incremental flows from the SPARROW streamflow model, was the most significant variable in the model (highest $t$-value determined during model calibration). Runoff had a positive coefficient, which suggests as runoff increases, phosphorus delivery to streams increases. Drainage density of streams and soil erodibility had positive coefficients, which suggest that areas having more stream length per catchment area had a higher delivery of phosphorus than areas with lower drainage density, and because much of the TP load is in particulate forms, there was an increased delivery of phosphorus to streams in areas with highly erodible soils. The negative coefficient for tile drains suggests that these agricultural features decreased phosphorus delivery to streams. This negative relation may be caused by much of the runoff being lost into the soil in areas with tile drains and unavailable for overland transport. This is opposite of the relation found for nitrogen transport. The coefficient for the NRCS-estimated reduction in TP loss variable had a negative sign, which suggests that in areas with larger reductions in the amount TP loss, there was lower phosphorus delivery to streams. Many other studies have also indicated that the combination of BMPs in agricultural areas has reduced phosphorus delivery to streams (Sharpley and others, 2006).

\section{Simulated Total Phosphorus Transport throughout the Midwest}

Incremental TP yields from catchments throughout the Midwest are shown in figure 15. Mean and median incremental mean-annual TP yields for the study area were 128 and $52 \mathrm{~kg} / \mathrm{km}^{2} / \mathrm{yr}$, respectively. A few catchments, primarily those dominated by WWTPs, had high TP yields, which were primarily the result of large point-source inputs into catchments with very small areas. The highest incremental yields (greater than $131 \mathrm{~kg} / \mathrm{km}^{2} / \mathrm{yr}$ ) were generally from the Corn Belt and along the lower Mississippi River, and the lowest yields (less than $9 \mathrm{~kg} / \mathrm{km}^{2} / \mathrm{yr}$ ) were from areas just east of the Rocky Mountains in the southeastern part of the study area and in northern parts of Michigan.

The areally weighted aggregated TP yields from major drainage basins in the Midwest ranged from $23.4 \mathrm{~kg} / \mathrm{km}^{2} /$ yr from the Lake Superior Basin to $160 \mathrm{~kg} / \mathrm{km}^{2} / \mathrm{yr}$ from the Lower Mississippi River Basin (fig. 16 and table 8). The aggregated TP yields from the Great Lakes Basin, Mississippi River Basin, and Midwest area were 61.2, 79.6, and $75.9 \mathrm{~kg} /$ $\mathrm{km}^{2} / \mathrm{yr}$, respectively. The major source of TP was highly variable among areas (fig. 16). For the Lake Superior and St. Lawrence River Basins, natural/background input (natural losses from the landscape) was the dominant source. For the Lake Erie, Lake Michigan, Lake Huron, and Lake Ontario Basins, urban and agricultural inputs were the dominant sources. For all other major drainage basins and summary areas, agricultural input was the dominant source. In general, the dominant agricultural source was loss from fertilizer inputs, except in the Lake Superior and St. Lawrence River Basins where loss from manure inputs was the dominant agricultural source. WWTPs contributed between about 3 percent (St. Lawrence River and Red River Basins) and 23 percent (Lake Erie Basin) of the TP delivered to streams (percentages are based on the contributions given in table 8). For the Great Lakes and Mississippi River Basins, WWTPs contributed about 17 and 11 percent of the TP delivered to streams in those areas, respectively.

Not all of the phosphorus reaching the end of the SPARROW catchments is delivered to its downstream receiving waterbody because some phosphorus is lost through settling in streams and reservoirs. Mean and median delivered incremental TP yields from catchments throughout the Midwest area to the downstream receiving waterbody were 101 and $33 \mathrm{~kg} / \mathrm{km}^{2} / \mathrm{yr}$, respectively. The highest annual delivered incremental yields were again from the Corn Belt, and the lowest yields were from areas just east of the Rocky 
Mountains and in northern areas of Minnesota, Wisconsin, and Michigan (fig. 15B). The major differences in the distributions in incremental and delivered incremental yields were that delivered yields were lower in the western part of the study area and in areas away from the Mississippi River. These differences in the incremental yields and delivered incremental yields were primarily caused by losses in small streams and reservoirs in the western part of the Midwest.

The areally weighted aggregated TP yields delivered to either the Great Lakes, Gulf of Mexico, or Canada from each major drainage basin ranged from $20.0 \mathrm{~kg} / \mathrm{km}^{2} / \mathrm{yr}$ from the Lake Superior Basin to $131 \mathrm{~kg} / \mathrm{km}^{2} / \mathrm{yr}$ from the Lower Mississippi River Basin (table 8). The aggregated delivered TP yields from the Great Lakes and Mississippi River Basins were $52.0 \mathrm{~kg} / \mathrm{km}^{2} / \mathrm{yr}$ and $61.2 \mathrm{~kg} / \mathrm{km}^{2} / \mathrm{yr}$, respectively. The aggregated TP yields delivered from the Midwest area was $56.7 \mathrm{~kg} / \mathrm{km}^{2} / \mathrm{yr}$; therefore, about 15 percent of the phosphorus that reaches the stream network is lost during transport to the Great Lakes, compared to about 23 percent lost during transport to the Gulf of Mexico. The larger percentage of phosphorus lost during transport to the Gulf of Mexico likely was because of the longer transport distance and more, large reservoirs in the Mississippi River Basin than in the Great Lakes Basin. The largest percentage of phosphorus lost during transport (42 percent) was from the Missouri River Basin, which has several large reservoirs and a long distance of transport to the Gulf of Mexico. 
Table 7. Summary of calibration results for the 2012 Midwest SPARROW total phosphorus model. Calibration included thinning closely spaced sites and incorporated adjustments for the amount of the upstream watershed that was included in watersheds of other calibration sites.

[SPARROW, SPAtially Referenced Regression On Watershed attributes; $p$-value, probability value; $t$-value, $t$-statistic; $\mathrm{t}$, metric ton; $<$ less than; $\mathrm{kg}$, kilogram; $\mathrm{km}{ }^{2}$, square kilometer; $\mathrm{kg} / \mathrm{km}^{2} / \mathrm{yr}$, kilogram per square kilometer per year; --, not computed; ln, natural logarithm; mm, millimeter; $\mathrm{km} / \mathrm{km}^{2}$, kilometer per square kilometer; USDA-NRCS, U.S. Department of Agriculture, National Resources Conservation Service; TP, total phosphorus; $\mathrm{kg} / \mathrm{ha}$, kilogram per hectare; $\mathrm{m}^{3} / \mathrm{s}$, cubic meter per second; yr/m, year per meter; $\mathrm{m} / \mathrm{yr}$, meter per year; km, kilometer; RMSE, root mean square error; Moran's $I$, measure of spatial autocorrelation; $R^{2}$, coefficient of determination]

\begin{tabular}{|c|c|c|c|c|c|c|c|c|c|}
\hline \multirow[t]{2}{*}{ Variable } & \multirow[t]{2}{*}{ Variable unit } & \multirow[t]{2}{*}{ Coefficient unit } & \multirow{2}{*}{$\begin{array}{c}\text { Model } \\
\text { coefficient } \\
\text { value }\end{array}$} & \multicolumn{2}{|c|}{$\begin{array}{l}\text { 90-percent confidence } \\
\text { interval for the model } \\
\text { coefficients }\end{array}$} & \multirow{2}{*}{$\begin{array}{c}\text { Standard error } \\
\text { of the model } \\
\text { coefficient }\end{array}$} & \multirow[t]{2}{*}{$p$-value } & \multirow[t]{2}{*}{$t$-value } & \multirow{2}{*}{$\begin{array}{c}\text { Variance } \\
\text { inflation } \\
\text { factor }\end{array}$} \\
\hline & & & & Low & High & & & & \\
\hline \multicolumn{10}{|c|}{ Source } \\
\hline Natural (background) sources & $\mathrm{t}$ & Fraction, dimensionless & 0.014 & 0.011 & 0.018 & 0.002 & $<0.0001$ & 6.7 & 2.8 \\
\hline Wastewater treatment plants & $\mathrm{kg}$ & Fraction, dimensionless & 0.817 & 0.552 & 1.083 & 0.162 & $<0.0001$ & 5.1 & 1.1 \\
\hline Urban and open areas & $\mathrm{km}^{2}$ & $\mathrm{~kg} / \mathrm{km}^{2} / \mathrm{yr}$ & 64.0 & 39.1 & 88.9 & 15.1 & $<0.0001$ & 4.2 & 2.3 \\
\hline Fertilizers (farm) & $\mathrm{kg}$ & Fraction, dimensionless & 0.078 & 0.056 & 0.100 & 0.013 & $<0.0001$ & 5.9 & 4.3 \\
\hline Manure & $\mathrm{kg}$ & Fraction, dimensionless & 0.049 & 0.035 & 0.064 & 0.009 & $<0.0001$ & 5.7 & 2.4 \\
\hline Canada load & $\mathrm{kg}$ & Fraction, dimensionless & 1.0 & -- & -- & -- & -- & -- & -- \\
\hline \multicolumn{10}{|c|}{ Land-to-water delivery } \\
\hline Ln (runoff, in mm) & Unitless & Unitless & 0.519 & 0.426 & 0.613 & 0.057 & $<0.0001$ & 9.1 & 3.7 \\
\hline Ln (soil erodibility, $K$ factor) & Unitless & Unitless & 5.230 & 3.772 & 6.688 & 0.886 & $<0.0001$ & 5.9 & 1.3 \\
\hline Ln (tile drains, percent of catchment) & Unitless & Unitless & -0.091 & -0.156 & -0.026 & 0.040 & 0.0221 & -2.3 & 2.0 \\
\hline Ln (drainage density, in $\mathrm{km} / \mathrm{km}^{2}$ ) & Unitless & Unitless & 0.339 & 0.194 & 0.484 & 0.088 & $<0.0001$ & 3.8 & 0.2 \\
\hline $\begin{array}{l}\text { Ln (USDA-NRCS-estimated reduction in TP loss, } \\
\text { in } \mathrm{kg} / \mathrm{ha} \text { ) }\end{array}$ & Unitless & Unitless & -0.196 & -0.273 & -0.118 & 0.047 & $<0.0001$ & -4.2 & 3.1 \\
\hline \multicolumn{10}{|c|}{ Aquatic loss } \\
\hline Instream decay (mean streamflow $<1.4 \mathrm{~m}^{3} / \mathrm{s}$ ) & Days & Days $^{-1}$ & 0.514 & 0.325 & 0.704 & 0.115 & $<0.0001$ & 4.5 & 6.2 \\
\hline Reservoir loss & $\mathrm{yr} / \mathrm{m}$ & $\mathrm{m} / \mathrm{yr}$ & 3.513 & 2.639 & 4.388 & 0.532 & $<0.0001$ & 6.6 & 1.1 \\
\hline Surface-water withdrawal for public supply & $\begin{array}{l}\ln (1-\text { fraction of unre- } \\
\text { moved streamflow) }\end{array}$ & Unitless & 1.0 & -- & -- & -- & -- & -- & -- \\
\hline
\end{tabular}

\begin{tabular}{|c|c|c|c|c|c|}
\hline Spatial test & Number & $\begin{array}{c}\text { Correlation/ } \\
\text { value }\end{array}$ & $p$-value & Model summary statistic & $\begin{array}{c}\text { Model summary } \\
\text { statistic value }\end{array}$ \\
\hline Tight clusters - pairs of nested sites within $5 \mathrm{~km}$ & 62 & -0.246 & 0.0540 & Conditioned $\mathrm{RMSE}^{\mathrm{b}}$, in natural logarithmic units & 0.773 \\
\hline Tight clusters - pairs of nonnested sites (and dissimilarly sized nested sites) within $5 \mathrm{~km}$ & 92 & 0.180 & 0.0840 & Conditioned $\mathrm{RMSE}^{\mathrm{b}}$, percentage in real space units ${ }^{\mathrm{c}}$ & 90.5 \\
\hline Nested sites (weighting): coefficient for $\ln$ (nested share) & 1,333 & 0.563 & $4.3 \times 10^{-9}$ & Unconditioned $\mathrm{RMSE}^{\mathrm{d}}$, in natural logarithmic units & 0.885 \\
\hline \multirow[t]{5}{*}{ Loose clusters: Moran's $I$} & 1,271 & 0.199 & 0.0004 & Unconditioned RMSEd, percentage in real space units ${ }^{\mathrm{c}}$ & 109 \\
\hline & & & & Mean exponentiated weighted error & 1.448 \\
\hline & & & & $R^{2}$ & 0.875 \\
\hline & & & & Yield $R^{2}$ & 0.741 \\
\hline & & & & Number of sites & 1,271 \\
\hline
\end{tabular}

${ }^{a}$ Expressed in $-\ln$ (1-fraction of unremoved load).

${ }^{b}$ Conditioned RMSE is the root mean square error of the difference between the natural logarithm of measured calibration loads and the natural logarithm of predicted accumulated loads that were reset to the measured loads at the calibration sites upstream in the basin.

${ }^{\circ}$ RMSE in terms of percentage in real space units was computed as $100 \times\left(\exp \left[\mathrm{RMSE}^{2}\right]-1\right)^{0.5}$; RMSE in this equation is in natural logarithmic units (Hoos and Roland, 2019).

Unconditioned RMSE is similar to the conditioned RMSE except the predicted accumulated loads were not reset to the measured loads at the calibration sites upstream in the basin. 


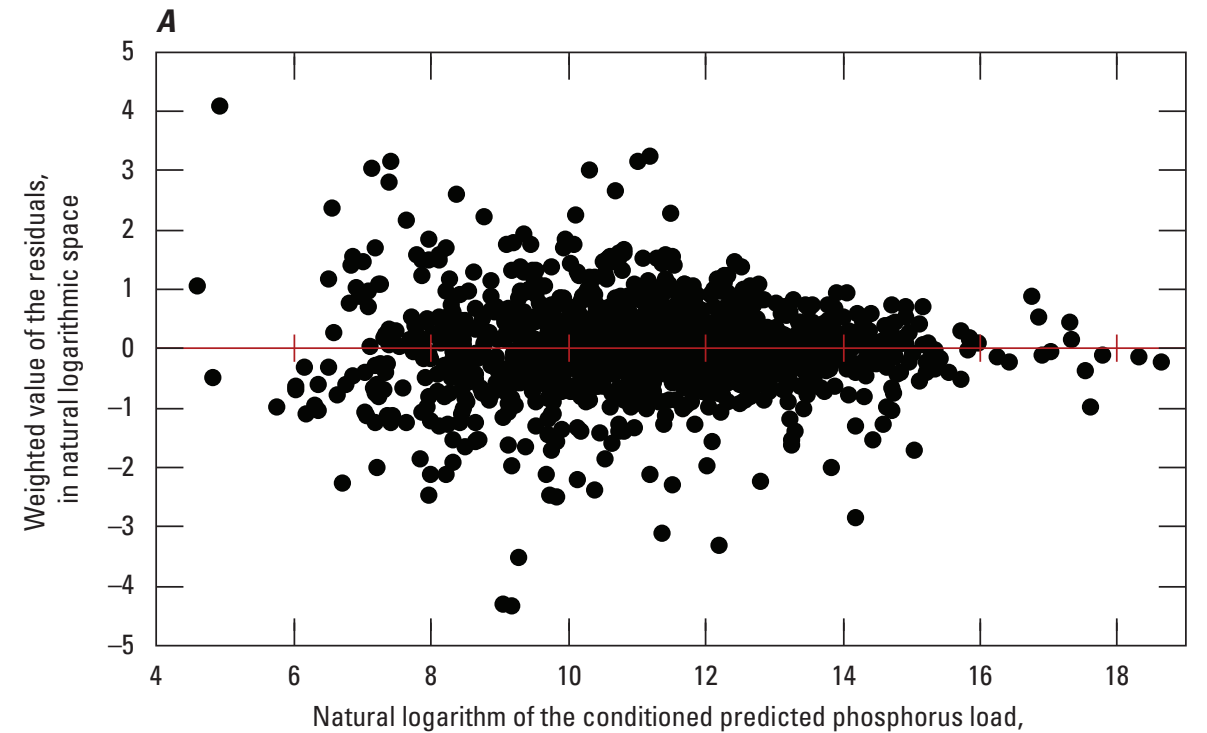

in kilograms per year

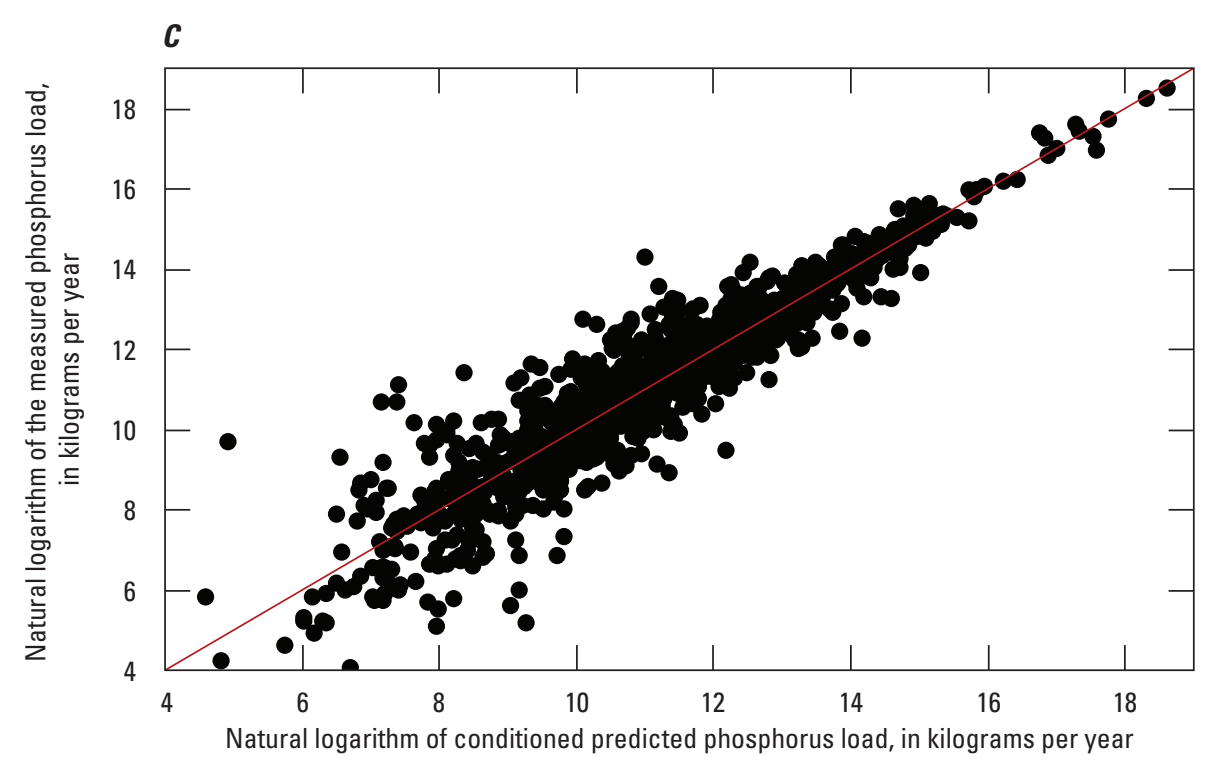

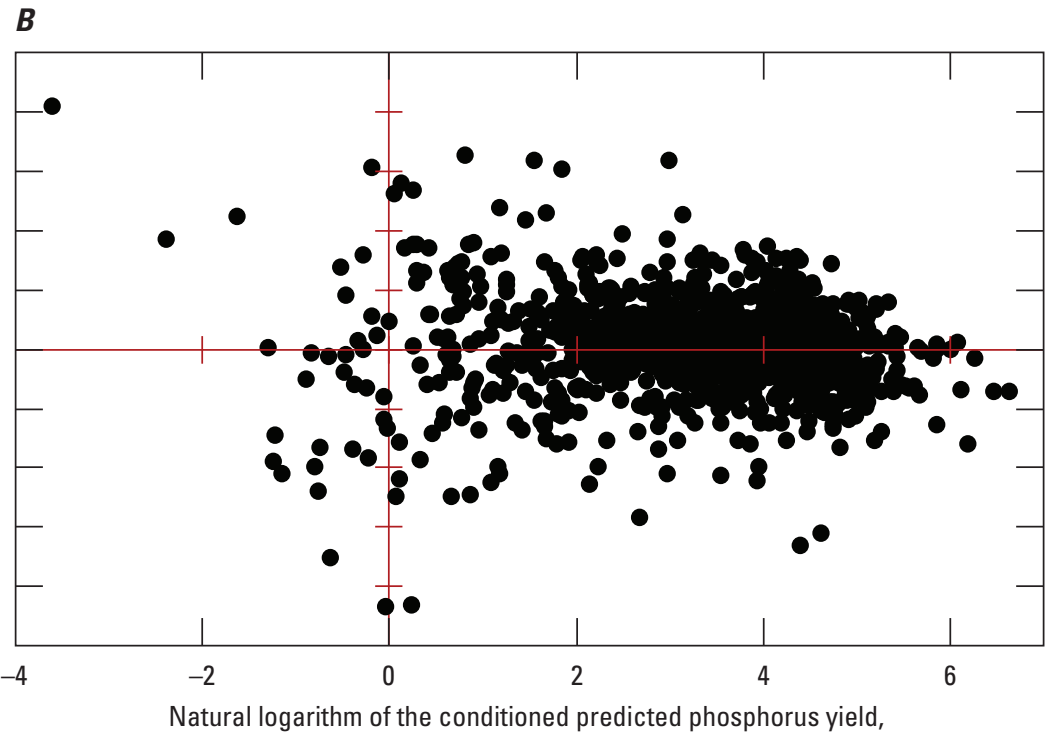

in kilograms per square kilometer per year

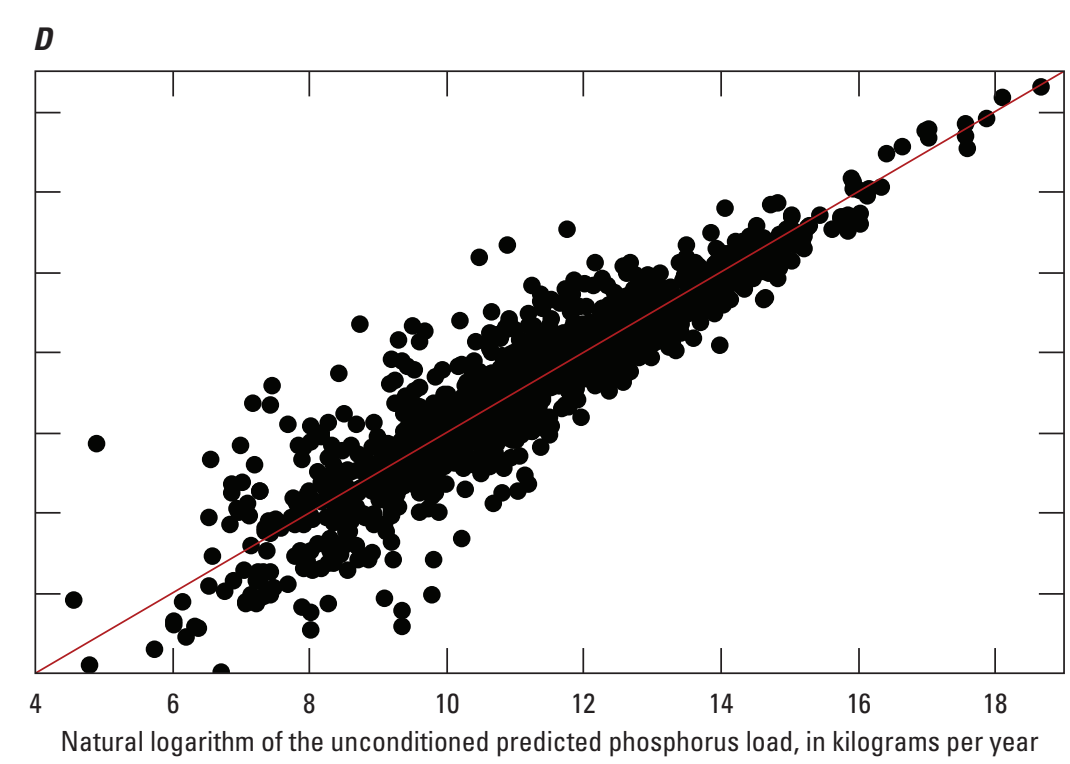

Figure 13. Diagnostic plots for the Midwest SPARROW (SPAtially Referenced Regression On Watershed attributes) total phosphorus model for all calibration sites. $A$, weighted residuals versus conditioned predicted loads; $B$, weighted residuals versus conditioned predicted yields; $C$, measured loads versus conditioned predicted loads (model calibration); $D$, measured loads versus unconditioned predicted loads (full simulation). 

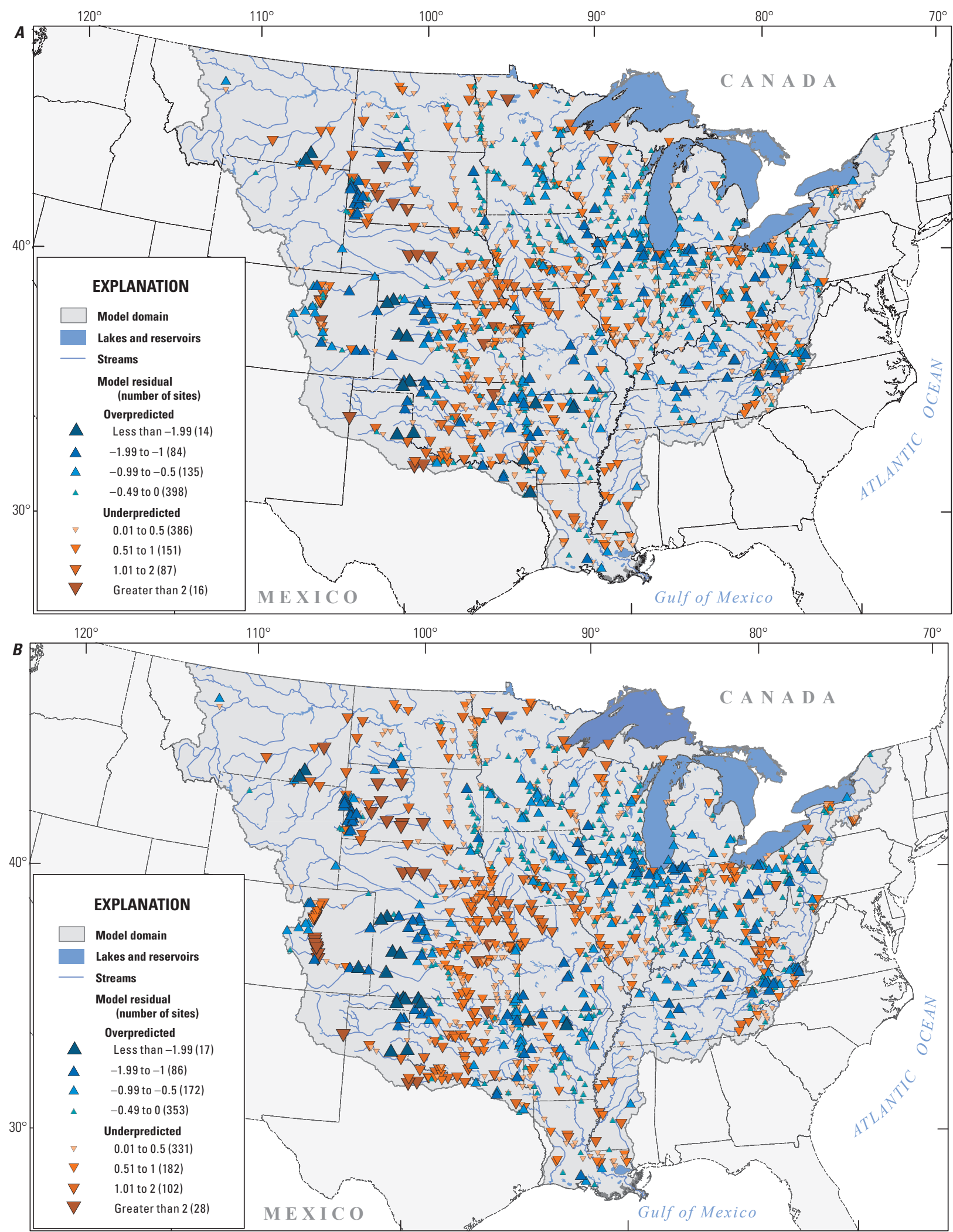

Base from National Hydrography Data Plus Version 2 (NHDPlusV2), 1:100,000, 2012

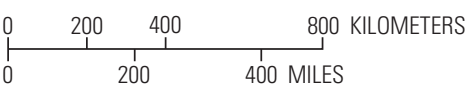

Figure 14. Spatial distribution of residuals, in natural logarithmic units, from the Midwest total phosphorus model. $A$, conditioned residuals; $B$, unconditioned residuals. 

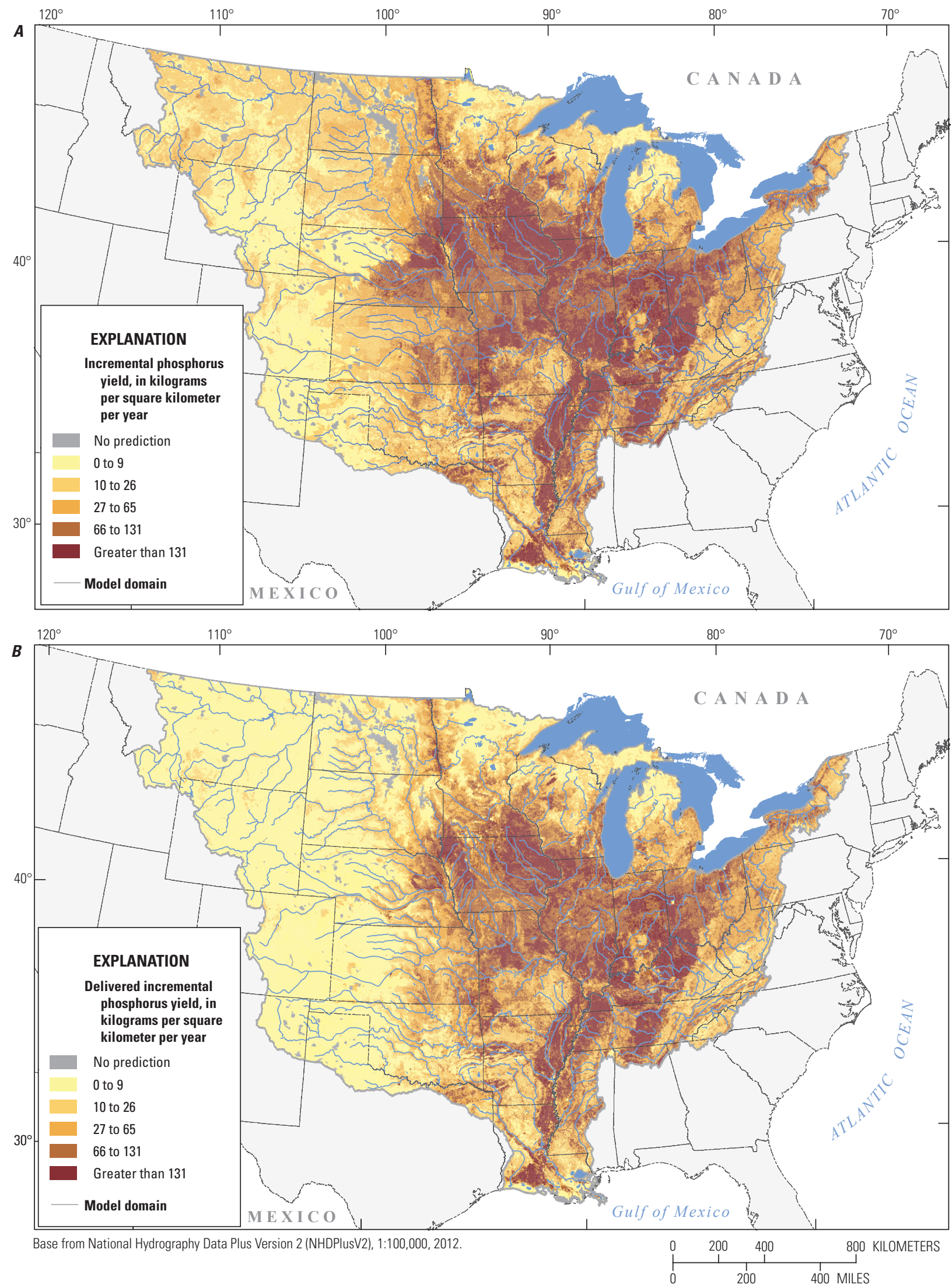

Figure 15. Distribution of incremental mean-annual yields of total phosphorus, in kilograms per square kilometer per year, from the Midwest SPARROW (SPAtially Referenced Regression On Watershed attributes) total phosphorus model. $A$, incremental mean-annual yields from each catchment; $B$, delivered incremental mean-annual yields to the final receiving waterbody. 


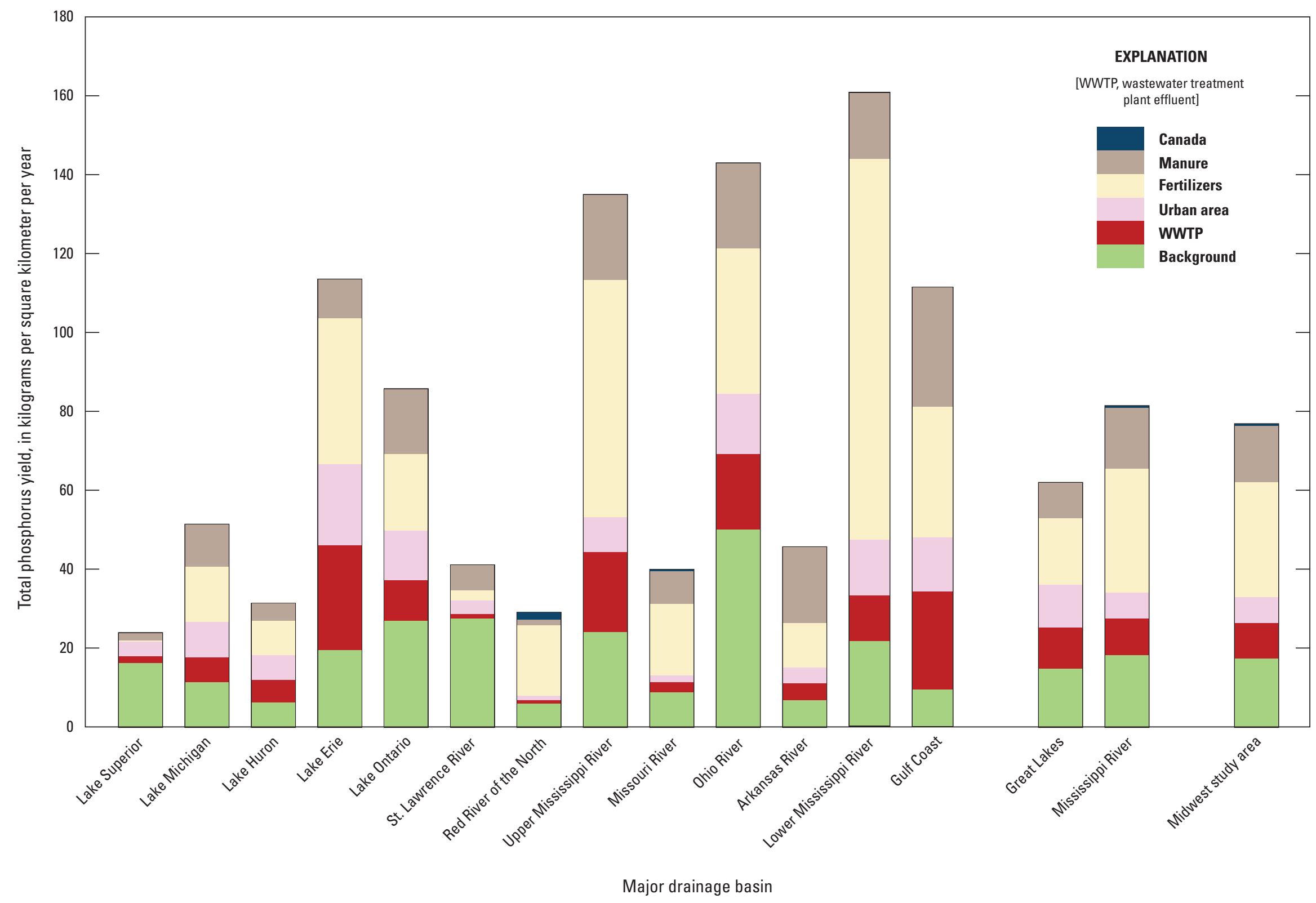

Figure 16. Predicted mean-annual total phosphorus yields, by source, for the Midwest, Great Lakes Basin, Mississippi River Basin, and selected major drainage basins in the Midwest region of the United States. 
Table 8. Mean-annual yields of total phosphorus, in kilograms per square kilometer per year, by source, to streams and delivered yield and total delivered load, in kilograms per year, to the downstream receiving waterbody from each of the major drainage basins in the Midwest. Aggregated yields also are summarized for the Great Lakes and Mississippi River Basins, and the Midwest area.

[WWTP, wastewater treatment plants]

\begin{tabular}{|c|c|c|c|c|c|c|c|c|c|}
\hline Major drainage basin & Background & WWTP & Urban area & Fertilizers & Manure & Canada & $\begin{array}{l}\text { Aggregated } \\
\text { yield }\end{array}$ & $\begin{array}{c}\text { Delivered } \\
\text { aggregated } \\
\text { yield }\end{array}$ & $\begin{array}{c}\text { Total } \\
\text { delivered } \\
\text { load }\end{array}$ \\
\hline Lake Superior & 16.0 & 1.8 & 3.9 & 0.3 & 1.5 & 0.0 & 23.4 & 20.0 & $8.79 \times 10^{5}$ \\
\hline Lake Michigan & 11.4 & 6.2 & 8.7 & 14.1 & 10.5 & 0.0 & 50.8 & 41.1 & $4.77 \times 10^{6}$ \\
\hline Lake Huron & 6.0 & 5.8 & 6.1 & 8.8 & 4.1 & 0.0 & 30.9 & 26.1 & $1.15 \times 10^{6}$ \\
\hline Lake Erie & 19.3 & 26.3 & 20.3 & 36.8 & 9.7 & 0.0 & 112 & 99.6 & $6.54 \times 10^{6}$ \\
\hline Lake Ontario & 26.7 & 10.1 & 12.5 & 19.3 & 16.3 & 0.0 & 84.9 & 71.1 & $2.56 \times 10^{6}$ \\
\hline St. Lawrence River & 27.1 & 1.2 & 3.4 & 2.7 & 6.3 & 0.0 & 40.7 & 36.1 & $6.56 \times 10^{5}$ \\
\hline Red River of the North & 6.0 & 0.7 & 1.1 & 17.9 & 1.2 & 1.8 & 28.6 & 18.8 & $3.84 \times 10^{6}$ \\
\hline Upper Mississippi River & 24.0 & 20.0 & 8.8 & 59.6 & 21.2 & 0.0 & 134 & 108 & $5.31 \times 10^{7}$ \\
\hline Missouri River & 8.9 & 2.3 & 1.9 & 17.8 & 8.2 & 0.1 & 39.2 & 22.7 & $2.98 \times 10^{7}$ \\
\hline Ohio River & 49.7 & 18.7 & 15.1 & 36.8 & 21.1 & 0.0 & 141 & 125 & $6.58 \times 10^{7}$ \\
\hline Arkansas River & 6.7 & 4.2 & 4.1 & 10.9 & 19.0 & 0.0 & 45.0 & 29.8 & $1.89 \times 10^{7}$ \\
\hline Lower Mississippi River & 21.5 & 11.6 & 13.8 & 96.3 & 16.9 & 0.0 & 160 & 131 & $2.63 \times 10^{7}$ \\
\hline Gulf Coast & 9.3 & 24.6 & 13.8 & 33.0 & 29.9 & 0.0 & 111 & 76.2 & $6.38 \times 10^{6}$ \\
\hline Great Lakes & 14.8 & 10.3 & 10.6 & 16.8 & 8.8 & 0.0 & 61.2 & 52.0 & $1.59 \times 10^{7}$ \\
\hline Mississippi River & 18.4 & 8.8 & 6.3 & 31.0 & 15.1 & 0.0 & 79.6 & 61.2 & $1.94 \times 10^{8}$ \\
\hline Midwest & 17.2 & 8.8 & 6.6 & 29.1 & 14.1 & 0.1 & 75.9 & 56.7 & $2.14 \times 10^{8}$ \\
\hline
\end{tabular}




\section{SPARROW Suspended-Sediment Model}

\section{Specification of the Suspended-Sediment Model}

Long-term mean-annual loads based on suspendedsediment and TSS concentrations throughout a stream network represent the net result of the balance between sediment inputs from erosion from the landscape and from channels in the stream network and sediment deposition during transport down the river network into streams and reservoirs. The Midwest SPARROW SS model was designed to describe the delivery of SS loads; therefore, all TSS measured loads were converted to SS loads within SPARROW using a coefficient estimated during model calibration. The sources of sediment to the Midwest SPARROW SS model were described in terms of 10 land-use/surficial-material type combinations based on 3 general land-use categories (urban, agriculture, and other land-use categories) for 3 general surficial-material types (alluvial, medium-coarse sediments; colluvial, residual, carbonate materials; and fine-grained and silty sediments) plus 1 "all other" category representing all land uses on a combination of all other surficial materials (table 2). The "other" land-use category primarily represents natural/background sources of sediment on the three main surficial-material types; therefore, these other land-use categories are referred to as background sources. In addition to these general land-use sources, the net contribution of suspended sediment from stream channels (channel length) and inputs from Canada (Canada load) were included in the model. During calibration, the SS model was evaluated to determine if the monitoring sites should be thinned and if many of the sites being nested may affect the model. Results from preliminary evaluations indicated thinning was not necessary (no significant negative spatial correlation for nested or nonnested sites within $5 \mathrm{~km}$ of one another); therefore, 1,185 monitoring sites with either SS or TSS loads were included in model calibration. Additional model evaluation indicated that the nested monitoring sites may have unequal effect during model calibration $\left(p=1.2 \times 10^{-13}\right.$; table 9$)$; therefore, weights were applied to all monitoring sites based on the percentage of the basin area that was nested during the final calibration of the SS model. Adjusting for the effects of nested monitoring sites had little effect on the summary statistics of the model (RMSE, standard errors, and $p$-values), but it did result in modifications to coefficients for several variables.

The 2012 Midwest SPARROW SS model has 20 variables (table 9). The model has 12 sources of sediment described in the paragraph above. The model has four land-towater delivery variables that represent factors that collectively enhance or reduce sediment delivery to streams: the natural logarithm of runoff, the natural logarithm of the $K$ factor (soil erodibility), the natural logarithm of soil clay content, and the natural logarithm of catchment slope in areas where the elevation was less than $1,500 \mathrm{~m}$. The specific breakpoint in elevation was determined during the calibration process, by iteratively modifying the elevation breakpoint and examining the model summary statistics. The model has three aquatic loss (decay) variables that describe losses of sediment into freeflowing streams and impoundments. Two of the decay variables represent naturally occurring processes, assuming that the cultural processes were accurately accounted for: loss into streams (instream decay) that had mean-annual flows less than $1.4 \mathrm{~m}^{3} / \mathrm{s}\left(50 \mathrm{ft}^{3} / \mathrm{s}\right)$ and loss into lakes and reservoirs (reservoir loss). The specific breakpoint in streamflow for instream decay also was found during the calibration process, by iteratively modifying the flow rate breakpoint and examining the model summary statistics. One decay variable represents human activities: surface-water withdrawals from streams for public supply. The amount of withdrawals for public supply were estimated and directly included in the model without calibration (coefficient set to 1.0). In addition, a variable was added to the model to describe systematic differences in SS loads and TSS loads based on whether the stream was sampled for suspended-sediment or TSS concentration (TSS conversion factor, see eq. 1).

All of the coefficients for the variables in the SPARROW SS model, except one, were statistically significant $(p<0.05)$, which indicates each variable was an important factor in describing SS loads in the Midwest. The one exception was the coefficient for background land use on fine-silt sediments that had a $p$-value of 0.1831 . Although the coefficient was not significantly different from 0.0 , this delivery rate was the best available estimate for these areas and allows the model to provide a complete mass accounting for all catchments; therefore, this coefficient was kept in the model. Coefficients for the sources and land-to-water delivery variables included in the SS model generally had small standard errors, with an average coefficient of variation for the source variables of 0.41 and average coefficient of variation for the land-to-water delivery variables of 0.23 .

An analysis of the residuals from the SS model indicated that the weighted residuals for SS loads and yields (figs. 17A and $B$ ) were both relatively homoscedastic. There was slight improvement in the homoscedasticity of the residuals (observed visually) when weighting of the sites was considered. Comparisons of the measured loads computed based on suspended-sediment and TSS concentrations with their respective model predictions during the calibration process (conditioned) and during full model simulation (unconditioned) are shown in figures $17 C$ and $D$, respectively. Before making this comparison, all measured TSS loads were converted to SS loads. Because the measured TSS loads and conditioned predicted SS loads are presented in logarithmic space, the conversion from TSS loads to SS loads was made by simply subtracting the coefficient for the TSS conversion factor (-1.029 in table 9; see eq. 1) from the TSS loads. When making these comparisons, the conditioned predicted SS loads, which represent a combination of measured upstream SS and TSS loads, also had to be adjusted for the TSS to SS conversion. The SS model explained 84 percent of the variance in SS loads (fig. 17C) and 65 percent of the variance in SS yields (not shown), respectively. The RMSE obtained during model 
Table 9. Summary of calibration results for the 2012 Midwest SPARROW suspended-sediment model. Calibration incorporated adjustments for the amount of the upstream watershed that was included in watersheds of other calibration sites.

[SPARROW, SPAtially Referenced Regression On Watershed attributes; $p$-value, probability value; $t$-value, $t$-statistic; $\mathrm{km}^{2}$, square kilometer; $t / \mathrm{km}^{2} / \mathrm{yr}$, metric ton per square kilometer per year; $<$, less than; background, a combination of nonurban and nonagricultural sources; $\mathrm{m}^{3} / \mathrm{s}$, cubic meter per second; $\mathrm{km}$, kilometer; $\mathrm{kg}$, kilogram; --, not computed; ln, natural logarithm; m, meter; yr/m, year per meter; m/yr, meter per year; TSS, total suspended solids; RMSE, root mean square error; Moran's $I$, measure of spatial autocorrelation; $R^{2}$, coefficient of determination]

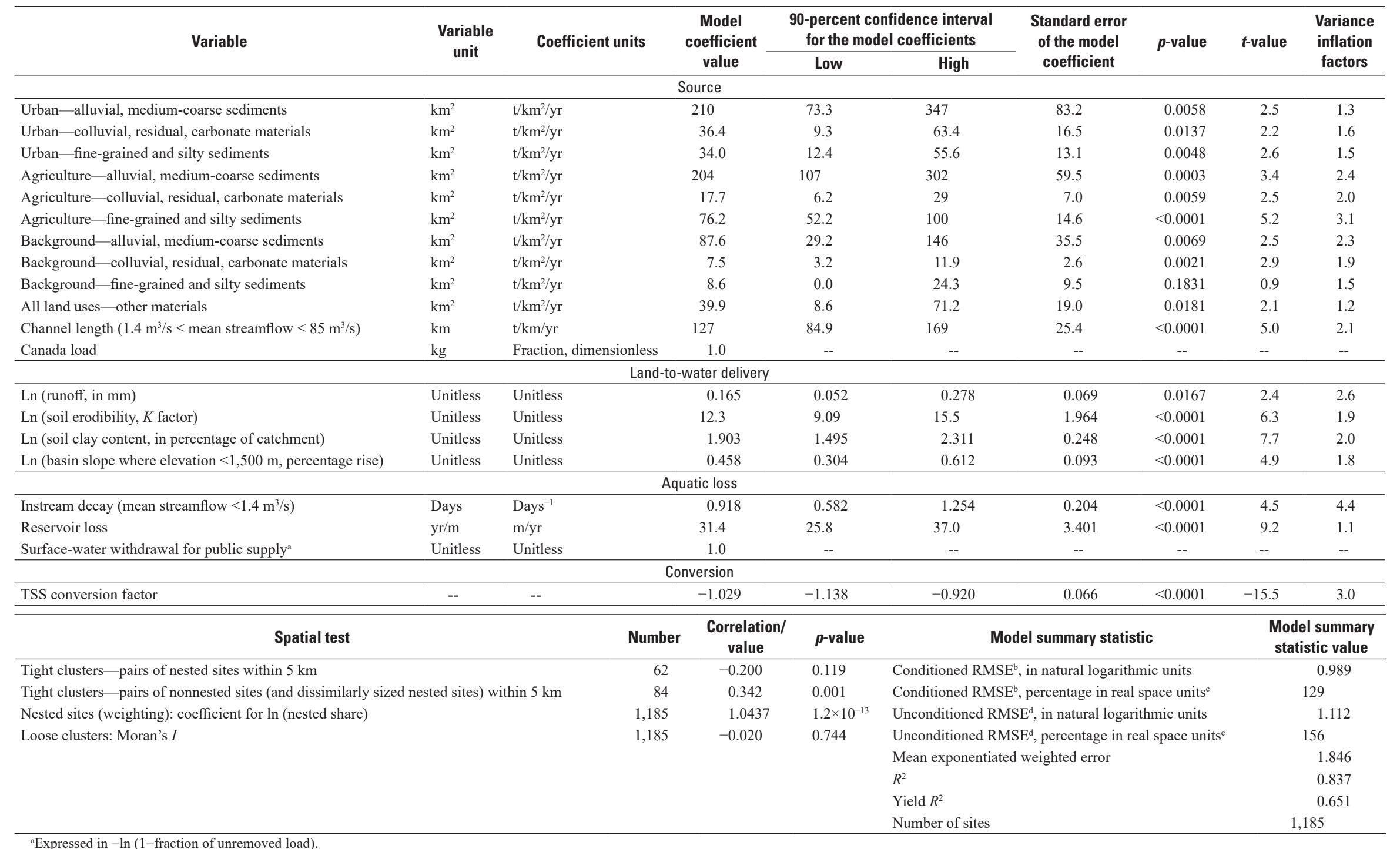

Expressed in - $\ln (1-$ fraction of unremoved load).

${ }^{b}$ Conditioned RMSE is the root mean square error of the difference between the natural logarithm of measured calibration loads and the natural logarithm of predicted accumulated loads that were reset to the measured loads at the calibration sites upstream in the basin.

${ }^{C} \mathrm{RMSE}$ in terms of percentage in real space units was computed as $100 \times\left(\exp \left[\mathrm{RMSE}^{2}\right]-1\right)^{0.5} ; \mathrm{RMSE}$ in this equation is in natural logarithmic units (Hoos and Roland, 2019).

${ }^{d}$ Unconditioned RMSE is similar to the conditioned RMSE except the predicted accumulated loads were not reset to the measured loads at the calibration sites upstream in the basin. 

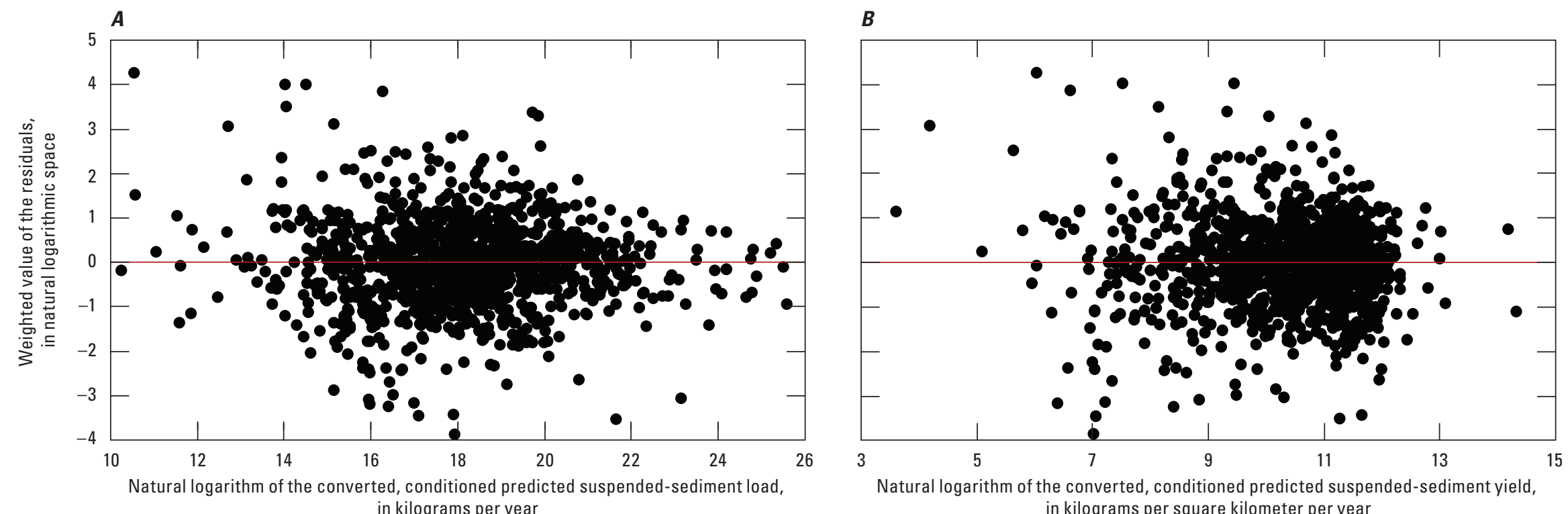

in kilograms per year
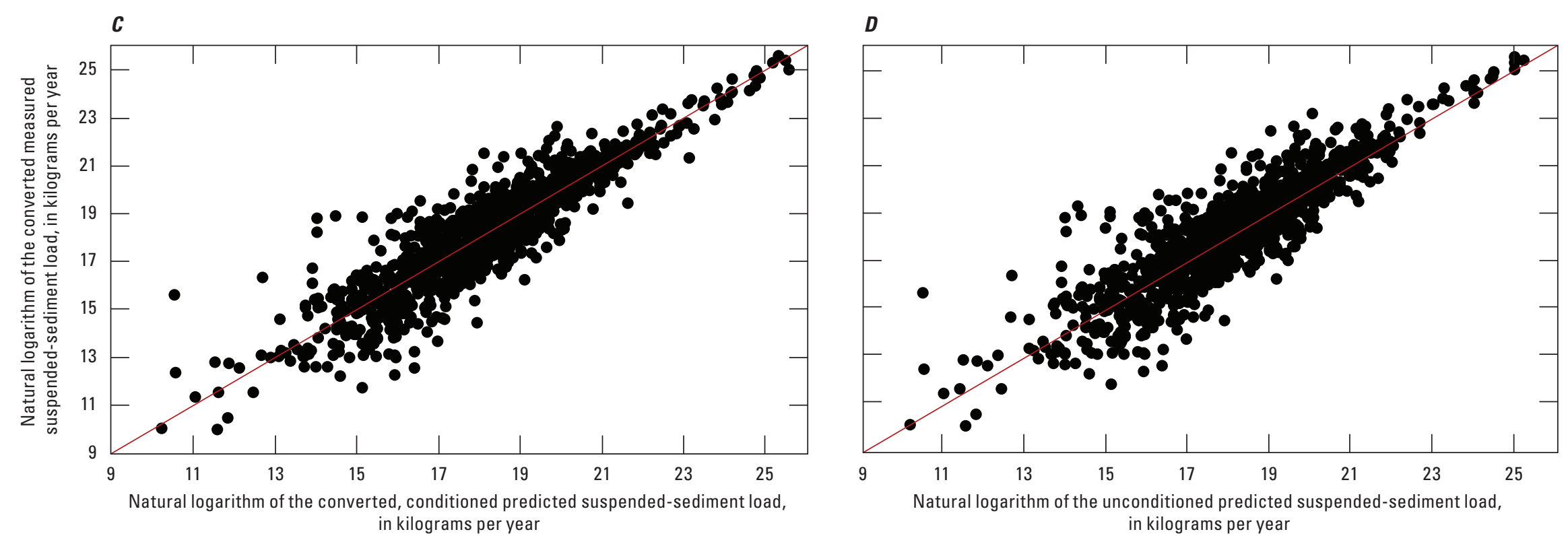

Figure 17. Diagnostic plots for the Midwest SPARROW (SPAtially Referenced Regression On Watershed attributes) suspended-sediment model for all calibration sites. $A$, weighted residuals versus converted, conditioned predicted loads; $B$, weighted residuals versus converted, conditioned predicted yields; $C$, converted measured loads versus converted conditioned predicted loads (model calibration); $D$, converted measured loads versus unconditioned predicted loads (full simulation). Conditioned predicted loads and yields are based on the upstream loads at the calibration sites reset to the measured loads. Unconditioned predicted loads are based on the upstream loads at the calibration sites not reset to the measured loads. 
calibration (conditioned RMSE) was 0.989 and the RMSE when the model was used for full prediction (unconditioned RMSE) was 1.112 (both in natural logarithmic units). Residuals and RMSE values were based on TSS loads converted to SS loads using the TSS conversion factor. These values equate to an RMSE of 129 percent for conditioned predictions and an RMSE of 156 percent for unconditioned predictions in real (metric tons per year) space. This model did not predict the SS loads as well as the TN and TP models predicted their respective loads (comparing RMSEs and their respective mean errors), but this model predicted small loads almost as well as large loads.

The evaluation of the spatial correlation of the weighted residuals throughout the study area indicated that although the residuals were larger than the residuals for the other constituents, there were no significant regional patterns (Moran's $I$ value of -0.020 with $p=0.744$ ). The distribution in the unconditioned residuals was similar to that found during model calibration and also demonstrated weak patterns in the residuals (fig. 18B), but the unconditioned residuals often had residuals of similar signs that propagated down several large rivers.

The coefficients for each of the 10 land-use/surficialmaterial combinations demonstrate the SS yields from each of these landscape types (fig. 19). SS yields were highest from alluvial, medium-coarse material, and relatively similar from the colluvial, residual, carbonate materials, and finegrained and silty material. For each surficial-material type, the SS yields increased with anthropogenic disturbance. For alluvial, medium-coarse surficial material, both urban and agricultural uses increased SS delivery by about a factor of 2 (from about 88 to about 200 metric tons per square kilometer per year $\left.\left[\mathrm{t} / \mathrm{km}^{2} / \mathrm{yr}\right]\right)$. For colluvial, residual, carbonate surficial materials, urban development increased SS yields more than agricultural practices. For fine-grained and silty surficial materials, agricultural practices increased SS yields more than urban development. The limited areas with a mixture of other surficial materials had SS delivery rates between the other nine categories. The coefficient for channel length, suggests that streams with streamflows between 1.4 and $85 \mathrm{~m}^{3} / \mathrm{s}$ generate 127 metric tons of SS per kilometer of channel length.

The coefficients associated with the land-to-water delivery variables suggest how each of these characteristics is related to sediment transport to streams. Runoff (nondecayed incremental streamflows from the SPARROW streamflow model), $K$ factor (soil erodibility), soil clay content, and basin slope for moderate-sized streams) all had positive coefficients, which suggests that as runoff, soil erodibility, soil clay content, and basin slope increase, sediment delivery to streams increases. All these land-to-water delivery variables are commonly included in process-driven sediment models, such as the Soil and Water Assessment Tool (SWAT; Arnold and others, 2012) and the Hydrologic Simulation Program-Fortran (HSPF; Johanson and others, 1980).
The coefficient of the TSS conversion factor, which quantifies the systematic differences in sediment loads based on whether the stream was sampled for suspended-sediment or TSS concentration, was -1.029 . This value results in a TSS conversion factor of 2.8 (eq. 1); therefore, SS loads=TSS loads $\times 2.8$. Several studies in Minnesota compared samples analyzed for TSS collected using surface-grab techniques and samples analyzed for suspended sediment collected concurrently using cross-sectionally integrated techniques (Groten and Johnson, 2018; Ellison and others, 2013). These studies determined that the ratios of suspended-sediment to TSS concentrations were typically around 2 , but the ratios ranged from less than 1 to more than 3 . The area examined in these Minnesota studies represented only a small part of the Midwest area, but the conversion factor for the Midwest SS model is within the range found for converting TSS concentrations to suspended-sediment concentrations.

\section{Simulated Suspended-Sediment Transport throughout the Midwest}

Incremental SS yields from catchments throughout the Midwest are shown in figure 20. Mean and median incremental SS yields for the study area were 177 and $70 \mathrm{t} / \mathrm{km}^{2} / \mathrm{yr}$, respectively. The highest mean-annual incremental yields (greater than $176 \mathrm{t} / \mathrm{km}^{2} / \mathrm{yr}$ ) were generally from the southern parts of the Corn Belt and along the lower Mississippi River, and the lowest yields (less than $7 \mathrm{t} / \mathrm{km}^{2} / \mathrm{yr}$ ) were from areas just east of the Rocky Mountains in the southeastern part of the Midwest and in northern parts of Minnesota, Wisconsin, and Michigan.

The areally weighted aggregated SS yields from major drainage basins in the Midwest ranged from $46.6 \mathrm{t} / \mathrm{km}^{2} / \mathrm{yr}$ from the Lake Huron Basin to $203 \mathrm{t} / \mathrm{km}^{2} / \mathrm{yr}$ from the Lower Mississippi River Basin (fig. 21 and table 10). The aggregated SS yields from the Great Lakes Basin, Mississippi River Basin, and Midwest area were 92.9, 123, and $117 \mathrm{t} / \mathrm{km}^{2} / \mathrm{yr}$, respectively. Inputs from background sources represented between 5.2 percent of the SS input to streams for the Lake Erie Basin and 38.7 percent for the Lake Superior Basin. For the Great Lakes and Mississippi River Basins, background sources represented 10.8 percent and 20.5 percent, respectively, of the suspended sediment in streams in these areas. For the study area, background sources represented 19.6 percent of the suspended sediment in the streams. Inputs from moderatesized channels represented between 8.3 percent of the total suspended sediment in streams in the Missouri River Basin and about 31 percent for the Lake Michigan and Lake Huron Basins. For the Great Lakes and Mississippi River Basins, inputs from channels in moderate-sized streams represented 19.2 and 10.5 percent, respectively, of the suspended sediment in streams in these areas. For the study area, inputs from channels in moderate-sized streams represented 11.3 percent of the suspended sediment in the streams. 

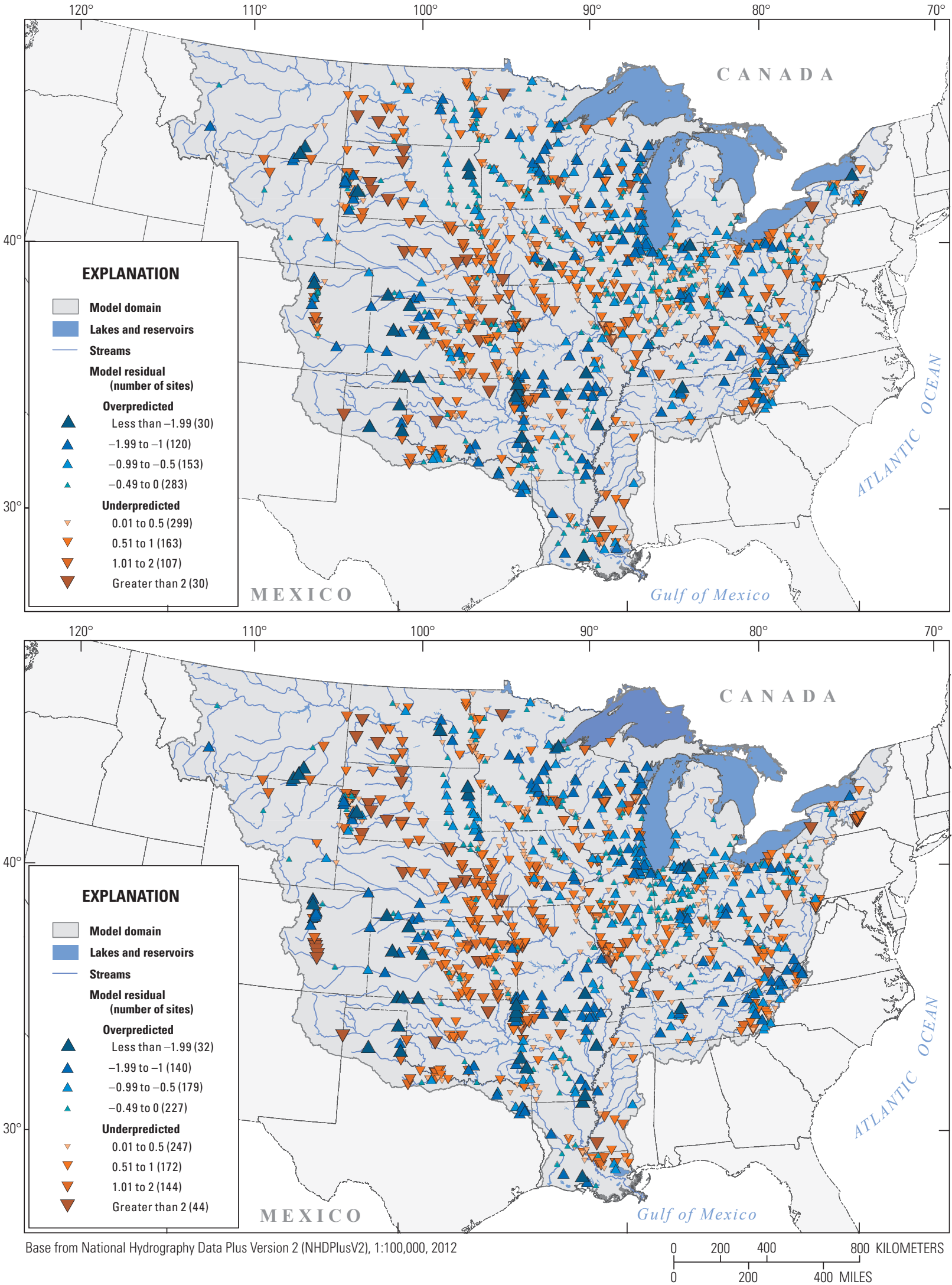

Figure 18. Spatial distribution of residuals, in natural logarithmic units, from the Midwest suspended-sediment model. $A$, conditioned residuals; $B$, unconditioned residuals. 

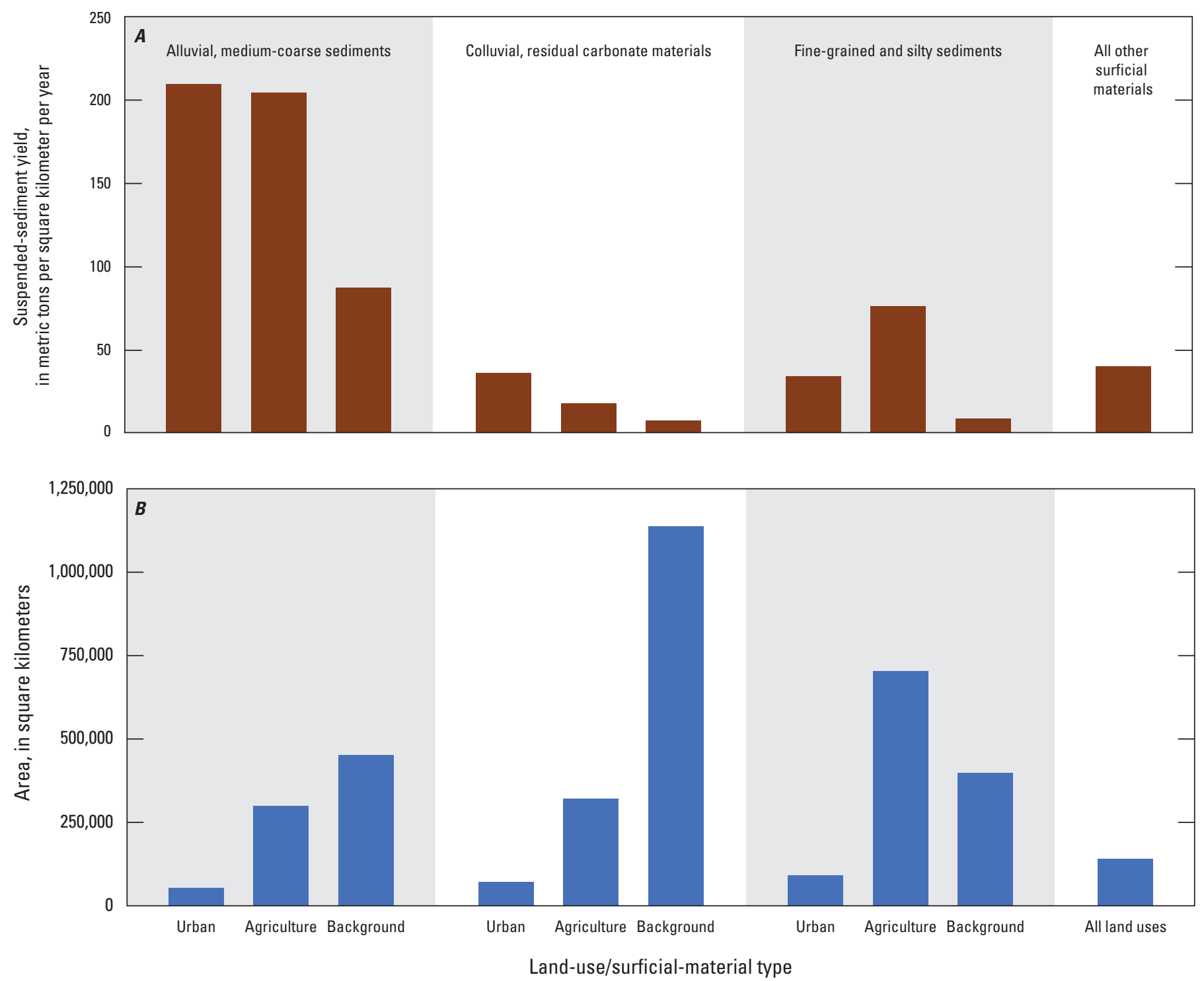

Figure 19. Mean-annual yields of suspended sediment. $A$, yields, in millions of metric tons per square kilometer per year, for the 10 land-use/surficial-material combinations; $B$, their corresponding areas for each land-use/surficial-material combination within the Midwest. 

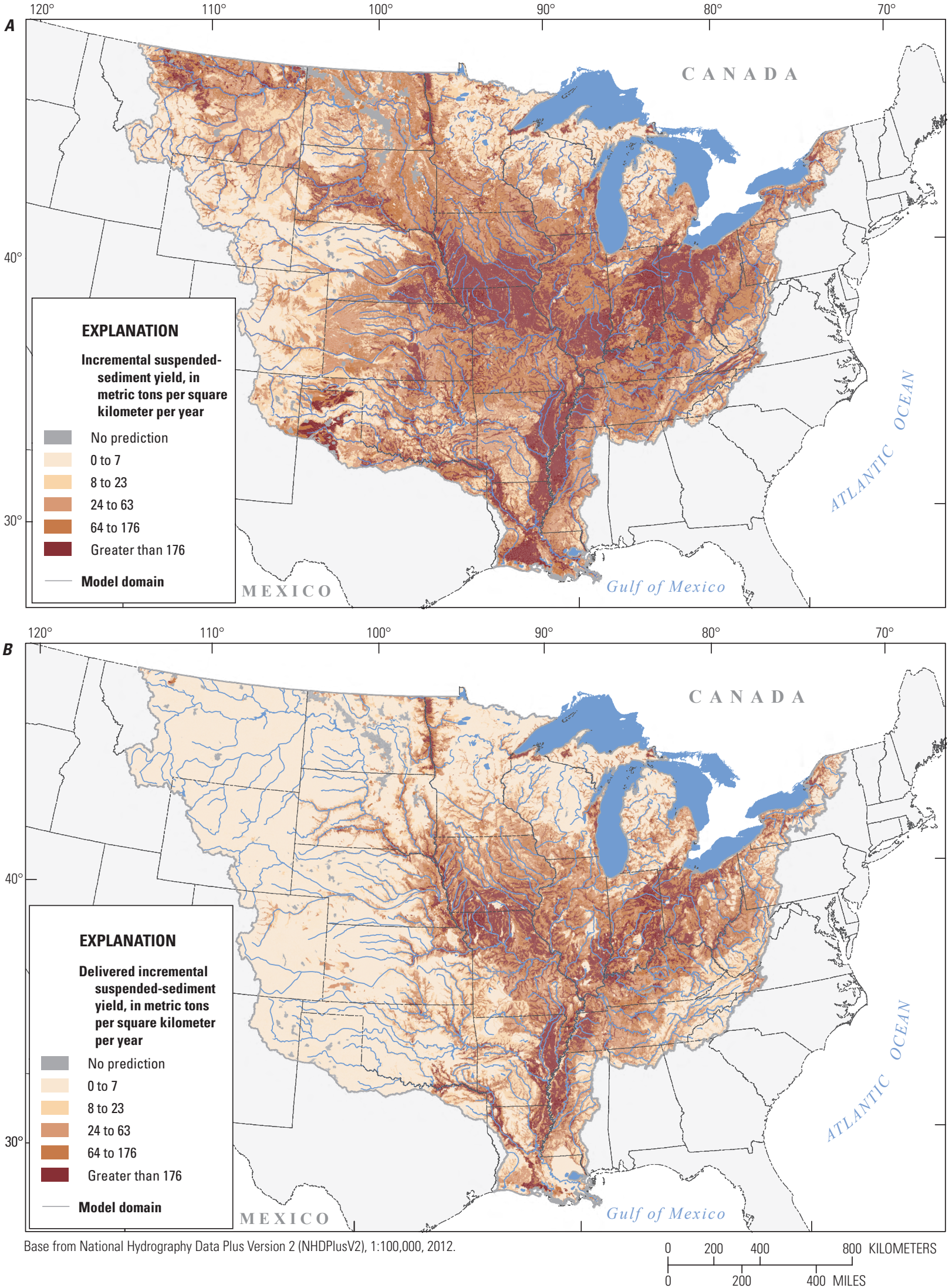

Figure 20. Distribution of incremental mean-annual yields of total suspended sediment, in metric tons per square kilometer per year, from the Midwest SPARROW (SPAtially Referenced Regression On Watershed attributes) suspended-sediment model. $A$, incremental mean-annual yields from each catchment; $B$, delivered incremental mean-annual yields to the final receiving waterbody. 


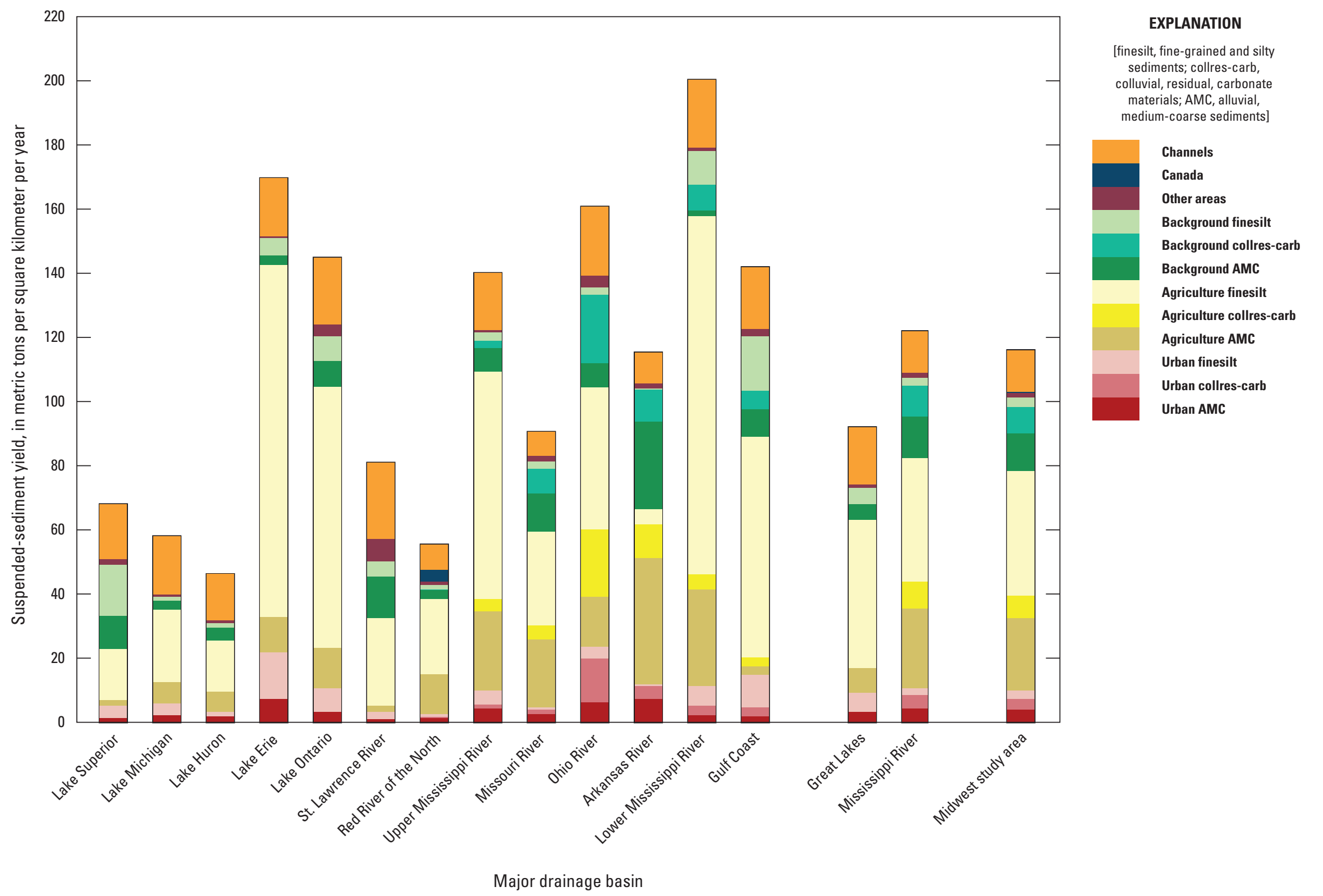

Figure 21. Predicted mean-annual suspended-sediment yield, by source, for the Midwest, Great Lakes Basin, Mississippi River Basin, and selected major drainage basins in the Midwest region of the United States. 
Table 10. Mean-annual yields of suspended sediment, in metric tons per square kilometer per year, by source, to streams and delivered yield and total delivered load, in metric tons per year, to the downstream receiving waterbody from each of the major drainage basins in the Midwest. Aggregated yields also are summarized for the Great Lakes and Mississippi River Basins, and the Midwest area.

[AMC, alluvial, medium-coarse sediments; collres-carb, colluvial, residual, carbonate materials; finesilt, fine-grained and silty sediments]

\begin{tabular}{|c|c|c|c|c|c|c|c|c|c|c|c|c|c|c|c|}
\hline $\begin{array}{l}\text { Major drainage } \\
\text { basin }\end{array}$ & $\begin{array}{l}\text { Urban } \\
\text { AMC }\end{array}$ & $\begin{array}{l}\text { Agri- } \\
\text { culture } \\
\text { AMC }\end{array}$ & $\begin{array}{c}\text { Other/ } \\
\text { back- } \\
\text { ground } \\
\text { AMC }\end{array}$ & $\begin{array}{c}\text { Urban } \\
\text { collres- } \\
\text { carb }\end{array}$ & $\begin{array}{l}\text { Agri- } \\
\text { culture } \\
\text { collres- } \\
\text { carb }\end{array}$ & $\begin{array}{c}\text { Other/ } \\
\text { back- } \\
\text { ground } \\
\text { collres- } \\
\text { carb }\end{array}$ & $\begin{array}{l}\text { Urban } \\
\text { finesilt }\end{array}$ & $\begin{array}{c}\text { Agri- } \\
\text { culture } \\
\text { finesilt }\end{array}$ & $\begin{array}{l}\text { Other/ } \\
\text { back- } \\
\text { ground } \\
\text { finesilt }\end{array}$ & $\begin{array}{l}\text { Other } \\
\text { areas }\end{array}$ & Canada & Channels & $\begin{array}{l}\text { Aggregated } \\
\text { yield }\end{array}$ & $\begin{array}{c}\text { Delivered } \\
\text { aggregated } \\
\text { yield }\end{array}$ & $\begin{array}{c}\text { Total } \\
\text { delivered } \\
\text { load }\end{array}$ \\
\hline Lake Superior & 1.42 & 1.66 & 10.25 & 0.00 & 0.00 & 0.00 & 3.95 & 16.2 & 16.35 & 1.86 & 0.00 & 17.0 & 68.7 & 57.3 & $2.52 \times 10^{6}$ \\
\hline Lake Michigan & 2.27 & 6.83 & 2.96 & 0.00 & 0.00 & 0.00 & 3.56 & 22.9 & 1.27 & 0.52 & 0.00 & 18.4 & 58.7 & 36.3 & $4.21 \times 10^{6}$ \\
\hline Lake Huron & 2.06 & 6.44 & 3.97 & 0.00 & 0.00 & 0.00 & 1.27 & 16.2 & 1.48 & 0.60 & 0.00 & 14.6 & 46.6 & 32.9 & $1.45 \times 10^{6}$ \\
\hline Lake Erie & 7.36 & 11.2 & 3.30 & 0.00 & 0.00 & 0.00 & 14.6 & 111 & 5.60 & 0.32 & 0.00 & 18.1 & 171 & 130 & $8.55 \times 10^{6}$ \\
\hline Lake Ontario & 3.55 & 12.6 & 7.94 & 0.00 & 0.00 & 0.00 & 7.43 & 82.2 & 7.86 & 3.85 & 0.00 & 20.9 & 146 & 101 & $3.63 \times 10^{6}$ \\
\hline $\begin{array}{l}\text { St. Lawrence } \\
\text { River }\end{array}$ & 1.25 & 2.07 & 13.3 & 0.00 & 0.00 & 0.00 & 2.08 & 27.4 & 4.87 & 6.98 & 0.00 & 23.7 & 81.6 & 55.2 & $1.00 \times 10^{6}$ \\
\hline $\begin{array}{l}\text { Red River of the } \\
\text { North }\end{array}$ & 1.69 & 12.9 & 3.14 & 0.02 & 0.06 & 0.08 & 0.76 & 23.3 & 1.46 & 1.23 & 3.44 & 8.13 & 56.2 & 28.9 & $5.91 \times 10^{6}$ \\
\hline $\begin{array}{l}\text { Upper Mississippi } \\
\text { River }\end{array}$ & 4.47 & 24.9 & 7.68 & 1.22 & 4.02 & 2.10 & 4.39 & 71.6 & 2.71 & 0.68 & 0.00 & 17.9 & 142 & 80.1 & $3.93 \times 10^{7}$ \\
\hline Missouri River & 2.64 & 21.2 & 12.0 & 1.30 & 4.53 & 7.78 & 1.03 & 29.5 & 2.24 & 1.66 & 0.03 & 7.56 & 91.5 & 33.1 & $4.34 \times 10^{7}$ \\
\hline Ohio River & 6.25 & 15.5 & 7.40 & 14.0 & 21.1 & 21.8 & 3.85 & 44.9 & 2.35 & 3.61 & 0.00 & 21.9 & 163 & 105 & $5.54 \times 10^{7}$ \\
\hline Arkansas River & 7.39 & 40.14 & 27.7 & 4.35 & 10.3 & 10.3 & 0.14 & 4.89 & 0.18 & 1.35 & 0.00 & 9.81 & 117 & 35.1 & $2.24 \times 10^{7}$ \\
\hline $\begin{array}{l}\text { Lower Mississippi } \\
\text { River }\end{array}$ & 2.11 & 30.4 & 1.98 & 3.10 & 4.73 & 8.05 & 6.30 & 113 & 10.7 & 0.89 & 0.00 & 21.5 & 203 & 137 & $2.77 \times 10^{7}$ \\
\hline Gulf Coast & 1.90 & 2.62 & 8.63 & 3.06 & 2.82 & 5.82 & 10.0 & 69.6 & 17.4 & 2.06 & 0.00 & 19.5 & 143 & 50.2 & $4.21 \times 10^{6}$ \\
\hline Great Lakes & 3.36 & 7.65 & 4.81 & 0.00 & 0.00 & 0.00 & 6.12 & 46.8 & 5.17 & 1.07 & 0.00 & 17.9 & 92.9 & 66.6 & $2.04 \times 10^{7}$ \\
\hline Mississippi River & 4.44 & 25.2 & 13.1 & 4.12 & 8.36 & 9.75 & 2.17 & 38.9 & 2.45 & 1.72 & 0.01 & 12.9 & 123 & 59.4 & $1.88 \times 10^{8}$ \\
\hline Midwest & 4.14 & 22.5 & 11.8 & 3.53 & 7.07 & 8.31 & 2.59 & 39.4 & 2.96 & 1.67 & 0.20 & 13.2 & 117 & 58.1 & $2.20 \times 10^{8}$ \\
\hline
\end{tabular}


Not all the sediment reaching the end of the SPARROW catchments is delivered to its downstream receiving waterbody because some sediment is lost through settling in streams and reservoirs. Mean and median delivered incremental yields from catchments throughout the Midwest area to the downstream receiving waterbody were 92 and $12 \mathrm{t} / \mathrm{km}^{2} / \mathrm{yr}$, respectively. The highest annual delivered incremental yields, similar to the other constituents, were from the southern part of the Corn Belt and along the lower Mississippi River, and the lowest yields were from areas just east of the Rocky Mountains and in northern areas of Minnesota, Wisconsin and Michigan (fig. 20B). The main differences in the distribution of the incremental and delivered incremental SS yields were that delivered yields were lower in the western part of the study area and in areas distant from the Mississippi River. These differences in the incremental yields and delivered incremental yields were primarily caused by losses in small streams and reservoirs in the western part of the Midwest.

The areally weighted aggregated SS yields delivered to either the Great Lakes, Gulf of Mexico, or Canada from each major drainage basin ranged from $28.9 \mathrm{t} / \mathrm{km}^{2} / \mathrm{yr}$ from the Red River Basin to $137 \mathrm{t} / \mathrm{km}^{2} / \mathrm{yr}$ from the Lower Mississippi River Basin (table 10). The aggregated SS yields from the Great Lakes and Mississippi River Basins were $66.6 \mathrm{t} / \mathrm{km}^{2} / \mathrm{yr}$ and $59.4 \mathrm{t} / \mathrm{km}^{2} / \mathrm{yr}$, respectively. The aggregated SS yield delivered from the Midwest area to its downstream receiving waterbodies was $58.1 \mathrm{t} / \mathrm{km}^{2} / \mathrm{yr}$; therefore, about 28 percent of the sediment that reaches or generated in parts of the stream network is lost during transport to the Great Lakes, compared to about 52 percent lost during transport to the Gulf of Mexico. The larger percentage of sediment lost during transport to the Gulf of Mexico was likely because of the longer transport distance and more large reservoirs in the Mississippi River Basin than in the Great Lakes Basin. The largest percentage of sediment lost during transport was from the Arkansas (70 percent) and Missouri (64 percent) River Basins, both of which have several large reservoirs.

\section{Model Limitations and Future SPARROW Model Development}

As with all models, the SPARROW models described in this report are simplifications of the real world; therefore, they have limitations in their accuracy and how their results should be interpreted and used. One primary assumption in developing the models was that the quantity and quality of the explanatory and calibration data were adequate. Every effort was made to identify and quantify the sources of water, nutrients, and sediment and the landscape properties that affect their transport. But the models might not have accounted for all sources and important landscape properties in all areas of the modeled area because of limitations in data availability (especially in the western part of the study area) and accuracy of the input data.
In SPARROW models, it is typically assumed that the sources and land-to-water delivery variables interact in the same manner throughout the modeled area, based on the use of spatially constant source and land-to-water delivery model coefficients. However, because of large differences in climate that exist in the Midwest, different land practices and environmental interactions may occur, especially from east to west, which may be difficult to represent using spatially constant coefficients. In this study, spatially varying land-to-water delivery variables were included in the models to better describe these differences; however, relatively large residuals were still identified in the western part of the study area. One approach to overcome this problem would be to develop separate, smaller scale SPARROW models for different areas of the Midwest; however, this approach commonly results in a limited number of calibration sites and a smaller range in environmental conditions in any single model that can make model calibration difficult (Benoy and others, 2016). A Bayesian hierarchical method that uses the estimation of regionally varying coefficients for the specific sources and delivery variables in a single model, which was not used in this study, has recently been applied to SPARROW models (Alexander, 2015; Strickling and Obenour, 2018) and could improve their predictability.

Although the catchments used in constructing the SPARROW models described in this study were relatively small (about $2 \mathrm{~km}^{2}$ ), much of the source data and landscape data used to describe variability in land-to-water delivery were derived from county-wide averages or totals. These averages or totals were usually apportioned to the catchment based on fine-scale land-use information. In addition, most of the sites used to calibrate the SPARROW models were located on medium to large streams and may not represent the smallest streams in the Midwest. For example, for the SPARROW TP model, only 5 percent of the calibration sites were on streams with drainage areas less than about $31 \mathrm{~km}^{2}$; therefore, it is difficult to know how well the model predicted loads in drainages smaller than this. Until fine scale landscape data and monitoring data on small streams are available, caution should be taken when interpreting the finest scale model results (for example, predictions for the individual incremental drainages of the reaches) that are output from the SPARROW models.

As with any regression analysis, the accuracy of SPARROW predictions needs to be considered when interpreting results of the models. One way to evaluate the accuracy of SPARROW predictions is to compare the measured flows and loads at the calibration stations with all the predicted flows and loads, as was done for each constituent (figs. 6, 10, 14, and 18). Statistical methods were used in this study to identify whether there were areas with consistent regional errors. One approach that has been used to minimize the effects of model errors is to use measured loads (conditioned model predictions) for monitored reaches, and to use the unconditioned model predictions or simulated loads only for unmonitored reaches (Robertson and others, 2019). Methods are currently (2019) being developed to adjust SPARROW-simulated 
predictions for relatively consistent regional model errors. Similarly, the accuracy in model coefficients should be considered when interpreting the importance of individual sources and instream and in-reservoir losses. Coefficients in the models (described in appendix 1) are typically estimated using nonlinear least-squares regression (Schwarz and others, 2006) and used to place confidence limits on each of the source, land-to-water delivery and aquatic loss terms included in the model (tables 3, 5, 7, and 9).

The source variables interact with the land-to-water delivery factors to describe regional variability in the transport of constituents to the stream network. However, the sources and land-to-water delivery variables included in the models may not represent all the factors affecting an actual ecosystem. This can result in the load response to any individual variable reflecting the effects of one or more correlated sources and watershed properties, thereby complicating the determination of the specific properties or processes that are actually responsible for the correlation with stream loads. A strong correlation between source variables (such as agricultural fertilizers and manure) is not a statistical problem in identifying a specified source variable in the model, but it can make it difficult to completely distinguish the relative importance of the individual source variables. These correlations result in large variance inflation factors that are evaluated during calibration and relatively large confidence limits for their respective coefficients. Correlated potential land-to-water delivery variables commonly result in one of the variables being omitted from the model (see appendix 2 for all of the variables examined during model calibrations) and the variables that are included in the final model representing their combined effects. Therefore, caution should be taken when interpreting the coefficients of each of the individual land-to-water delivery factors, similar to that which should be used when interpreting individual coefficients obtained with simple multiple regression approaches (Box, 1966). Because of this difficulty in interpreting the effects of individual land-to-water delivery variables, caution should be taken when using calibrated SPARROW models to predict the effects on stream loads of adjusting specific landto-water delivery variables.

Most SPARROW models simulate long-term meanannual transport (steady-state loads) given source inputs and management practices similar to those in a given base year (in this case 2012). These SPARROW models simulate long-term mean-annual transport that incorporates a range in hydrological conditions. This feature enables model results to be used to rank areas based on their typical losses of a specific constituent (Robertson and others, 2009, 2014); however, this feature does not allow areas to be ranked during any specific year or season. Methods are currently being developed to create SPARROW models that simulate dynamic (season-to-season and decadal scale) changes in loading throughout the modeled area (Smith and others, 2016).

\section{Summary and Conclusions}

Excessive nutrient and sediment losses from the landscape have led to persistent problems in streams, estuaries, and downstream waterbodies throughout the United States. A few of the major problems in the Midwest resulting from these losses include hypoxia in the Gulf of Mexico, harmful algal blooms in the western bay of Lake Erie and in many smaller lakes, and poor benthic habitats in many streams and estuaries caused by siltation. To reduce this export in an efficient manner, it is important to understand where and from what sources the nutrients and sediment originate. This information is important to determine where to concentrate management efforts and decide on what types of actions are needed to reduce this export. Several regional SPAtially Referenced Regression On Watershed attributes (SPARROW) models were previously developed to describe total nitrogen (TN) and total phosphorus (TP) loads throughout the different areas of the Midwest and were used to describe where and from what sources the nutrients originate. These previous models were developed based on nutrient inputs and management practices similar to or before 2002. Since 2002, many nutrient inputs (especially losses from wastewater treatment plants) and management practices have changed.

In this report, updated SPARROW models were developed for the entire Midwest part of the United States based on water, nitrogen, and phosphorus inputs and management practices similar to around 2012. In addition, SPARROW models were developed to describe suspended-sediment (SS) transport for the entire Midwest. The 2012 SPARROW models for the Midwest were developed at a much finer spatial resolution than the previous SPARROW models (mean catchment size of 2.7 square kilometers compared to 480 square kilometers).

In developing the 2012 SPARROW models, several improvements were made to the datasets used in the models and the statistical approaches used to calibrate the models. Major improvements in the inputs for the SPARROW models included updates to point-source wastewater treatment plant effluent information, incorporation of natural background phosphorus inputs, and improved methods to compute the long-term mean-annual loads used to calibrate the models. Most long-term mean-annual loads used to calibrate the SPARROW models were computed using a modified Beale ratio-estimator technique, which had been shown to have little bias and provide more accurate estimates of the longterm mean-annual loads for less conservatively transported constituents, such as TP and suspended sediment, than most regression approaches.

The 2002 and earlier SPARROW models were calibrated without compensating for the unequal effect of each calibration site. In the 2012 SPARROW models described in this study, new algorithms were used to determine if thinning of the closely spaced monitoring sites was needed and if each of 
the sites should be adjusted for the effects of monitoring sites being that are located closely downstream from other monitoring sites and thus underrepresented in the calibration process. Compensating for the unequal effect of each calibration site had little effect on the summary statistics of the model (root mean square error [RMSE], standard errors, and $p$-values), but it did result in modifications to coefficients for several of the variables in the models. By thinning the number of sites and adjusting for the effects of nesting, we feel that the final SPARROW models more properly represent the entire study area and especially instream and reservoir losses. This approach could have a greater effect than documented in this study for models developed with fewer calibration sites, a more nonhomogeneous distribution of sites, or in areas where most monitoring sites are along major rivers. These additional steps in calibration should be incorporated into developing future SPARROW models.

The overall predictability of the SPARROW models varied among constituents as demonstrated by their respective RMSEs (in logarithmic space) and mean percentage error (in real space). The SPARROW models were best at describing the spatial differences in streamflow (unconditioned RMSE $=0.425$, mean error of 44.5 percent), followed by TN (unconditioned RMSE $=0.555$, mean error of 60.0 percent), TP (unconditioned RMSE $=0.885$, mean error of 109 percent), and suspended sediment (unconditioned RMSE $=1.112$, mean error of 156 percent). In general, the models performed most accurately in the eastern part of the study area where flows and loads were largest. In the southwestern part of the study area, where flows and loads were relatively small, the models generally overpredicted the flow and loads, possibly because of a lack of detailed information describing the numerous anthropogenic processes that remove and divert water, mainly for agriculture.

Results of the models were used to describe the major sources of nitrogen and phosphorus reaching the stream network and the factors affecting this delivery. Nitrogen from atmospheric deposition was the dominant source in most anthropogenically unaffected areas (especially in the Rocky Mountains and north-central areas), whereas nitrogen from fertilizers, manure, and fixation were dominant sources in agricultural areas, especially the Corn Belt and near the Mississippi River. Phosphorus from natural background sources was the dominant source in most unaffected areas, whereas fertilizers and manure were the dominant sources of phosphorus in agricultural areas, especially the Corn Belt and near the Mississippi River. Although urban sources of phosphorus were typically quite localized, they were still important in some larger areas, especially the Lake Erie Basin. The major factors affecting the land-to-water delivery of nutrients and sediment were those that are typically included in most process-driven watershed models, such as runoff, soil erodibility, basin slope, and the amount of the catchment underlain with tile drains. In the SPARROW TN and TP models, some best management practices were determined to be significant in reducing the delivery of nutrients to streams.
Results of the 2012 SPARROW streamflow model were used to describe flows throughout the Midwest. The highest flows were in streams in the northeastern part of the study area, whereas the lowest flows were in streams of the western part of the study area. The direct results from the 2012 SPARROW streamflow model more accurately estimated mean streamflows throughout the Midwest than those available in the National Hydrographic Dataset Version 2 at a 1:100,000 scale for the 2000-14 period based on comparisons of RMSE values. Results from the SPARROW streamflow model were then used in the SPARROW TN, TP, and SS models to simulate instream and in-reservoir decay and describe variability in the delivery of TN, TP, and SS to the stream network. Rather than using the direct results of the SPARROW streamflow models in the other SPARROW constituent models, the SPARROW-simulated streamflows were adjusted (conditioned) to the measured streamflows during 2000-14 where they were available. This conditioning further improved the flow estimates throughout the modeled area.

The 2012 SPARROW TN, TP, and SS models were used to describe loads and yields of these constituents throughout the Midwest and used to describe yields from major drainage basins (including each of the Great Lakes) within the Midwest and from the entire Mississippi River Basin, the U.S. part of the Great Lakes Basin, and the entire Midwest. Highest TN, TP, and SS yields were typically from the Lake Erie, Ohio River, Upper Mississippi River, and Lower Mississippi River Basins, whereas the lowest yields were spread over most other areas. Deposition (and volatilization for nitrogen) in streams and reservoirs resulted in part of the TN, TP, and SS that was delivered to the stream not reaching downstream receiving waters. Instream deposition was especially important for suspended sediment. The largest losses were for nutrients and sediments in streams originating long distances from their downstream receiving waterbody and which flowed into large reservoirs, such as in the Missouri River and Arkansas River Basins. Losses during downstream delivery resulted in 14, 15, and 28 percent of the TN, TP, and SS, respectively, being lost during delivery to the Great Lakes and 19,23, and 52 percent of the TN, TP, and SS, respectively, being lost during delivery to the Gulf of Mexico.

Inputs and outputs from the 2012 Midwest SPARROW models are available in an associated U.S. Geological Survey data release (https://doi.org/10.5066/P93QMXC9).

Information from the Midwest SPARROW models can help managers prioritize the location and type of efforts to reduce nutrient and sediment loading to the Gulf of Mexico, Great Lakes, and Lake Winnipeg by understanding which sources are most important in various locations. By implementing the most appropriate actions in the most influential areas, it may be possible to reduce nutrient loading from the Mississippi River Basin, and thus reduce the size of the hypoxic zone in the Gulf of Mexico; reduce nutrient loading into lakes, and thus reduce the occurrence of harmful algal blooms; and reduce sediment losses; and thus improve the benthic habitat in streams and rivers throughout the Midwestern part of the United States. 


\section{Acknowledgments}

The authors would like to acknowledge Greg Schwarz, John Brakebill, Stephen Preston, Ken Skinner, David Anning, Scott Ator, Anne Hoos, Victor Roland, and Daniel Wise, from the U.S. Geological Survey, for their contributions in the development of the 2012 regional SPARROW models. This group developed new datasets and new model evaluation and model calibration procedures that greatly improved the models described in this report. This group also provided assistance in describing many of the methods used in this study. The authors also would like to thank Rich Alexander and Ana Maria García, from the U.S. Geological Survey, for reviewing this report and providing valuable comments.

\section{References Cited}

Alexander, R.B., 2015, Advances in quantifying streamflow variability using hierarchical Bayesian methods with SPARROW: University Park, Penn., Pennsylvania State University, College of Agricultural Sciences, Ph.D. dissertation, $281 \mathrm{p}$.

Alexander, R.B., Smith, R.A., Schwarz, G.E., Boyer, E.W., Nolan, J.V., and Brakebill, J.W., 2008, Differences in phosphorus and nitrogen delivery to the Gulf of Mexico from the Mississippi River Basin: Environmental Science \& Technology, v. 42, no. 3, p. 822-830. [Also available at https://doi. org/10.1021/es0716103.]

American Public Health Association, American Water Works Association, and Water Pollution Control Federation, 2012, Standard methods for the examination of water and wastewater (22d ed.): Washington, D.C., American Public Health Association, 1,496 p.

American Society for Testing and Materials, 2006, Standard test methods for determining sediment concentration in water samples: American Society of Testing Methods, D3977-97, v. 11.02, p. 395-400.

Arnold, J.G., Moriasi, D.N., Gassman, P.W., Abbaspour, K.C., White, M.J., Srinivasan, R., Santhi, C., Harmel, R.D., Griensven, A. van, Van Liew, M.W., Kannan, N., and Jha, M.K., 2012, SWAT - Model use, calibration, and validation: American Society of Agricultural and Biological Engineers, v. 55, no. 4, p. 1491-1508.

Ator, S.W., 2019, Spatially referenced models of streamflow and nitrogen, phosphorus, and suspended-sediment loads in streams of the Northeastern United States: U.S. Geological Survey Scientific Investigations Report 2019-5118, 57 p., https://doi.org/10.3133/sir20195118.
Ator, S.W., Brakebill, J.W., and Blomquist, J.D., 2011, Sources, fate, and transport of nitrogen and phosphorus in the Chesapeake Bay watershed-An empirical model: U.S. Geological Survey Scientific Investigations Report 2011-5167, 27 p. [Also available at https://doi.org/10.3133/ sir20115167.]

Barlow, P.M., and Leake, S.A., 2012, Streamflow depletion by wells - Understanding and managing the effects of groundwater pumping on streamflow: U.S. Geological Survey Circular 1376, 84 p. [Also available at https://doi.org/10.3133/ cir1376.]

Beale, E.M.L., 1962, Some uses of computers in operational research: Industrielle Organisation, v. 31, p. 27-28.

Benoy, G.A., Jenkinson, W., Robertson, D.M., and Saad, D.A., 2016, Nutrient delivery to Lake Winnipeg from the Red-Assiniboine River Basin-A binational application of the SPARROW model: Canadian Water Resources Journal, v. 41, no. 3, p. 429-447, accessed February 2018 at https:// doi.org/10.1080/07011784.2016.1178601.

Box, G.E.P., 1966, Use and abuse of regression: Technometrics, v. 8, no. 4, p. 625-629. [Also available at https://doi. org/10.2307/1266635.]

Brakebill, J.W., Schwarz, G.E., and Wieczorek, M.E., in press, An enhanced hydrologic stream network based on the NHDPlus medium resolution data set: U.S. Geological Survey Scientific Investigations Report 2019-5127.

Bricker, S.B., Longstaff, B., Dennison, W., Jones, A., Boicourt, K., Wicks, C., and Woerner, J., 2008, Effects of nutrient enrichment in the nation's estuaries-A decade of change: Harmful Algae, v. 8, no. 1, p. 21-32. [Also available at https://doi.org/10.1016/j.hal.2008.08.028.]

Brown, J.B., Sprague, L.A., and Dupree, J.E., 2011, Nutrient sources and transport in the Missouri River Basin, with emphasis on the effects of irrigation and reservoirs: Journal of the American Water Resources Association, v. 47, no. 5, p. 1034-1060. [Also available at https://doi.org/10.1111/ j.1752-1688.2011.00584.x.]

Carpenter, S.R., Caraco, N.F., Correll, D.L., Howarth, R.W., Sharpley, A.N., and Smith, V.H., 1998, Nonpoint pollution of surface waters with phosphorus and nitrogen: Ecological Applications, v. 8, no. 3, p. 559-568. [Also available at https://doi.org/10.1890/1051-0761(1998)008[0559:NPOSW $\mathrm{W}] 2.0 . \mathrm{CO} ; 2$.

Cliff, A.D., and Ord, J.K., 1973, Spatial autocorrelation: London, Pion Limited, 178 p.

Cochran, W.G., 1977, Sampling techniques(3d ed.): New York, Wiley, $428 \mathrm{p}$. 
Colorado Division of Water Resources, 2019, Colorado's surface water conditions: Colorado Division of Water Resources web page, accessed October 24, 2019, at https:// dwr.state.co.us/surfacewater/.

Daryanto, S., Wang, L., and Jacinthe, P., 2017, Impacts of notillage management on nitrate loss from corn, soybean and wheat cultivation-A meta-analysis: Scientific Reports, v. 7, no. 1, art. 12117. [Also available at https://doi.org/10.1038/ s41598-017-12383-7.]

Domagalski, J.L., and Saleh, D., 2015, Sources and transport of phosphorus to rivers in California and adjacent States, U.S., as determined by SPARROW modeling: Journal of the American Water Resources Association, v. 51, no. 6, p. 1463-1486. [Also available at https://doi. org/10.1111/1752-1688.12326.]

Ellison, C.A., Savage, B.E., and Johnson, G.D., 2014, Suspended-sediment concentrations, loads, total suspended solids, turbidity, and particle-size fractions for selected rivers in Minnesota, 2007 through 2011: U.S. Geological Survey Scientific Investigations Report 2013-5205, 43 p., accessed February 2019 at https://doi.org/10.3133/sir20135205.

Farm Service Agency, 2012, Conservation reserve program statistics: U.S. Department of Agriculture web page, accessed November 13, 2018, at https://www.fsa.usda.gov/ programs-and-services/conservation-programs/reports-andstatistics/conservation-reserve-program-statistics/index.

Finocchiaro, R.G., 2014, Agricultural subsurface drainage tile locations by permits in South Dakota: U.S. Geological Survey data release, http://dx.doi.org/10.5066/F7KS6PNW.

Finocchiaro, R.G., 2016, Agricultural subsurface drainage tile locations by permits in North Dakota: U.S. Geological Survey data release, http://dx.doi.org/10.5066/F7QF8QZW.

García, A.M., Alexander, R.B., Arnold, J.G., Norfleet, L., White, M.J., Robertson, D.M., and Schwarz, G., 2016, Regional effects of agricultural conservation practices on nutrient transport in the Upper Mississippi River Basin: Environmental Science \& Technology, v. 50, no. 13, p. 6991-7000. [Also available at https://doi.org/10.1021/ acs.est.5b03543.]

García, A.M., Hoos, A.B., and Terziotti, S., 2011, A regional modeling framework of phosphorus sources and transport in streams of the southeastern United States: Journal of the American Water Resources Association, v. 47, no. 5, p. 991-1010. [Also available at https://doi.org/10.1111/ j.1752-1688.2010.00517.x.]
Gellis, A.C., Fitzpatrick, F.A., and Schubauer-Berigan, J.P., 2016, A manual to identify sources of fluvial sediment: Washington, D.C., U.S. Environmental Protection Agency, EPA/600/R-16/210, 117 p. [Also available at https://nepis.epa.gov/Exe/ZyPDF.cgi/P100QVM1. PDF?Dockey=P100QVM1.PDF.]

Gray, J.R., Glysson, G.D., Turcios, L.M., and Schwarz, S.E., 2000, Comparability of suspended-sediment concentration and total suspended solids data: U.S. Geological Survey Water-Resources Investigations Report 00-4191, 14 p. [Also available at https://water.usgs.gov/osw/pubs/ WRIR00-4191.pdf.]

Gronberg, J.M., and Arnold, T.L., 2017, County-level estimates of nitrogen and phosphorus from animal manure (2007 and 2012) and 30-meter-resolution grid of counties (2010) for the conterminous United States: U.S. Geological Survey data release, https://doi.org/10.5066/F7X34VMZ.

Groten, J.T., and Johnson, G.D., 2018, Comparability of river suspended-sediment sampling and laboratory analysis methods: U.S. Geological Survey Scientific Investigations Report 2018-5023, 23 p., accessed February 2019 at https://doi.org/10.3133/sir20185023.

Guy, H.P., 1969, Laboratory theory and methods for sediment analysis: U.S. Geological Survey Techniques of WaterResources Investigations, book 5, chap. 1, 58 p. [Also available at https://pubs.usgs.gov/twri/twri5c1/pdf/TWRI_5-C1. pdf.]

Heath, R.C., 1983, Basic ground-water hydrology: U.S. Geological Survey Water Supply Paper 2220, 86 p. [Also available at https://doi.org/10.3133/wsp2220.]

Heimann, D.C., Sprague, L.A., and Blevins, D.W., 2011, Trends in suspended-sediment loads and concentrations in the Mississippi River Basin, 1950-2009: U.S. Geological Survey Scientific Investigations Report 2011-5200, 33 p. [Also available at https://doi.org/10.3133/sir20115200.]

Homer, C.G., Dewitz, J.A., Yang, L., Jin, S., Danielson, P., Xian, G., Coulston, J., Herold, N.D., Wickham, J.D., and Megown, K., 2015, Completion of the 2011 National Land Cover Database for the conterminous United StatesRepresenting a decade of land cover change information: Photogrammetric Engineering and Remote Sensing, v. 81, no. 5, p. 345-354.

Hoos, A.B., and Roland, V.L. II, 2019, Spatially referenced models of streamflow and nitrogen, phosphorus, and suspended-sediment loads in streams of the southeastern United States: U.S. Geological Survey Scientific Investigations Report 2019-5135, 87 p., https:// doi.org/10.3133/sir20195135. 
Horizon Systems, 2013, NHDPlus Version 2: Horizon Systems database, accessed March 18, 2013, at http:/www.horizonsystems.com/nhdplus/.

Howarth, R.W., Billen, G., Swaney, D., Townsend, A., Jaworski, N., Lajtha, K., Downing, J.A., Elmgren, R., Caraco, N., Jordan, T., Berendse, F., Freney, J., Kudeyarov, V., Murdoch, P., and Zhao-Liang, Z., 1996, Regional nitrogen budgets and riverine $\mathrm{N} \& \mathrm{P}$ fluxes for the drainages to the North Atlantic Ocean-Natural and human influences: Biogeochemistry, v. 35, no. 1, p. 75-139. [Also available at https://doi.org/10.1007/BF02179825.]

Howarth, R.W., Sharpley, A., and Walker, D., 2002, Sources of nutrient pollution to coastal waters in the United States-Implications for achieving coastal water quality goals: Estuaries, v. 25, no. 4, p. 656-676. [Also available at https://doi.org/10.1007/BF02804898.]

Jobson, H.E., 1996, Prediction of traveltime and longitudinal dispersion in rivers and streams: U.S. Geological Survey Water-Resources Investigations Report 96-4013, 69 p. [Also available at https://pubs.usgs.gov/wri/1996/4013/.]

Johanson, R.C., Imhoff, J.C., and Davis, H.H., Jr., 1980, Users manual for Hydrological Simulation ProgramFortran (HSPF): U.S. Environmental Protection Agency, EPA/600/9-80/015, 685 p.

LaMotte, A.E., 2015, Selected items from the Census of Agriculture at the county level for the conterminous United States, 1950-2012: U.S. Geological Survey data release, http://dx.doi.org/10.5066/F7H13016.

Lee, C.J., and Glysson, G.D., 2013, Compilation, quality control, analysis, and summary of discrete suspended-sediment and ancillary data in the United States, 1901-2010: U.S. Geological Survey Data Series 776, 35 p., accessed February 2019 at https://doi.org/10.3133/ds776.

Lee, C.J., Hirsch, R.M., Schwarz, G.E., Holtschlag, D.J., Preston, S.D., Crawford, C.G., and Vecchia, A.V., 2016, An evaluation of methods for estimating decadal stream loads: Journal of Hydrology (Amsterdam), v. 542, p. 185-203. [Also available at https://doi.org/10.1016/j. jhydrol.2016.08.059.]

Lorenz, D.L., Robertson, D.M., Hall, D.W., and Saad, D.A., 2009, Trends in streamflow and nutrient and suspendedsediment concentrations and loads in the Upper Mississippi, Ohio, Red, and Great Lakes River Basins, 1975-2004: U.S. Geological Survey Scientific Investigations Report 2008-5213, 81 p. [Also available at https://doi.org/10.3133/ sir20085213.]
Maupin, M.A., Kenny, J.F., Hutson, S.S., Lovelace, J.K., Barber, N.L., and Linsey, K.S., 2014, Estimated use of water in the United States in 2010: U.S. Geological Survey Circular 1405, 56 p., [Also available at https://doi.org/10.3133/ cir1405.]

McCabe, G.J., and Wolock, D.M., 2011, Independent effects of temperature and precipitation on modeled runoff in the conterminous United States: Water Resources Research, v. 47, no. 11, art. W11522, 11 p. [Also available at https:// doi.org/10.1029/2011WR010630.]

McCullough, G.K., Page, S.J., Hesslein, R.H., Stainton, M.P., Kling, H.J., Salki, A.G., and Barber, D.G., 2012, Hydrological forcing of a recent trophic surge in Lake Winnipeg: Journal of Great Lakes Research, v. 38, p. 95-105. [Also available at https://doi.org/10.1016/j.jglr.2011.12.012.]

Michalak, A.M., Anderson, E.J., Beletsky, D., Boland, S., Bosch, N.S., Bridgeman, T.B., Chaffin, J.D., Cho, K., Confesor, R., Daloglu, I., DePinto, J.V., Evans, M.A., Fahnenstiel, G.L., He, L., Ho, J.C., Jenkins, L., Johengen, T.H., Kuo, K.C., LaPorte, E., Liu, X., McWilliams, M.R., Moore, M.R., Posselt, D.J., Richards, R.P., Scavia, D., Steiner, A.L., Verhamme, E., Wright, D.M., and Zagorski, M.A., 2013, Record-setting algal bloom in Lake Erie caused by agricultural and meteorological trends consistent with expected future conditions: Proceedings of the National Academy of Sciences of the United States of America, v. 110, no. 16, p. 6448-6452. [Also available at https://doi.org/10.1073/ pnas. 1216006110.]

Minnesota Department of Natural Resources, 2019, Minnesota Department of Natural Resource: Minnesota Department of Natural Resources web page, accessed October 24, 2019, at https://www.dnr.state.mn.us/.

Minnesota Pollution Control Agency, 2019, Minnesota Pollution Control Agency: Minnesota Pollution Control Agency web page, accessed October 24, 2019, at https:/www.pca. state.mn.us.

Mississippi River/Gulf of Mexico Watershed Nutrient Task Force, 2008, Gulf hypoxia action plan 2008: Washington, D.C., U.S. Environmental Protection Agency, 64 p. [Also available at http://water.epa.gov/type/watersheds/named/ msbasin/upload/2008_update082608.pdf.]

Moore, R.B., Johnston, C.M., Robinson, K.W., and Deacon, J.R., 2004, Estimation of total nitrogen and phosphorus in New England streams using spatially referenced regression models: U.S. Geological Survey Scientific Investigations Report 2004-5012, 42 p. [Also available at https://doi. org/10.3133/sir20045012.] 
Nakagaki, N., and Wieczorek, M.E., 2016, Estimates of subsurface tile drainage extent for 12 Midwest states, 2012: U.S. Geological Survey data release, http://dx.doi. org/10.5066/F7W37TDP.

Nardi, M.R., 2014, Watershed potential to contribute phosphorus from geologic materials to receiving streams, conterminous United States: U.S. Geological Survey web page, accessed August, 2018, at https://water.usgs.gov/lookup/ getspatial?pmapnatl.

Nolan, J.V., Brakebill, J.W., Alexander, R.B., and Schwarz, G.E., 2003, Enhanced river reach File 2: U.S. Geological Survey Open-File Report 2002-40. [Also available at https://doi.org/10.3133/ofr0240.]

Preston, S.D., Alexander, R.B., and Wolock, D.M., 2011, SPARROW modeling to understand water-quality conditions in major regions of the United States - A featured collection introduction: Journal of the American Water Resources Association, v. 47, no. 5, p. 887-890. [Also available at https://doi.org/10.1111/j.1752-1688.2011.00585.x.]

Preston, S.D., Alexander, R.B., Woodside, M.D., and Hamilton. P.A., 2009, SPARROW modeling-Enhancing understanding of the Nation's water quality: U.S. Geological Survey Fact Sheet 2009-3019, 6 p. [Also available at https://pubs.usgs.gov/fs/2009/3019/.]

PRISM Climate Group, 2015, PRISM climate data: Oregon State University web page, accessed August 31, 2015, at http://prism.oregonstate.edu.

Qian, S.S., Reckhow, K.H., Zhai, J., and McMahon, G., 2005, Nonlinear regression modeling of nutrient loads in streams-A Bayesian approach: Water Resources Research, v. 41, no. 7, art. W07012, 10 p. [Also available at https:// doi.org/10.1029/2005WR003986.]

Rebich, R.A., Houston, N.A., Mize, S.V., Pearson, D.K., Ging, P.B., and Hornig, C.E., 2011, Sources and delivery of nutrients to the northwestern Gulf of Mexico from streams in the South-Central United States: Journal of the American Water Resources Association, v. 47, no. 5, p. 10611086. [Also available at https://doi.org/10.1111/j.17521688.2011.00583.x.]

Richards, R.P., Alameddine, I., Allan, J.D., Baker, D.B., Bosch, N.S., Confesor, R., DePinto, J.V., Dolan, D.M., Reutter, J.M., and Scavia, D., 2013, Discussion-Nutrient inputs to the Laurentian Great Lakes by source and watershed estimated using SPARROW watershed models by D.M. Robertson and D.A. Saad: Journal of the American Water Resources Association, v. 49, no. 3, p. 715-724. [Also available at https://doi.org/10.1111/jawr.12006.]
Robertson, D.M., and Saad, D.A., 2011, Nutrient inputs to the Laurentian Great Lakes by source and watershed estimated using SPARROW watershed models: Journal of the American Water Resources Association, v. 47, no. 5, p. 1011-1033. [Also available at https://doi.org/10.1111/ j.1752-1688.2011.00574.x.]

Robertson, D.M., and Saad, D.A., 2013, SPARROW models used to understand nutrient sources in the Mississippi/ Atchafalaya River Basin: Journal of Environmental Quality, v. 42, no. 5, p. 1422-1440. [Also available at https://doi. org/10.2134/jeq2013.02.0066.]

Robertson, D.M., Saad, D.A., Benoy, G.A., Vouk, I., and Schwarz, G.E., 2019, Phosphorus and nitrogen transport in the binational Great Lakes Basin estimated using SPARROW watershed models: Journal of the American Water Resources Association 1-24. [Also available at https://doi.org/10.1111/1752-1688.12792.]

Robertson, D.M., Saad, D.A., and Schwarz, G.E., 2014, Spatial variability in nutrient transport by HUC8, state, and subbasin based on Mississippi/Atchafalaya River Basin SPARROW models: Journal of the American Water Resources Association, v. 50, no. 4, p. 988-1009. [Also available at https://doi.org/10.1111/jawr.12153.]

Robertson, D.M., Schwarz, G.E., Saad, D.A., and Alexander, R.A., 2009, Incorporating uncertainty into the ranking of SPARROW model nutrient yields from Mississippi/Atchafalaya River Basin watersheds: Journal of the American Water Resources Association, v. 45, p. 534-549. [Also available at https://doi.org/10.1111/j.1752-1688.2009.00310.x.]

Ruddy, B.C., Lorenz, D.L., and Mueller, D.K., 2006, Countylevel estimates of nutrient inputs to the land surface of the conterminous United States, 1982-2001: U.S. Geological Survey Scientific Investigations Report 2006-5012, 17 p., accessed February 2019 at https://pubs.usgs.gov/ sir/2006/5012/pdf/sir2006_5012.pdf.

Saad, D.A., Schwarz, G.E., Argue, D.M., Anning, D.W., Ator, S.W., Hoos, A.B., Preston, S.D., Robertson, D.M., and Wise, D., 2019, Estimates of long-term mean daily streamflow and annual nutrient and suspended-sediment loads considered for use in regional SPARROW models of the conterminous United States, 2012 Base Year: U.S. Geological Survey Scientific Investigations Report 2019-5069, 51 p., https://doi.org/10.3133/sir20195069.

Saad, D.A., Schwarz, G.E., Robertson, D.M., and Booth, N.L., 2011, A multi-agency nutrient dataset used to estimate loads, improve monitoring design, and calibrate regional nutrient SPARROW models: Journal of the American Water Resources Association, v. 45, p. 933-949. [Also available at https://doi.org/10.1111/j.1752-1688.2011.00575.x.] 
Saad, D.A., and Robertson, D.M., 2019, SPARROW model inputs and simulated streamflow, nutrient and suspendedsediment loads in streams of the Midwest region of the United States, 2012 base year: U.S. Geological Survey data release, https://doi.org/10.5066/P93QMXC9.

Schindler, D.W., Carpenter, S.R., Chapra, S.C., Hecky, R.E., and Orihel, D.M., 2016, Reducing phosphorus to curb lake eutrophication is a success: Environmental Science \& Technology, v. 50, no. 17, p. 8923-8929. [Also available at https://doi.org/10.1021/acs.est.6b02204.]

Schwarz, G.E., and Alexander, R.B., 1995, Soils data for the conterminous United States derived from the NRCS State Soil Geographic (STATSGO) Data Base: U.S. Geological Survey Open-File Report 95-449, accessed November 16, 2018, at https://water.usgs.gov/lookup/getspatial?ussoils.

Schwarz, G.E., Hoos, A.B., Alexander, R.B., and Smith, R.A., 2006, The SPARROW surface water-quality model-Theory, application and user documentation: U.S. Geological Survey Techniques and Methods, book 6, chap. B3, 248 p. [Also available at https://pubs.usgs.gov/tm/2006/tm6b3/.]

Seaber, P.R., Kapinos, F.P., and Knapp, G.L., 1987, Hydrologic unit maps: U.S. Geological Survey Water Supply Paper 2294, 63 p., accessed March 9, 2015, at https://doi. org/10.3133/wsp2294.

Sharpley, A.N., Daniel, T., Gibson, G., Bundy, L., Cabrera, M., Sims, T., Stevens, R., Lemunyon, J., Kleinman, P., and Parry, R., 2006, Best management practices to minimize agricultural phosphorus impacts on water quality: U.S. Department of Agriculture, Agricultural Research Service, ARS-163, 52 p., accessed November 18, 2018, at https://www.ars.usda.gov/is/np/bestmgmtpractices/best $\% 20$ management $\% 20$ practices.pdf.

Simley, J.D., and Carswell, W.J., Jr., 2009, The National Map-Hydrography: U.S. Geological Survey Fact Sheet 2009-3054, 4 p. [Also available at https://pubs.usgs.gov/ fs/2009/3054/pdf/FS2009-3054.pdf.]

Skinner, K.D., and Maupin, M.A., 2019, Point-source nutrient loads to streams of the conterminous United States, 2012: U.S. Geological Survey Data Series 1101, 13 p., accessed February 2019 at https://doi.org/10.3133/ds1101.

Smith, D.B., Cannon, W.F., Woodruff, L.G., Solano, F., Kilburn, J.E., and Fey, D.L., 2013, Geochemical and mineralogical data for soils of the conterminous United States: U.S. Geological Survey Data Series 801, 19 p. [Also available at https://pubs.usgs.gov/ds/801/.]
Smith, R.A., Schwarz, G.E., and Alexander, R.B., 1997, Regional interpretation of water-quality monitoring data: Water Resources Research, v. 33, no. 12, p. 2781-2798. [Also available at https://doi.org/10.1029/97WR02171.]

Smith, R., Sekellick, A., Baker, A., Sanford, W., Blomquist, J., Schwarz, G., and LaMotte, A., 2016, Delayed response to management of watershed nitrogen sources caused by long-term storage of nitrogen in groundwater: Proceedings of the 2016 International Nitrogen Initiative Conference, Melbourne, Australia, December 4-8, 2016, 4 p.

Soller, D.R., Reheis, M.C., Garrity, C.P., and Van Sistine, D.R., 2009, Map database for surficial materials in the conterminous United States (version 1.0, July 2011): U.S. Geological Survey Data Series 425, scale 1:5,000,000, accessed February 2019 at https://pubs.usgs.gov/ds/425.

Stenback, G.A., Crumpton, W.G., Schilling, K.E., and Helmers, M.J., 2011, Rating curve estimation of nutrient loads in Iowa rivers: Journal of Hydrology (Amsterdam), v. 396, nos. 1-2, p. 158-169. [Also available at https://doi.org/10.1016/j.jhydrol.2010.11.006.]

Stewart, J.S., Schwarz, G.E., Brakebill, J.W., and Preston, S.D., 2018, Catchment-level estimates of nitrogen and phosphorus agricultural use from commercial fertilizer sales for the conterminous United States, 2012: U.S. Geological Survey Scientific Investigations Report 2018-5145, 52 p., accessed February, 2019 at https://doi.org/10.3133/ $\operatorname{sir} 20185145$.

Strickling, H.L., and Obenour, D.R., 2018, Leveraging spatial and temporal variability to probabilistically characterize nutrient sources and export rates in a developing watershed: Water Resources Reseach, v. 54, p. 5143-5162.

Swanson, F.J., Gregory, S.V., Sedell, J.R., and Campbell, A.G., 1982, Land-water interactions-The riparian zone, in Edmonds, R.L., ed., Analysis of coniferous forest ecosystems in the western United States: Stroudsburg, Penn., Academic Press, p. 267-91.

Terziotti, S., Hoos, A.B., Harned, D.A., and García, A.M, 2010, Mapping watershed potential to contribute phosphorus from geologic materials to receiving streams, southeastern United States: U.S. Geological Survey Scientific Investigations Map 3102, 1 sheet. [Also available at https://pubs.usgs.gov/sim/3102/.]

U.S. Army Corps of Engineers, 2016, National Inventory of Dams: U.S. Army Corps of Engineers web page, accessed November 13, 2018, at https://nid-test.sec.usace.army.mil/ ords/f?p=105:1. 
U.S. Army Corps of Engineers, 2019, U.S. Army Corps of Engineers Headquarters: U.S. Army Corps of Engineers web page, accessed October 24, 2019, at https://www.usace. army.mil/.

U.S. Department of Agriculture, National Agriculture Statistics Service, 2018, Agriculture counts-National cropland data layers: U.S. Department of Agriculture web page, accessed November 2018 at https://www.nass.usda.gov/ Research_and_Science/CropScape/.

U.S. Department of Agriculture, Natural Resources Conservation Service, 2016, Conservation Effects Assessment Project (CEAP): U.S. Department of Agriculture web page, accessed November 2018 at https://www.nrcs.usda.gov/ wps/portal/nrcs/detail/national/technical/nra/ceap/?.

U.S. Environmental Protection Agency, 1996, National water quality inventory - 1996 report to Congress: Washington, D.C., U.S. Environmental Protection Agency, Office of Water, EPA-R-97-008, 527 p.

U.S. Environmental Protection Agency, 1998, National strategy for the development of regional nutrient criteria: Washington, D.C., U.S. Environmental Protection Agency, Office of Water, EPA-822-R-98-002, 47 p.

U.S. Environmental Protection Agency, 2000, Nutrient criteria technical guidance manual-Lakes and reservoirs: Washington, D.C., U.S. Environmental Protection Agency, Office of Water, EPA-822-B-00-001, 232 p.

U.S. Environmental Protection Agency, 2007, Hypoxia in the Northern Gulf of Mexico-An update by the Environmental Protection Agency Science Advisory Board: Washington, D.C., U.S. Environmental Protection Agency, Office of Water, EPA-SAB-08-003, 275 p.

U.S. Environmental Protection Agency, 2018a, Storage and retrieval and water quality exchange: U.S. Environmental Protection Agency Water Quality Portal, accessed April 4, 2019, at https://www.epa.gov/waterdata/storage-andretrieval-and-water-quality-exchange.

U.S. Environmental Protection Agency, 2018b, Atmospheric modeling and analysis research-Watershed deposition modeling tool: U.S. Environmental Protection Agency web page, accessed November 13, 2018, at https://www.epa.gov/ AMD/Tools/wdt.html.

U.S. Geological Survey, 2015, USGS water data for the Nation: U.S. Geological Survey National Water Information System database, accessed March 9, 2015, at https://doi.org/10.5066/F7P55KJN.

U.S. Geological Survey, 2018a, National field manual for the collection of water-quality data: U.S. Geological Survey Techniques and Methods, book 9, accessed November 11, 2018, at https://water.usgs.gov/owq/FieldManual/.
U.S. Geological Survey, 2018b, USGS surface-water data for the Nation: U.S. Geological Survey National Water Information System database, accessed November 11, 2018, at https://waterdata.usgs.gov/nwis/sw/. [Also available at https://doi.org/10.5066/F7P55KJN.]

Watson, S.B., Miller, C., Arhonditsis, G., Boyer, G.L., Carmichael, W., Charlton, M.N., Confesor, R., Depew, D.C., Höök, T.O., Ludsin, S.A., Matisoff, G., McElmurry, S.P., Murray, M.W., Peter Richards, R., Rao, Y.R., Steffen, M.M., and Wilhelm, S.W., 2016, The re-eutrophication of Lake Erie-Harmful algal blooms and hypoxia: Harmful Algae, v. 56, p. 44-66, accessed November 20, 2018, at https://doi.org/10.1016/j.hal.2016.04.010.

Wellen, C., Kamran-Disfani, A.R., and Arhonditsis, G.B., 2015, Evaluation of the current state of distributed watershed nutrient water quality modeling: Environmental Science \& Technology, v. 49, no. 6, p. 3278-3290. [Also available at https://doi.org/10.1021/es5049557.]

Wieczorek, M.E., Jackson, S.E., and Schwarz, G.E., 2019, Select attributes for NHDPlus Version 2.1 reach catchments and modified network routed upstream watersheds for the conterminous United States (version 2.0, October 2019): U.S. Geological Survey data release, https://doi.org/10.5066/F7765D7V.

Wise, D.R., and Johnson, H.M., 2013, Application of the SPARROW model to assess surface-water nutrient conditions and sources in the United States Pacific Northwest: U.S. Geological Survey Scientific Investigations Report 2013-5103, 32 p. [Also available at https://doi.org/10.3133/ sir20135103.]

Wise, D.R., 2019, Spatially referenced models of streamflow and nitrogen, phosphorus, and suspended-sediment loads in streams of the Pacific United States: U.S. Geological Survey Scientific Investigations Report 2019-5112, 64 p., https://doi.org/10.3133/sir20195112.

Wise, D.R., Anning, D.W., and Miller, O., 2019, Spatially referenced models of streamflow and nitrogen, phosphorus, and suspended-sediment loads in streams of the Southwestern United States: U.S. Geological Survey Scientific Investigations Report 2019-5106, 66 p., https://doi.org/10.3133/ sir20195106.

Wischmeier, W.H., and Smith, D.D., 1978, Predicting rainfall erosion losses-A guide to conservation planning: U.S. Department of Agriculture, Agriculture Handbook no. 537, 67 p. [Also available at https://naldc.nal.usda.gov/download/CAT79706928/PDF.]

Wolock, D.M., and McCabe, G.J., 2018, Water balance model inputs and outputs for the conterminous United States, 1900-2015: U.S. Geological Survey data release, https://doi.org/10.5066/F71V5CWN. 


\section{Appendixes 1-5}

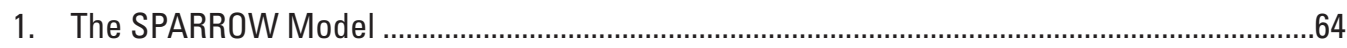

\section{Tables}

2.1. Source, land-to-water delivery, and instream and in-reservoir decay variables tested and used in the 2012 Midwest SPARROW models .

3.1. Sampling agencies that collected water-quality data used to calculate total nitrogen, total phosphorus, suspended sediment, and suspended solid loads considered for use in the 2012 Midwest SPARROW models

4.1. Wastewater treatment plant effluent load for total nitrogen and total phosphorus, by State and by percentage, based on measured versus typical pollutant concentration used in the 2012 Midwest SPARROW models

5.1. Original, generalized, and final surficial-materials categories considered for use in the 2012 Midwest SPARROW models. 


\section{Appendix 1. The SPARROW Model}

The SPAtially Referenced Regression On Watershed attributes (SPARROW) model is a spatially referenced watershed model that uses a hybrid statistical/mechanistic approach to estimate nutrient sources, transport, and transformation in terrestrial and aquatic ecosystems of watersheds under long-term steady-state conditions (Smith and others, 1997; Schwarz and others, 2006). SPARROW includes nonconservative transport, mass-balance constraints, and water flowpaths defined by topography, streams, and reservoirs, based on a stream-reach network with delineated reach catchments. For each reach in a hydrologic network, SPARROW predicts mean-annual instream constituent load as a function of sources, land-to-water delivery rates, and aquatic-phase attenuation rates. Conceptually, the instream load or flux at the downstream node of a reach can be expressed as the sum of two components:

$$
L(\text { instream })_{i}=L(\text { catchment })_{i}+L(\text { upstream })_{i}
$$

where:

$$
\begin{aligned}
& L \text { (instream) } i \quad \text { is the instream load at the downstream node of reach, } \\
& L \text { (catchment })_{i} \quad \text { is the load originating within the catchment for reach } i \text { and } \\
& \text { delivered to the downstream node of reach } i \text {, and } \\
& L(\text { upstream })_{i} \quad \text { is the load generated within catchments for upstream } \\
& \text { reaches and transported to the downstream node of } \\
& \text { reach } i \text { via the stream network. }
\end{aligned}
$$

The load originating within the catchment for reach $i\left(L\left[\right.\right.$ catchment $\left._{i}\right)$ is determined by

$$
L(\text { catchment }) i=\sum_{n=1}^{N_{S}} S_{n, i} \alpha_{n} D_{n}\left(Z_{i}^{D} ; \theta_{D}\right) A\left(Z_{i}^{S}, Z_{i}^{R} ; \theta_{S}, \theta_{R}\right)
$$

where:

$$
\begin{aligned}
& n, N_{s} \quad \text { is the source index ( } N s \text { is the total number of individual sources); } \\
& \sum \quad \text { represents summation across all individual sources; } \\
& S_{n i} \quad \text { is the vector of source variables for reach } i \text { (for example, a } \\
& \text { measurement of mass placed in the watershed, or the area } \\
& \text { of a particular land cover); } \\
& \alpha_{n} \quad \text { is the vector of coefficients, estimated by the model, in units that } \\
& \text { convert source variable units to flux units. For land-applied sources, } \\
& \alpha_{n} \text { is the model estimate of the average land-phase delivery ratio } \\
& \text { across all catchments in the study area. For land-applied sources } \\
& \text { represented by characteristics other than mass input (for example, } \\
& \text { area of developed land), } \alpha \text { expresses the conversion of source } \\
& \text { units to mass applied to the watershed, as well as the average } \\
& \text { land-phase delivery ratio for the source. The model-estimated } \\
& \text { source coefficient, } \alpha \text {, describes the land-to-water delivery ratio: } \alpha= \\
& \text { [streamflow or mass of constituent delivered to the adjacent stream } \\
& \text { channel] / [monitored input to the catchment]; } \\
& D_{n}() \quad \text { is the delivery variation factor, defining the variation among } \\
& \text { catchments in land-phase attenuation processes and, therefore, in } \\
& \text { land-phase delivery ratio. The delivery variation factor is modeled as } \\
& \text { a series of exponential functions of physical landscape } \\
& \text { characteristics that influence nutrient attenuation; } \\
& Z_{i}^{D} \quad \text { is the vector of physical landscape variables for reach } i \text { (for example, } \\
& \text { measured landform or soil characteristics, area of long-hydroperiod } \\
& \text { wetlands, and so forth); }
\end{aligned}
$$



$\theta_{D} \quad$ is the vector of coefficients, estimated by the model, for the physical landscape variables;
$A$ ( ) is the aquatic-phase delivery function, representing the result of attenuation processes acting on flux as it travels along the stream channel. Modeled as first-order decay, the aquatic-phase delivery function defines the fraction of flux originating in, and delivered to, reach $i$ that is transported to the reach's downstream node;
$Z_{i}^{S}, Z_{i}^{R} \quad$ are vectors of measured stream and reservoir variables, respectively, for reach $i$ (examples include stream-water depth or velocity, width of riparian corridor, and reservoir areal hydraulic loading); and
$\theta_{S}, \theta_{R} \quad$ are vectors of coefficients, estimated by the model, for the stream and reservoir variables, respectively.

The delivery variation factor $D_{n}()$ allows the model to estimate variation in land-to-water delivery rates among catchments. Values of $D_{n}()$ greater than 1 for a catchment indicate a larger fraction of nutrient reaching streams than the median for the study area. Values of $D_{n}()$ less than 1 indicate a smaller fraction of nutrient reaching streams than the median for the study area.

The second component in equation 1.2, the flux entering reach $i$ from upstream reaches, is the sum of the flux from any upstream catchment $\left(L[\text { catchment }]_{i-1}, L[\text { catchment }]_{i-2}\right.$, and so forth) adjusted for losses caused by stream and reservoir attenuation processes acting on flux along the reach pathway to and including reach $i$. For headwater reaches, equation 1.1 is simplified to include only the $L$ (catchment $)_{i}$ term. More information about the model form and assumptions is available in Schwarz and others (2006).

A visual representation of the model is available in Preston and others (2009).

The SPARROW_V2_10 version of the model was used in this study.

\section{References Cited}

Preston, S.D., Alexander, R.B., Woodside, M.D., and Hamilton. P.A., 2009, SPARROW modeling-Enhancing understanding of the Nation's water quality: U.S. Geological Survey Fact Sheet 2009-3019, 6 p. [Also available at https://pubs.usgs.gov/fs/2009/3019/.]

Schwarz, G.E., Hoos, A.B., Alexander, R.B., and Smith, R.A., 2006, The SPARROW surface water-quality model - Theory, application and user documentation: U.S. Geological Survey Techniques and Methods, book 6, chap. B3, 248 p. [Also available at https://pubs.usgs.gov/ $\mathrm{tm} / 2006 / \mathrm{tm} 6 \mathrm{~b} 3 /$.

Smith, R.A., Schwarz, G.E., and Alexander, R.B., 1997, Regional interpretation of water-quality monitoring data: Water Resources Research, v. 33, no. 12, p. 2781-2798. [Also available at https://doi.org/10.1029/97WR02171.] 
Table 2.1. Source, land-to-water delivery, and instream and in-reservoir decay variables tested and used in the 2012 Midwest SPARROW models.

[SPARROW, SPAtially Referenced Regression On Watershed attributes; TN, total nitrogen; TP, total phosphorus; SS, suspended sediment; AET, actual evapotranspiration; fts, cubic foot per second; $\mathrm{X}$, indicates variable was used in calibrated model; --, no data or not applicable; $\mathrm{kg}$, kilogram; $\mathrm{km}^{2}$, square kilometer; t, ton; $\mathrm{km}$, kilometer; $\mathrm{km} \times$ joules $/ \mathrm{s}$, kilometer times joule per second; $\mathrm{km} \times$ newtons $/ \mathrm{m}^{2}$, kilometer times newton per square meter; $\mathrm{ft} / \mathrm{s}$, foot per second; ${ }^{\circ} \mathrm{C}$, degrees Celsius; $\mathrm{mm}$, millimeter; $\mathrm{m}$, meter; <, less than; $\mathrm{km} / \mathrm{km}^{2}$, kilometer per square kilometer; in $/ \mathrm{hr}$, inch per hour; $\mathrm{kg} / \mathrm{m}^{3}$, kilogram per cubic meter; PET, potential evapotranspiration; CRP, Conservation Reserve Program; NRCS, U.S. Department of Agriculture National Resources Conservation Service; BMP, best management practice; kg/ $\mathrm{km}^{2}$, kilogram per square kilometer; $\mathrm{yr} / \mathrm{m}$, year per meter]

\begin{tabular}{|c|c|c|c|c|c|c|}
\hline \multirow{2}{*}{$\begin{array}{l}\text { Description of variables tested in Midwest } \\
\text { SPARROW models }\end{array}$} & \multirow{2}{*}{ Unit } & \multicolumn{4}{|c|}{ Used in calibrated model } & \multirow{2}{*}{ Variable name in calibrated SPARROW model } \\
\hline & & Streamflow & TN & TP & SS & \\
\hline \multicolumn{7}{|c|}{ Source variables } \\
\hline Precipitation minus AET & $\mathrm{ft}^{3} / \mathrm{s}$ & $\mathrm{X}$ & -- & -- & -- & PPT_AET_CFS \\
\hline $\begin{array}{l}\text { Wastewater treatment plant water discharge } \\
\text { from external sources }\end{array}$ & $\mathrm{ft}^{3} / \mathrm{s}$ & $\mathrm{X}$ & -- & -- & -- & PTSRC_WWTP_FLOW_EXT \\
\hline $\begin{array}{l}\text { Water diversions into the SPARROW model } \\
\text { area }\end{array}$ & $\mathrm{ft}^{3} / \mathrm{s}$ & $\mathrm{X}$ & -- & -- & -- & ARDISCHARGE \\
\hline Spring flow & $\mathrm{ft}^{3} / \mathrm{s}$ & $\mathrm{X}$ & -- & -- & -- & SPRING_FLOW_CFS \\
\hline Streamflow or constituent load from Canada & $\mathrm{ft}^{3} / \mathrm{s}$ or $\mathrm{kg}$ & $\mathrm{X}$ & $\mathrm{X}$ & $\mathrm{X}$ & $\mathrm{X}$ & CAN_X_LOAD \\
\hline Wastewater treatment plant effluent load & $\mathrm{kg}$ & -- & $\mathrm{X}$ & $\mathrm{X}$ & -- & SUM_PTSRC_KGX_WWTP \\
\hline Agricultural fertilizers & $\mathrm{kg}$ & -- & $\mathrm{X}$ & $\mathrm{X}$ & -- & FERT_SW_N_KG, FERT_SW_P_KG \\
\hline Manure & $\mathrm{kg}$ & -- & $\mathrm{X}$ & $\mathrm{X}$ & -- & MANN2012, MANP2012 \\
\hline Atmospheric deposition & $\mathrm{kg}$ & -- & $\mathrm{X}$ & -- & -- & CMAQ_TN_12_KG \\
\hline Urban land & $\mathrm{km}^{2}$ & -- & $\mathrm{X}$ & $\mathrm{X}$ & -- & URB_KM2 \\
\hline Agricultural land & $\mathrm{km}^{2}$ & -- & -- & -- & -- & -- \\
\hline Forest and wetland & $\mathrm{km}^{2}$ & -- & -- & -- & -- & -- \\
\hline Nitrogen-fixing crops & $\mathrm{km}^{2}$ & -- & $\mathrm{X}$ & -- & -- & NFIX_KM2 \\
\hline Nitrogen from population served by septic & $\mathrm{kg}$ & -- & -- & -- & -- & -- \\
\hline Phosphorus in geologic materials & $\mathrm{t}$ & -- & -- & $\mathrm{X}$ & -- & NATL_P \\
\hline Channel length & $\mathrm{km}$ & -- & -- & -- & $\mathrm{X}$ & -- \\
\hline Channel length multiplied by stream power & $\mathrm{km} \times$ joules $/ \mathrm{s}$ & -- & -- & -- & -- & -- \\
\hline Channel length multiplied by shear strength & $\mathrm{km} \times$ newtons $/ \mathrm{m}^{2}$ & -- & -- & -- & -- & -- \\
\hline Surficial geologic materials & $\mathrm{km}^{2}$ & -- & -- & -- & -- & -- \\
\hline $\begin{array}{l}\text { Urban land intersected with surficial geologic } \\
\text { materials }\end{array}$ & $\mathrm{km}^{2}$ & -- & -- & -- & $\mathrm{X}$ & URB_AMC, URB_COLLRESCARB, URB_FINESILT \\
\hline $\begin{array}{l}\text { Agricultural land intersected with surficial } \\
\text { geologic materials }\end{array}$ & $\mathrm{km}^{2}$ & -- & -- & -- & $\mathrm{X}$ & AG_AMC, AG_COLLRESCARB, AG_FINESILT \\
\hline $\begin{array}{l}\text { Other land-use categories intersected with } \\
\text { surficial geologic materials }\end{array}$ & $\mathrm{km}^{2}$ & -- & -- & -- & $\mathrm{X}$ & $\begin{array}{l}\text { OTHER2_AMC, OTHER2_COLLRESCARB, } \\
\text { OTHER2_FINESILT }\end{array}$ \\
\hline
\end{tabular}


Table 2.1. Source, land-to-water delivery, and instream and in-reservoir decay variables tested and used in the 2012 Midwest SPARROW models.-Continued

[SPARROW, SPAtially Referenced Regression On Watershed attributes; TN, total nitrogen; TP, total phosphorus; SS, suspended sediment; AET, actual evapotranspiration; f $\mathrm{t}^{3} / \mathrm{s}$, cubic foot per second; $\mathrm{X}$, indicates variable was used in calibrated model; --, no data or not applicable; $\mathrm{kg}$, kilogram; $\mathrm{km}^{2}$, square kilometer; $\mathrm{t}$, ton; $\mathrm{km}$, kilometer; $\mathrm{km} \times$ joules $/ \mathrm{s}$, kilometer times joule per second; $\mathrm{km} \times$ newtons $/ \mathrm{m}^{2}$, kilometer times newton per square meter; $\mathrm{ft} / \mathrm{s}$, foot per second; ${ }^{\circ} \mathrm{C}$, degrees Celsius; mm, millimeter; $\mathrm{m}$, meter; <, less than; km/km², kilometer per square kilometer; in $/ \mathrm{hr}$, inch per hour; $\mathrm{kg} / \mathrm{m}^{3}$, kilogram per cubic meter; PET, potential evapotranspiration; CRP, Conservation Reserve Program; NRCS, U.S. Department of Agriculture National Resources Conservation Service; BMP, best management practice; kg/ $\mathrm{km}^{2}$, kilogram per square kilometer; yr/m, year per meter]

\begin{tabular}{|c|c|c|c|c|c|c|}
\hline \multirow{2}{*}{$\begin{array}{l}\text { Description of variables tested in Midwest } \\
\text { SPARROW models }\end{array}$} & \multirow{2}{*}{ Unit } & \multicolumn{4}{|c|}{ Used in calibrated model } & \multirow{2}{*}{ Variable name in calibrated SPARROW mode } \\
\hline & & Streamflow & TN & TP & SS & \\
\hline \multicolumn{7}{|c|}{ Land-to-water delivery variables } \\
\hline Air temperature & ${ }^{\circ} \mathrm{C}$ & $\mathrm{X}$ & $\mathrm{X}$ & -- & -- & TAV_AVE, DTTAV2012 \\
\hline Precipitation & $\mathrm{mm}$ & -- & -- & -- & -- & -- \\
\hline Catchment elevation & $\mathrm{m}$ & $\mathrm{X}$ & -- & -- & -- & CAT_ELEV \\
\hline Basin slope where elevation $<1,500 \mathrm{~m}$ & percent & -- & -- & -- & $\mathrm{X}$ & LBSLOPE_LT1500 \\
\hline Soil clay content & percent & $\mathrm{X}$ & $\mathrm{X}$ & -- & $\mathrm{X}$ & CAT_STCLAY, LCAT_STCLAY \\
\hline Soil erodibility & unitless & -- & -- & $\mathrm{X}$ & $\mathrm{X}$ & LCAT_KFCTUP \\
\hline Precipitation intensity & $\begin{array}{l}\mathrm{mm} / \text { number of wet } \\
\text { days }\end{array}$ & $\mathrm{X}$ & -- & -- & -- & LPPT_INT \\
\hline Runoff & $\mathrm{mm}$ & -- & $\mathrm{X}$ & $\mathrm{X}$ & $\mathrm{X}$ & LWBM_INCQ_MM \\
\hline Drainage density & $\mathrm{km} / \mathrm{km}^{2}$ & -- & -- & $\mathrm{X}$ & -- & LDRAINDEN \\
\hline Tile drains (agricultural) & percent of catchment & -- & $\mathrm{X}$ & $\mathrm{X}$ & -- & LTILES13_PERC2 \\
\hline Distance to stream & $\mathrm{m}$ & -- & -- & -- & -- & -- \\
\hline Winter wheat & $\mathrm{km}^{2}$ & -- & -- & -- & -- & -- \\
\hline Stream channel sinuosity & $\mathrm{m} / \mathrm{m}$ & -- & -- & -- & -- & -- \\
\hline Bankfull depth and width & $\mathrm{m}$ & -- & -- & -- & -- & -- \\
\hline Soil permeability & $\mathrm{in} / \mathrm{hr}$ & -- & -- & -- & -- & -- \\
\hline Soil sand content & percent & -- & -- & -- & -- & -- \\
\hline Soil silt content & percent & -- & -- & -- & -- & -- \\
\hline Soil bulk density & $\mathrm{kg} / \mathrm{m}^{3}$ & -- & -- & -- & -- & -- \\
\hline Soil organic matter content & percent & -- & -- & -- & -- & -- \\
\hline Soil depth & $\mathrm{m}$ & -- & -- & -- & -- & -- \\
\hline Stream power & joules/s & -- & -- & -- & -- & -- \\
\hline Stream shear strength & newtons $/ \mathrm{m}^{2}$ & -- & -- & -- & -- & -- \\
\hline Stream velocity & $\mathrm{ft} / \mathrm{s}$ & -- & -- & -- & -- & -- \\
\hline Stream slope & $\mathrm{m} / \mathrm{m}$ & -- & -- & -- & -- & -- \\
\hline Water level changes in High Plains Aquifer & $\mathrm{m}$ & -- & -- & -- & -- & -- \\
\hline PET and AET & $\mathrm{mm}$ & -- & -- & -- & -- & -- \\
\hline
\end{tabular}


[SPARROW, SPAtially Referenced Regression On Watershed attributes; TN, total nitrogen; TP, total phosphorus; SS, suspended sediment; AET, actual evapotranspiration; ft $/$ s, cubic foot per second; $\mathrm{X}$, indicates variable was used in calibrated model; --, no data or not applicable; $\mathrm{kg}$, kilogram; $\mathrm{km}^{2}$, square kilometer; $\mathrm{t}$, ton; $\mathrm{km}$, kilometer; $\mathrm{km} \times \mathrm{joules} / \mathrm{s}, \mathrm{kilometer}$ times joule per second; $\mathrm{km} \times$ newtons $/ \mathrm{m}^{2}$, kilometer times newton per square meter; $\mathrm{ft} / \mathrm{s}$, foot per second; ${ }^{\circ} \mathrm{C}$, degrees Celsius; $\mathrm{mm}$, millimeter; $\mathrm{m}$, meter; $<$, less than; $\mathrm{km} / \mathrm{km}^{2}, \mathrm{kilometer} \mathrm{per} \mathrm{square} \mathrm{kilometer;} \mathrm{in} / \mathrm{hr}$, inch per hour; $\mathrm{kg} / \mathrm{m}^{3}, \mathrm{kilogram}$ per cubic meter; PET, potential evapotranspiration; CRP, Conservation Reserve Program; NRCS, U.S. Department of Agriculture National Resources Conservation Service; BMP, best management practice; kg/ $\mathrm{km}^{2}$, kilogram per square kilometer; $\mathrm{yr} / \mathrm{m}$, year per meter]

\begin{tabular}{|c|c|c|c|c|c|c|}
\hline \multirow{2}{*}{$\begin{array}{l}\text { Description of variables tested in Midwest } \\
\text { SPARROW models }\end{array}$} & \multirow{2}{*}{ Unit } & \multicolumn{4}{|c|}{ Used in calibrated model } & \multirow{2}{*}{ Variable name in calibrated SPARROW model } \\
\hline & & Streamflow & TN & TP & SS & \\
\hline \multicolumn{7}{|c|}{ Land-to-water delivery variables-Continued } \\
\hline Base-flow index & fraction & -- & -- & -- & -- & -- \\
\hline Enhanced vegetation index (greenness index) & scale from 0 to 1 & -- & -- & -- & -- & -- \\
\hline CRP acres relative to total farmland & fraction & -- & $\mathrm{X}$ & -- & -- & CAT_PFARM1 \\
\hline $\begin{array}{l}\text { NRCS-estimated reduction in phosphorus loss } \\
\text { due to BMPs }\end{array}$ & $\mathrm{kg} / \mathrm{km}^{2}$ & -- & -- & $\mathrm{X}$ & -- & LTPLOSS_2012 \\
\hline $\begin{array}{l}\text { Conservation practice, percent of catchment in } \\
\text { "no till" }\end{array}$ & percent of catchment & -- & $\mathrm{X}$ & -- & -- & LCAT_NOTILL \\
\hline $\begin{array}{l}\text { Other conservation practices (ditches, tile, con- } \\
\text { servation till, conventional till, cover crops, } \\
\text { conservation easement) }\end{array}$ & percent of catchment & -- & -- & -- & -- & -- \\
\hline \multicolumn{7}{|c|}{ Aquatic loss variables } \\
\hline Precipitation minus PET (aridity) & $\mathrm{ft}^{3} / \mathrm{s}$ & $\mathrm{X}$ & -- & -- & -- & ARIDITY \\
\hline Length of nonperennial streams & $\mathrm{km}$ & $\mathrm{X}$ & -- & -- & -- & NP_LENGTH \\
\hline Stream-reach time of travel & days & -- & $\mathrm{X}$ & $\mathrm{X}$ & $\mathrm{X}$ & RCHDECAY1 (Mean flow $<50 \mathrm{ft}^{3} / \mathrm{s}$ ) \\
\hline Reservoir inverse hydraulic load & $\mathrm{yr} / \mathrm{m}$ & -- & $\mathrm{X}$ & $\mathrm{X}$ & $\mathrm{X}$ & IRESLOAD \\
\hline Surface-water withdrawals for public supply & fraction of streamflow & $\mathrm{X}$ & $\mathrm{X}$ & $\mathrm{X}$ & $\mathrm{X}$ & ARLOSSRATE \\
\hline Groundwater withdrawals for public supply & fraction of streamflow & -- & -- & -- & -- & -- \\
\hline Surface-water pumping for irrigation & fraction of streamflow & -- & -- & -- & -- & -- \\
\hline Groundwater pumping for irrigation & fraction of streamflow & $\mathrm{X}$ & $\mathrm{X}$ & -- & -- & GW_IRR_RMV \\
\hline Water consumed by power generation plants & fraction of streamflow & -- & -- & -- & -- & -- \\
\hline Evaporation from surface-water bodies & fraction of streamflow & $\mathrm{X}$ & -- & -- & -- & RES_RMV \\
\hline $\begin{array}{l}\text { Water diversions out of the SPARROW model } \\
\text { area }\end{array}$ & fraction of streamflow & -- & -- & -- & -- & -- \\
\hline
\end{tabular}


Table 3.1. Sampling agencies that collected water-quality data used to calculate total nitrogen, total phosphorus, suspended-sediment, and suspended solid loads considered for use in the 2012 Midwest SPARROW (SPAtially Referenced Regression On Watershed attributes) models.

\begin{tabular}{|c|c|}
\hline Agency code & Agency name \\
\hline AL DEM & Alabama Department of Environmental Management. \\
\hline AR DEQ & Arkansas Department of Environmental Quality. \\
\hline CO CRWWN & The Rivers of Colorado Water Watch Network. \\
\hline CO CWSD & Centennial Water and Sanitation District. \\
\hline CO DPHE & Colorado Department of Public Health and Environment. \\
\hline CO MWRD & Metropolitan Waste Water Reclamation District. \\
\hline CO SACWSD & South Adams County Water and Sanitation District. \\
\hline CO THORN & City of Thornton, Colorado. \\
\hline IA DMWW & Des Moines Water Works, Iowa. \\
\hline IA DNR & Iowa Department of Natural Resources. \\
\hline IA GSWSP & Iowa Geological Survey Watershed Snapshots. \\
\hline IA ISUCOE & Des Moines River Water Quality Network. \\
\hline IA VWMP & Iowa Volunteer Water Monitoring Program. \\
\hline IL EPA & Illinois Environmental Protection Agency. \\
\hline IL MWRDGC & Metropolitan Water Reclamation District of Greater Chicago, Illinois. \\
\hline IL SWS & Illinois State Water Survey. \\
\hline IN CEG & Indianapolis Citizen Energy Group. \\
\hline IN DEM & Indiana Department of Environmental Management. \\
\hline IN EPWU & City of Elkhart Public Works and Utilities, Indiana. \\
\hline IN MBWQ & Muncie Bureau of Water Quality, Indiana. \\
\hline IN WREC & Wabash River Enhancement Corporation, Indiana. \\
\hline KS DHE & Kansas Department of Health and Environment. \\
\hline KY DEP & Kentucky Department for Natural Resources and Environmental Protection. \\
\hline LA DEQ & Louisiana Department of Environmental Quality. \\
\hline MD DNR & Maryland Department of Natural Resources. \\
\hline MD DOE & Maryland Department of the Environment. \\
\hline MI DEQ & Michigan Department of Environmental Quality. \\
\hline MI TLRBOI & Little River Band of Ottawa Indians, Michigan. \\
\hline MN DA & Minnesota Department of Agriculture. \\
\hline MN MCES & Metropolitan Council Environmental Services, Minnesota. \\
\hline MN PCA & Minnesota Pollution Control Agency. \\
\hline MN TRLDNR & Red Lake Division of Natural Resources, Minnesota. \\
\hline MO DNR & Missouri Department of Natural Resources. \\
\hline MO MACT & Mactec Incorporated, Missouri. \\
\hline MO MEC & Midwest Environmental Consultants, Missouri. \\
\hline MO VRSR & Versar Incorporated, Missouri. \\
\hline MS DEQ & Mississippi Department of Environmental Quality. \\
\hline NC DENR & North Carolina Department of Environment and Natural Resources. \\
\hline NC TEBCI & Eastern Band of Cherokee Indians, North Carolina. \\
\hline ND DOH & North Dakota Department of Health. \\
\hline NE DEQ & Nebraska Department of Environmental Quality. \\
\hline
\end{tabular}


Table 3.1. Sampling agencies that collected water-quality data used to calculate total nitrogen, total phosphorus, suspended-sediment, and suspended solid loads considered for use in the 2012 Midwest SPARROW (SPAtially Referenced Regression On Watershed attributes) models.-Continued

\begin{tabular}{ll}
\hline \multicolumn{1}{c}{ Agency code } & \multicolumn{1}{c}{ Agency name } \\
\hline NY COMSI & Community Science Institute. \\
NY DEC & New York Department of Environmental Conservation. \\
OH EPA & Ohio Environmental Protection Agency. \\
OH HDLBG & Heidelberg University, National Center for Water Quality Research, Ohio. \\
OH MCD & Miami Conservancy District, Ohio. \\
OH NEORSD & Northeast Ohio Regional Sewer District. \\
OK CONC & Oklahoma Conservation Commission. \\
OK DEQ & Oklahoma Department of Environmental Quality. \\
OK TKN & Kaw Nation of Oklahoma. \\
OK TSFN & Sac and Fox Nation, Oklahoma. \\
OK TWN & Wyandotte Nation, Oklahoma. \\
OK WRB & Oklahoma Water Resources Board. \\
PA DEP & Pennsylvania Department of Environmental Protection. \\
RG3 SJRWI & Saint Joseph River Watershed Initiative. \\
RG5 UMESC & Upper Midwest Environmental Sciences Center. \\
RG8 ORSANCO & Ohio River Valley Water Sanitation Commission (ORSANCO). \\
SD DENR & South Dakota Department of Environmental and Natural Resources. \\
TN DEC & Tennessee Department of Environment and Conservation. \\
TX CEQ & Texas Commission on Environmental Quality. \\
US ACE & U.S. Army Corps of Engineers. \\
US DA & U.S. Department of Agriculture. \\
US EPA & U.S. Environmental Protection Agency. \\
US GS & U.S. Geological Survey. \\
VA DEQ & Virginia Department of Environmental Quality. \\
WI DNR & Wisconsin Department of Natural Resources. \\
WI GBMSD & Green Bay Metropolitan Sewerage District, Wisconsin. \\
WI THCN & Ho-Chunk Nation, Wisconsin. \\
WI TSMC & Stockbridge-Munsee Community, Wisconsin. \\
WV DEP & West Virginia Department of Environmental Protection. \\
\hline &
\end{tabular}


Table 4.1. Wastewater treatment plant effluent load for total nitrogen and total phosphorus, by State and by percentage, based on measured versus typical pollutant concentration used in the 2012 Midwest SPARROW (SPAtially Referenced Regression On Watershed attributes) models.

[kg, kilogram]

\begin{tabular}{|c|c|c|c|c|c|c|}
\hline State & $\begin{array}{l}\text { Wastewater treatment } \\
\text { plant effluent total } \\
\text { nitrogen load (kg) }\end{array}$ & $\begin{array}{l}\text { Percent of total nitrogen } \\
\text { load based on measured } \\
\text { concentration }\end{array}$ & $\begin{array}{l}\text { Percent of total nitrogen } \\
\text { load based on "typical } \\
\text { pollutant concentration" }\end{array}$ & $\begin{array}{l}\text { Wastewater treatment } \\
\text { plant effluent total phos- } \\
\text { phorus load (kg) }\end{array}$ & $\begin{array}{l}\text { Percent of total phos- } \\
\text { phorus load based on } \\
\text { measured concentration }\end{array}$ & $\begin{array}{l}\text { Percent of total phos- } \\
\text { phorus load based } \\
\text { on "typical pollutant } \\
\text { concentration" }\end{array}$ \\
\hline Alaska & $1,260,647$ & 1.7 & 98.3 & 301,074 & 97.3 & 2.7 \\
\hline Arkansas & $3,632,502$ & 13.4 & 86.6 & 673,769 & 68.8 & 31.2 \\
\hline Colorado & $7,088,242$ & 2.7 & 97.3 & 52,575 & 7.9 & 92.1 \\
\hline Georgia & 30,209 & 27.1 & 72.9 & 6,152 & 78.9 & 21.1 \\
\hline Iowa & $5,268,072$ & 45.6 & 54.4 & $1,576,978$ & 43.5 & 56.5 \\
\hline Illinois & $41,552,601$ & 29.8 & 70.2 & $5,503,033$ & 75.5 & 24.5 \\
\hline Indiana & $16,288,656$ & 1.6 & 98.4 & $1,262,592$ & 67.2 & 32.8 \\
\hline Kansas & $5,475,289$ & 90.7 & 9.3 & 898,275 & 95.5 & 4.5 \\
\hline Kentucky & $9,558,422$ & 47.8 & 52.2 & $1,445,101$ & 75.7 & 24.3 \\
\hline Louisiana & $7,158,796$ & 6.7 & 93.3 & $1,692,047$ & 8.0 & 92.0 \\
\hline Maryland & 17,933 & 77.2 & 22.8 & 2,213 & 59.6 & 40.4 \\
\hline Michigan & $21,671,482$ & 8.0 & 92.0 & $1,178,661$ & 70.1 & 29.9 \\
\hline Minnesota & $6,809,134$ & 8.9 & 91.1 & 800,348 & 99.1 & 0.9 \\
\hline Missouri & $12,332,452$ & 19.1 & 80.9 & $1,884,518$ & 25.4 & 74.6 \\
\hline Mississippi & $2,936,638$ & 92.0 & 8.0 & 730,714 & 93.2 & 6.8 \\
\hline Montana & 989,965 & 94.7 & 5.3 & 146,363 & 95.5 & 4.5 \\
\hline North Carolina & 661,341 & 44.0 & 56.0 & 128,787 & 56.7 & 43.3 \\
\hline North Dakota & $1,146,719$ & 20.9 & 79.1 & 64,629 & 26.5 & 73.5 \\
\hline Nebraska & $2,462,115$ & 14.3 & 85.7 & 696,658 & 6.5 & 93.5 \\
\hline New Mexico & 10,607 & 77.7 & 22.3 & 2,032 & 55.1 & 44.9 \\
\hline New York & $5,918,580$ & 6.6 & 93.4 & 391,492 & 80.3 & 19.7 \\
\hline Ohio & $24,374,634$ & 7.4 & 92.6 & $3,307,366$ & 80.4 & 19.6 \\
\hline Oklahoma & $5,568,404$ & 4.3 & 95.7 & $1,146,237$ & 25.8 & 74.2 \\
\hline Pennsylvania & $5,513,119$ & 0.1 & 99.9 & 707,505 & 17.8 & 82.2 \\
\hline South Dakota & $1,019,078$ & 11.5 & 88.5 & 95,049 & 13.5 & 86.5 \\
\hline Tennessee & $22,517,105$ & 81.9 & 18.1 & $2,932,988$ & 69.2 & 30.8 \\
\hline Texas & $1,163,219$ & 5.4 & 94.6 & 118,258 & 5.3 & 94.7 \\
\hline Virginia & 211,557 & 1.0 & 99.0 & 9,062 & 3.0 & 97.0 \\
\hline Wisconsin & $7,201,399$ & 1.2 & 98.8 & 343,665 & 91.8 & 8.2 \\
\hline West Virginia & $1,666,787$ & 19.8 & 80.2 & 244,970 & 19.8 & 80.2 \\
\hline Wyoming & 528,640 & 40.7 & 59.3 & 68,890 & 39.6 & 60.4 \\
\hline Midwest total & $222,034,346$ & 25.5 & 74.5 & $28,412,003$ & 61.4 & 38.6 \\
\hline
\end{tabular}


Table 5.1. Original, generalized, and final surficial-materials categories considered for use in the 2012 Midwest SPARROW (SPAtially Referenced Regression On Watershed attributes) models.

\begin{tabular}{|c|c|c|}
\hline Original surficial-materials categories (Soller and others, 2009) & Generalized surficial-material categories & $\begin{array}{l}\text { Categories considered for use in Midwest } \\
\text { SPARROW models }\end{array}$ \\
\hline Alluvial sediments, thin & Alluvial sediments & Alluvial, medium-coarse sediments. \\
\hline Alluvial sediments, thick & Alluvial sediments & Alluvial, medium-coarse sediments. \\
\hline Basaltic and andesitic volcanic rocks & Basaltic and andesitic volcanic rocks & Other. \\
\hline Calcareous biological sediments & Calcareous biological sediments & Other. \\
\hline Glaciofluvial ice-contact sediments, mostly sand and gravel, discontinuous & Coarse sediments & Alluvial, medium-coarse sediments. \\
\hline Glaciofluvial ice-contact sediments, mostly sand and gravel, thin & Coarse sediments & Alluvial, medium-coarse sediments. \\
\hline Glaciofluvial ice-contact sediments, mostly sand and gravel, thick & Coarse sediments & Alluvial, medium-coarse sediments. \\
\hline Proglacial sediments, mostly coarse grained, discontinuous & Coarse sediments & Alluvial, medium-coarse sediments. \\
\hline Proglacial sediments, mostly coarse grained, thin & Coarse sediments & Alluvial, medium-coarse sediments. \\
\hline Proglacial sediments, mostly coarse grained, thick & Coarse sediments & Alluvial, medium-coarse sediments. \\
\hline Colluvial sediments, discontinuous & Colluvial sediments & Colluvial, residual, carbonate materials. \\
\hline Colluvial sediments, thin & Colluvial sediments & Colluvial, residual, carbonate materials. \\
\hline Colluvial and alluvial sediments & Colluvial sediments & Colluvial, residual, carbonate materials. \\
\hline Colluvial sediments and loess & Colluvial sediments & Colluvial, residual, carbonate materials. \\
\hline Colluvial sediments and residual material & Colluvial sediments & Colluvial, residual, carbonate materials. \\
\hline Coastal zone sediments, mostly fine grained & Fine-grained sediments & Fine-grained and silty sediments. \\
\hline Glacial till sediments, mostly clayey, discontinuous & Fine-grained sediments & Fine-grained and silty sediments. \\
\hline Glacial till sediments, mostly clayey, thin & Fine-grained sediments & Fine-grained and silty sediments. \\
\hline Glacial till sediments, mostly clayey, thick & Fine-grained sediments & Fine-grained and silty sediments. \\
\hline Lacustrine sediments & Fine-grained sediments & Fine-grained and silty sediments. \\
\hline Proglacial sediments, mostly fine grained, discontinuous & Fine-grained sediments & Fine-grained and silty sediments. \\
\hline Proglacial sediments, mostly fine grained, thin & Fine-grained sediments & Fine-grained and silty sediments. \\
\hline Proglacial sediments, mostly fine grained, thick & Fine-grained sediments & Fine-grained and silty sediments. \\
\hline Residual materials developed in igneous and metamorphic rocks & $\begin{array}{l}\text { Residual materials developed in igneous and metamor- } \\
\text { phic rocks }\end{array}$ & Other. \\
\hline Eolian sediments, mostly loess, thin & Eolian sediments, mostly loess & Fine-grained and silty sediments. \\
\hline Eolian sediments, mostly loess, thick & Eolian sediments, mostly loess & Fine-grained and silty sediments. \\
\hline Coastal zone sediments, mostly medium grained & Medium-grained sediments & Alluvial, medium-coarse sediments. \\
\hline Eolian sediments, mostly dune sand, thin & Medium-grained sediments & Alluvial, medium-coarse sediments. \\
\hline Eolian sediments, mostly dune sand, thick & Medium-grained sediments & Alluvial, medium-coarse sediments. \\
\hline Eolian sediments on southern High Plains & Medium-grained sediments & Alluvial, medium-coarse sediments. \\
\hline
\end{tabular}


Table 5.1. Original, generalized, and final surficial-materials categories considered for use in the 2012 Midwest SPARROW (SPAtially Referenced Regression On Watershed attributes) models.-Continued

\begin{tabular}{|c|c|c|}
\hline Original surficial-materials categories (Soller and others, 2009) & Generalized surficial-material categories & $\begin{array}{l}\text { Categories considered for use in Midwest } \\
\text { SPARROW models }\end{array}$ \\
\hline Glacial till sediments, mostly sandy, discontinuous & Medium-grained sediments & Alluvial, medium-coarse sediments. \\
\hline Glacial till sediments, mostly sandy, thin & Medium-grained sediments & Alluvial, medium-coarse sediments. \\
\hline Organic-rich muck and peat, thin & Organic-rich muck and peat & Other. \\
\hline Organic-rich muck and peat, thick & Organic-rich muck and peat & Other. \\
\hline Playa sediments & Playa sediments & Other. \\
\hline Residual materials developed in alluvial sediments & Residual materials developed in alluvial sediments & Colluvial, residual, carbonate materials. \\
\hline Residual materials developed in bedrock with alluvial sediments, discontinuous & Residual materials developed in bedrock & Colluvial, residual, carbonate materials. \\
\hline Residual materials developed in bedrock with alluvial sediments, thin & Residual materials developed in bedrock & Colluvial, residual, carbonate materials. \\
\hline Residual materials developed in bedrock, discontinuous & Residual materials developed in bedrock & Colluvial, residual, carbonate materials. \\
\hline Residual materials developed in bedrock, thin & Residual materials developed in bedrock & Colluvial, residual, carbonate materials. \\
\hline Residual materials developed in carbonate rocks, discontinuous & Residual materials developed in carbonate rocks & Colluvial, residual, carbonate materials. \\
\hline Residual materials developed in carbonate rocks, thin & Residual materials developed in carbonate rocks & Colluvial, residual, carbonate materials. \\
\hline Residual materials developed in fine-grained sedimentary rocks & $\begin{array}{l}\text { Residual materials developed in fine-grained sedimen- } \\
\text { tary rocks }\end{array}$ & Colluvial, residual, carbonate materials. \\
\hline Residual materials developed in sedimentary rocks, discontinuous & Residual materials developed in sedimentary rocks & Colluvial, residual, carbonate materials. \\
\hline Residual materials developed in sedimentary rocks, thin & Residual materials developed in sedimentary rocks & Colluvial, residual, carbonate materials. \\
\hline Rhyolitic volcanic rocks & Rhyolitic volcanic rocks & Other. \\
\hline Glacial till sediments, mostly silty, discontinuous & Glacial till sediments, mostly silty & Fine-grained and silty sediments. \\
\hline Glacial till sediments, mostly silty, thin & Glacial till sediments, mostly silty & Fine-grained and silty sediments. \\
\hline Glacial till sediments, mostly silty, thick & Glacial till sediments, mostly silty & Fine-grained and silty sediments. \\
\hline Water & Water & Other. \\
\hline
\end{tabular}




\section{Reference Cited}

Soller, D.R., Reheis, M.C., Garrity, C.P., and Van Sistine, D.R., 2009, Map database for surficial materials in the conterminous United States (version 1.0, July 2011): U.S. Geological Survey Data Series 425, scale 1:5, 000,000, accessed February 2019 at https://pubs.usgs.gov/ds/425. 
For additional information contact: NAWOA Science Team U.S. Geological Survey 12201 Sunrise Valley Drive Reston, VA 20192 https://water.usgs.gov/nawqa/

Publishing support provided by the Rolla and Madison Publishing Service Centers 
